Leandro Fontes Prezotto

\title{
Tipificação de linhagens de Wolbachia do complexo Anastrepha fraterculus (Diptera: Tephritidae) da Região Neotropical por análise de locos múltiplos.
}

Typification of Wolbachia's strains in the complex Anastrepha fraterculus (Diptera: Tephritidae) from the Neotropical Region by analysis of multiple loci.

São Paulo

2012 
Leandro Fontes Prezotto

\section{Tipificação de linhagens de Wolbachia do complexo Anastrepha fraterculus (Diptera: Tephritidae) da Região Neotropical por análise de locos múltiplos.}

Typification of Wolbachia's strains in the complex Anastrepha fraterculus (Diptera: Tephritidae) from the Neotropical Region by analysis of multiple loci.

Tese apresentada ao Instituto de Biociências da Universidade de São Paulo, para a obtenção de Título de Doutor em Ciências, na Área de Genética e Biologia Evolutiva.

Orientadora: Prof $^{\mathrm{a}}$. $\mathrm{Dr}^{\mathrm{a}}$.

Denise Selivon-Scheepmaker

São Paulo 


Prezotto, Leandro Fontes
Tipificação de linhagens de Wolbachia
do complexo Anastrepha fraterculus
(Diptera: Tephritidae) da Região
Neotropical por análise de locos
múltiplos.
102 páginas
Tese (Doutorado) - Instituto de
Biociências da Universidade de São
Paulo. Departamento de Genética e
Biologia Evolutiva.
1. Moscas-das-Frutas 2. MLST 3. wsp
I. Universidade de São Paulo. Instituto
de Biociências. Departamento de
Genética e Biologia Evolutiva.

\section{Comissão Julgadora:}

Prof(a). Dr(a).

$\operatorname{Prof}(a)$. Dr(a).
Prof(a). Dr(a).

Prof(a). Dr(a).

Prof(a). Dr(a). Denise Selivon-Scheepmaker

Orientador(a) 
Aos meus pais, 
"I don't want to believe. I want to know."

Carl Sagan (1934-1996) 


\section{Agradecimentos}

A Prof ${ }^{\mathrm{a}}$. Dr ${ }^{\mathrm{a}}$. Denise Selivon-Scheepmaker, por aceitar me orientar e pela ajuda e incentivo ao longo da execução deste trabalho. Ao Prof. Dr. André Luiz Paranhos Perondini, pela ajuda e incentivos nos momentos decisivos deste trabalho.

Ao Prof. Dr. Carlos Ribeiro Vilela por ceder o microscópio usado para tirar as fotos das lâminas.

Aos amigos que estão ou que passaram pelo laboratório: Ester, Fernando, Júlia, Paula, Pietro e Roberto, pela ajuda em diversos momentos deste trabalho.

A Elzi, técnica do laboratório, e ao Walmir, motorista do Instituto, pela ajuda nas coletas e manutenção do material biológico.

Aos meus pais, Tarcisio e Regina, e irmãs, Renata e Carolina, pelo carinho e apoio dado, principalmente nos momentos mais difíceis. 
Apoio Financeiro Capes (bolsa institucional de Doutorado) e FAPESP (Projeto 10/52040-8). 


\section{Índice}

\begin{tabular}{ll}
\hline Introdução & 01
\end{tabular}

Objetivos 13

Material e Métodos $\quad 14$

Amostras utilizadas $\quad 14$

Extração de DNA $\quad 18$

$\begin{array}{ll}\text { Amplificação dos fragmentos de genes } & 18\end{array}$

$\begin{array}{ll}\text { Eletroforese } & 19\end{array}$

$\begin{array}{lr}\text { Sequenciamento de DNA } & 19\end{array}$

Análise das sequências $\quad 20$

Estabelecimento de linhagens de Anastrepha isentas (curadas) de Wolbachia

Análise de efeitos da Wolbachia em A. sp.1 e em A. obliqua 22

Resultados $\quad 25$

1. Caracterização de linhagens de Wolbachia 25

2. "Multilocus Sequence Typing" (MLST) 25

2.1. Gene gatB 26

2.2. Gene $\operatorname{cox} A \quad 30$

2.3. Gene $h c p A \quad 31$

2.4. Gene ftsZ 33

2.5. Gene fbpA 34

2.6. Comparação entre as filogenias dos cinco genes do MLST 36

2.7. Sequências dos cinco genes concatenadas 38

3. Análise do gene wsp 42

4. Comparação entre as filogenias do MLST (genes concatenados) e do gene wsp $\quad 52$

5. Análise de efeitos da Wolbachia em A. sp.1 e em A. obliqua 56 Morfologia dos ovários $\quad 56$

Produção de espermatozoides $\quad 56$

Fecundidade $\quad 58$

Fertilidade $\quad 59$

Discussão $\quad 61$

Resumo 68

$\begin{array}{ll}\text { Abstract } & 70\end{array}$

$\begin{array}{ll}\text { Referências Bibliográficas } & 71\end{array}$

$\begin{array}{ll}\text { Anexos } & 94\end{array}$ 


\section{Introdução}

As bactérias Wobachia têm atraído um grande interesse nas últimas décadas, principalmente por sua vasta abundância e efeitos fascinantes sobre seus hospedeiros, que vão desde a manipulação reprodutiva, mutualismo e potenciais aplicações em controles de pragas e vetores de doenças (Werren et al. 2008; Brelsfoard \& Dobson, 2011). As bactérias Wolbachia são membros da ordem Rickettsiales, um grupo diverso de bactérias intracelulares que compreendem espécies com relações parasitárias, mutualistas e comensais com seus hospedeiros (Werren et al. 2008). As "rickettsias" são bactérias parasitas encontradas em intima associação com os tecidos de seus hospedeiros e os membros desta família pertencem à subdivisão "Alpha" de Proteobacteria (Weiss \& Moulder, 1984; Weisburg et al., 1989; Werren, 1997). Filogenias baseadas em sequências do gene ribossômico $16 S$ mostraram que as Wolbachia são monofiléticas em relação a outras "rickettsias" (Noda, 1984; Breeuwer et al. 1992; Southamer \& Luck, 1993) e posicionam-se filogeneticamente como grupo irmão de Ehrlichia, que é grupo-irmão de Rickettsia (Werren, 1997).

Descrita inicialmente em tecidos reprodutivos do mosquito Culex pipiens por Hertig \& Wolbach (1924) e posteriormente definida como Wolbachia pipientis (Hertig, 1936), essas bactérias infectam principalmente artrópodes, diferentemente das "rickettsias", que são bactérias patogênicas a vertebrados (Anderson \& Karr, 2001). Nos anos 1950, Ghelelovitch (1952) e Laven $(1951,1959,1967)$ descobriram que nos mosquitos Culex, diversos cruzamentos interespecíficos eram incompatíveis. Laven (1959, 1967) sugeriu uma ligação entre esta incompatibilidade a um padrão de herança citoplasmática, herdado maternalmente, chamando-a de incompatibilidade citoplasmática (IC). Posteriormente, Yen \& Barr (1971) ao eliminarem a bactéria com o antibiótico tetraciclina, observaram o desaparecimento do efeito de IC. Nos anos seguintes, a existência de IC foi novamente observada, como por exemplo, em besouros (Hsiao \& Hsiao, 1985; O’Neil, 1989; Leu, 1989; Wade \& Stevens, 1995; Werren, 1997), vespas parasitoides (Richardson et al., 1987); gafanhotos (Noda, 1984; Noda, 1987), Drosophila (Hoffman et al., 1986; Hoffmann, 1988; Binnington \& Hoffmann, 1989; Hoffman \& Turelli, 1988; Loius \& Nigro, 1989) e moscas-das-frutas (Rhagoletis cerasi) (Riegler \& Staufer, 2002).

Estudos filogenéticos baseados nos genes ribossômicos $16 \mathrm{~S}$ e do ciclo celular ftsZ indicaram que o gênero Wolbachia engloba oito supergrupos taxonômicos ("A" a "H") (Breeuwer et al. 1992; Stouthamer \& Luck, 1993; Werren et al. 1995, Lo et al., 
2002, Casiraghi et al., 2005). A definição rigorosa de supergrupo não existe, nem há um critério padrão para a atribuição de um novo supergrupo. Um supergrupo é geralmente definido como um conjunto de linhagens filogeneticamente relacionadas, embora tipo e número de genes utilizados para as inferências filogenéticas não estejam definidas (Baldo \& Werren, 2007). Os supergrupos "A" e "B" são encontrados em artrópodes. Os supergrupos "C" e "D" são encontrados em nematoides (Bandi et al., 1998). O supergrupo "E" é encontrado em Collembola (Vandekerckhove et al., 1999; Czarnetzk \& Tebbe, 2004), enquanto que o supergrupo "F" contém bactérias que infectam cupins e espécies do gênero Mansonella (Lo et al., 2002). O supergrupo "G" é encontrado em aranhas australianas (Rowley et al., 2004), embora tenha sido argumentado que estas cepas são recombinantes entre os supergrupos " $A$ " e "B" ao invés de representarem linhagens distintas (Baldo \& Werren, 2007). O supergrupo H é encontrado em cupins (Isoptera) (Bordenstein \& Rosengaus, 2005). Outras cepas diversas de Wolbachia foram detectadas em pulgas (Siphonaptera) (Gorham et al., 2003), no nematoide filarial Dipetalonema gracile (Spirurida) (Casiraghi et al., 2005), no pseudoescorpião Cordylochernes scorpioides (Pseudoscorpionida) (Zeh, et al., 2005) e no escorpião Tityus serrulatus (Suesdeck-Rocha et al., 2007), porém estas linhagens não foram identificadas quanto a que supergrupo estariam associadas.

Nematoides associados à Wolbachia mostram uma concordância entre a filogenia da bactéria e dos hospedeiros, mostrando mutualismo entre eles. Este padrão também é encontrado em muitos outros endossimbiontes herdados verticalmente, como em Buchnera aphidicola, simbionte intracelular obrigatório de pulgões (Werren et al., 2008). Em artrópodes, as bactérias Wolbachia se comportam geralmente como parasitas reprodutivos, tendo efeitos fenotípicos em seus hospedeiros. Não há concordância entre a filogenia dos artrópodes e a filogenia de Wolbachia, o que indica a existência de movimento horizontal da bactéria entre espécies hospedeiras (Werren et al., 2008).

A infestação por Wolbachia ocorre em artrópodes de regiões geográficas distintas. Em insetos, por exemplo, foram encontradas infecções em amostras do Panamá, América do Norte, Inglaterra e Indonésia (Werren et al., 1995; West et al., 1998; Werren \& Windror, 2000; Kittayapong et al., 2002), tendo sido observado um relativo equilíbrio entre o grau de infecção nos diferente continentes (Werren \& Windsor, 2000). No Brasil, Lavagnolli et al. (2005) encontraram 45\% de infecção numa amostragem de insetos de uma área de mata atlântica no litoral Norte do Estado de São Paulo. 
Wolbachia é encontrada tanto nos tecidos somáticos quanto nos reprodutivos (Dobson et al., 1999) de diversas espécies de artrópodes e nematódeos (Hilgenboecker et al., 2008). Sua taxa de infecção é estimada em aproximadamente $60 \%$ em artrópodes (Hilgenboeker et al., 2008; Baldo et al., 2010), embora Jeyaprakash \& Hoy (2000), utilizando a técnica de "Long PCR" a tenham estimado em $76 \%$. Dentro das espécies, Hilgenboecker et al. (2008), encontraram uma variação ou muito alta (>90\%) ou muito baixa $(<10 \%)$ de indivíduos infectados.

A Wolbachia é predominantemente transmitida através da linhagem germinativa feminina (Serbus et al., 2008). A taxa de transmissão mensurada para Drosophila melanogaster e Drosophila simulans são similares e em torno de $97 \%$ de eficiência no campo e 100\% em laboratório (Hoffmann et al., 1990; Hoffmann et al., 1998). Nos machos, a bactéria é excluída do esperma maduro, consequentemente, sua taxa de transmissão via linhagem germinativa masculina é da ordem de $2 \%$ (Hoffmann et al., 1998). Nas fêmeas infectadas, a bactéria está presente na linhagem germinativa durante toda a vida, assegurando a alta fidelidade na transmissão através dos ovos (Serbus, et al., 2008).

Infestações por Wolbachia têm sido associadas a diversas alterações na reprodução de seus hospedeiros, como incompatibilidade citoplasmática (IC) em muitas espécies de artrópodes (Wade \& Steven, 1985; Breewer et al., 1992; O’Neill et al., 1992; Bourtzis \& O'Neill, 1998), partenogênese em Hymenoptera (Stouthamer et al., 1993), feminização de machos genéticos em isópodas (Rigaud et al., 1991; Rousset et al., 1992; Juchault et al.,1994), morte dos machos na prole em Coleoptera (Hurst et al., 1999; Fialho et al., 2000), Lepidoptera (Jiggins et al., 2000), Diptera (Hurst et al., 2000) e Pseudoscorpiones (Zeh et al., 2005).

A incompatibilidade citoplasmática (IC), causada por Wolbachia, ocorre entre a célula ovo e o esperma e resulta na morte do zigoto em espécies diploides ou produção de machos em espécies haplodiplóides (Werren, 1997). A IC pode ocorrer em dois modos: unidirecional e bidirecionalmente. $O$ primeiro ocorre quando 0 esperma de um macho infectado fertiliza um ovo não infectado, sendo que os cruzamentos recíprocos são compatíveis (Werren, 1997). A incompatibilidade bidirecional ocorre tipicamente quando machos e fêmeas infectados por diferentes estirpes são mutuamente incompatíveis (Werren, 1997).

O mecanismo da IC não é conhecido, mas os resultados observados podem ser explicados por um modelo denominado "mod/resc" (Werren, 1997). A IC, aparentemente, envolve dois componentes: a "marcação" do espermatozoide (sistema mod) e o "resgate" (sistema rescue) no ovo fertilizado. De acordo com este modelo, 
durante a espermatogênese, os cromossomos paternos sofrem alguma forma de marcação pela ação de fatores secretados pelas bactérias. Para que o processo da mitose no zigoto se complete, o ovo deve estar infectado pela bactéria de uma mesma linhagem que, ao liberar outro fator (resc), realiza um processo de "recuperação" dos cromossomos paternos, viabilizando a singamia e o processo reprodutivo. Se este "resgate" não ocorrer, o ovo e o espermatozoide permanecem incompatíveis (Werren, 1997). O cruzamento incompatível é devido à assincronia dos pró-núcleos masculino e feminino na fase inicial da mitose; o atraso na ruptura do envelope nuclear masculino e fosforilação da histona H3 (uma modificação da histona é requerida para a iniciação da mitose) indica que a actividade de CDK1, uma quinase chave que comanda a célula em mitose, é retardada no pro-núcleo masculino (Reed \& Warren, 1995; Lassy \& Karr, 1996; Tram \& Sullivan, 2002). Como resultado, as cromátides da fêmea estão devidamente condensadas e encontram-se na primeira placa metafásica, mas os cromossomos do espermatozóide estão em estado semicondensado. Durante a anáfase os cromossomas femininos separam normalmente, enquanto que os pronúcleos masculinos ou são expandidos para os polos do centrossoma ou são excluídos totalmente (Lassy \& Karr, 1996; Tram et al., 2006). Em condições normais, em insetos, durante a primeira divisão mitótica, os cromossomos maternos e paternos permanecem separados em regiões distintas da placa metafásica. Os cromossomos permanecem separados durante a anáfase, e só se misturam durante a telófase. Esta organização do fuso, conhecido como o eixo gonomérico, é única para a primeira divisão mitótica em insetos (Callaini et al., 1997; Kawamura, 2001). Em embriões de Drosophila simulans com IC, os cromossomos maternos entram na transição metáfase/anáfase, enquanto os paternos permanecem indevidamente condensados permanecendo na metáfase, podendo ser resultado da ativação checkpoint do fuso (Callaini et al., 1997; Serbus et al., 2008). Em outras células, a ativação do checkpoint do fuso previne a segregação do conjunto de cromossomos. Entretanto, em embriões com IC, metade do eixo gonomérico permanece presa, enquanto a outra entra em anáfase, indicando a segregação independente (Serbus et al., 2008). Um resultado destes cruzamentos incompatíveis é desenvolvimento haploide, observados em moscas, vespas e mosquitos (Werren et al., 2008). Este controle independente da transição metáfase/anáfase explica os diferentes resultados da IC em insetos haplodiploides e diploides. Por exemplo, a IC resulta em morte do embrião em Nasonia longicornis e $N$. giraulti, enquanto em $N$. vitripennis resulta em machos haploides (Bordenstein et al., 2003). Este modelo é consistente com as observações tanto de IC unidirecional quanto da bidirecional. 
Embora menos comum que a IC, a Wolbachia também induz partenogênese (IP) em algumas espécies hospedeiras cujos machos se desenvolvem a partir de ovos não fertilizados, tais como ácaros, himenópteros e tisanópteros (Stouthamer et al., 1990; Weeks \& Breeuwer, 2001; Arakaki et al., 2001). Ovos não fertilizados de fêmeas infectadas produzem filhas, que, ao contrário dos machos, são capazes de transmitir as bactérias às gerações seguintes (Serbus et al., 2008). Como na IC, a IP induzida pela Wolbachia é causada pela interrupção do ciclo celular no início da embriogênese o que resulta em desenvolvimento diploide em ovos não fertilizados (Serbus et al., 2008). Em Trichogramma sp. e Leptopilina clavipes, a anáfase é abortiva durante a primeira divisão embrionária resultando em um núcleo diploide em vez de dois núcleos haploides (Stouthamer \& Kazmer, 1994; Pannebaker et al., 2004). No ácaro Bryobia praetiosa a IP parece ser funcionalmente apomítica alterando a meiose, resultando em gametas diploides (Weeks \& Breeuwer, 2001). Em alguns casos, a infecção é polimórfica dentro de uma espécie e os efeitos cromossômicos são suprimidos quando o esperma fertiliza os ovos, ao passo que em outras, a infecção é fixada dentro da espécie, o que resulta na IP induzida por Wolbachia (Serbus et al., 2008).

No efeito de feminização causada pela Wolbachia em isópodos há a supressão da glândula androgênica, convertendo machos em fêmeas reprodutivas competentes (Rigaud et al., 1991; Rousset et al., 1992; Juchault et al, 1994). Em insetos, a feminização foi descrita em Eurema hecabe (Lepidptera) (Hiroki et al., 2002) e em Zygnidia pullula (Hemiptera) (Negri et al., 2008). O mecanismo exato de feminização não está claro, embora em E. hecabe, a Wolbachia parece interferir com a via de determinação do sexo e deve atuar de forma contínua ao longo do desenvolvimento de feminização completa (Hiroki et al., 2002). Tem sido postulado que a feminização por Wolbachia pode levar à evolução de novos sistemas de determinação do sexo, tais como mudanças de fêmea heterogamética para macho heterogamético, embora a evidência conclusiva não fosse demonstrada (Werren \& Beukeboom, 1998).

A morte dos machos induzida pela Wolbachia ocorre durante a embriogênese (Serbus et al., 2008). Inicialmente, a prole totalmente de fêmeas em Ostrinia scapularis, fora descrita como feminização induzida por Wolbachia. Porém, Kageyama et al. (2002) ao eliminarem a Wolbachia das fêmeas com tetraciclina, observaram a produção de prole exclusivamente de machos. Na ausência da Wolbachia, fêmeas genéticas morrem durante o desenvolvimento larval, enquanto que na presença da bactéria, machos genéticos são feminizados e morrem durante o desenvolvimento larval (Kageyama et al., 2002). Ainda não está claro em que nível a Wolbachia interfere na determinação do sexo ou como isso pode variar entre taxa de hospedeiros diferentes (Serbus et al., 2008). Evidências recentes indicam que algumas mortes de 
machos podem chegar a altas frequências, resultando em mudanças nos sistemas de acasalamento para acomodar a escassez de machos (Serbus et al., 2008).

Outros efeitos nos hospedeiros também foram relatados. A Wolbachia pode reprimir mutações estéreis e vias apoptóticas das células germinativas dos hospedeiros (Dedeine et al., 2005). Resistência a patógenos foi descrita em Drosophila melanogaster. Populações tratadas com tetraciclina para eliminação da bactéria Wolbachia e inoculadas com um retrovírus DCV patógeno à Drosophila (Drosophila C Virus), apresentaram maior taxa de mortalidade que nas populações infectadas com Wolbachia (Teixeira et al., 2008; Hedges et al., 2008). Também em $D$. melanogaster e em $D$. simulans, os indivíduos de populações em que a bactéria foi eliminada, foram menos eficazes no acasalamento e respostas a estímulos olfativos (Crespigny et al., 2006; Peng et al., 2008). Em uma população de D. melanogaster da Califórnia (EUA), Weeks et al. (2007) observaram que fêmeas infectadas eram mais eficazes na fecundidade que fêmeas não-infectadas. Na vespa parasitoide Asobara tabita, fêmeas nas quais a bactéria Wolbachia fora eliminada, apresentaram apoptose nos ovários, podendo ser um indício de que a bactéria é importante para a ovogênese do hospedeiro (Pannebaker et al., 2007). Em Culex quinquefasciatus, além de IC, Almeida et al. (2011), observaram desenvolvimento e oviposição tardios de populações nas quais a Wolbachia fora eliminada. Além disso, observaram um maior desempenho reprodutivo nas populações tratadas, embora estas tivessem menor longevidade. Estes fatos sugerem que a relação bactéria-hospedeiro pode alterar-se de parasitismo para mutualismo (Pannebaker et al., 2007). Também em D. simulans, Snook et al. (2000) observaram que machos infectados com Wolbachia produziam menor número de cistos de espermatozoides e eram menos férteis que machos nãoinfectados.

Além destes efeitos, quando linhagens de Wolbachia de um hospedeiro são transferidas a outros, diversos efeitos são encontrados. Por exemplo, uma linhagem de Wolbachia que causa IC em Cadra cautella, quando transferida a Anagasta kuehniella, causa morte dos machos nestes hospedeiros (Sasaki \& Ishikawa, 2000). Em Drosophila bifasciata também causa morte dos machos, mas aqueles que escapam têm baixo nível de IC (Hurst et al., 2000). Drosophila recens, naturalmente infectada por Wolbaquia, na qual induz IC, quando transferia a Drosophila subquinaria, o mecanismo de morte dos machos é imediatamente acionado (Jaenike, 2007). Em Aedes aegypti infectados com cepas de Wolbachia originárias de D. melanogaster, são observados efeitos diminuição de longevidade (McMeniman et al, 2009), redução do sucesso na alimentação de sangue (Turley et al, 2009), malformação na probóscide 
(Moreira et al, 2009b), diminuição na resistência a patógenos (Moreira et al, 2009a), aumento da taxa metabólica (Evans et al, 2009). Em Aedes albopictus foram observadas redução da fecundidade e diminuição na taxa de eclosão quando infectado com linhagens de Wolbachia originárias de Culex pipiens (Calvitti et al, 2010).

Normalmente a transmissão de Wolbachia ocorre verticalmente entre indivíduos de mesma espécie através da célula-ovo, da fêmea infectada para sua progênie (Werren, 1997). Entretanto, cepas de Wolbachia-A que apresentam sequências idênticas ou muito similares do gene ftsZ foram encontradas em hospedeiros das ordens Coleoptera, Diptera, Hymenoptera e Lepidoptera (Werren, 1997), sugerindo fortemente uma transmissão horizontal. A transmissão horizontal também foi detectada em Wolbachia-B, na qual as estirpes de Wolbachia encontradas em vespas parasitoides (Nasonia giraulti) e moscas varejeiras (Protocalliphora) estão intimamente relacionadas filogeneticamente (Werren et al., 1995; Werren, 1997). Esses resultados sugerem haver uma transferência destas bactérias entre organismos ecologicamente relacionados que participam de relações presa-predador, parasitahospedeiro e parasitoide-hospedeiro (Werren, 1997). Diversos experimentos sugerem a ocorrência de transferência horizontal em espécies relacionadas: Vavre et al. (1999) encontraram Leptopilina heterotoma e $D$. simulans contaminadas com variantes semelhantes de Wolbachia (variante 1), o mesmo ocorrendo entre Asobara tabita e $D$. melanogaster (variante 2). Baldo et al. (2008) detectaram indícios de transferência horizontal em aranhas do gênero Agelenopsis. Raychoudry et al. (2009) encontraram evidências de transferência da bactéria entre gêneros diferentes de insetos, sendo adquiridas de moscas varejeiras, de vespa Muscidifurax uniraptor e de Drosophila sp. A transmissão entre clados geneticamente diferentes também foi observada por Panaram \& Marshall (2007) ao detectarem a presença do supergrupo F de Wolbachia, característico de nematoide, em insetos ortópteros. Kraaijeveld et al. (2011) encontraram vários indivíduos de Leptolina clavipes, vespa parasitoide infectada com IP-Wolbachia, contaminados com uma única linhagem da bactéria, sugerindo, segundo os autores, que a transmissão horizontal ocorre nos estágios iniciais da infecção. A transferência horizontal de Wolbachia por relação parasitoide-hospedeiro foi sugerida entre espécies de Anastrepha e microhimenopteros associados por Mascarenhas (2007), que encontrou linhagens idênticas de Wolbachia infectando as duas espécies de hospedeiros. Marcon (2009) também encontrou evidências de transferência horizontal entre Anastrepha e vespas parasitas de dípteros. 
Em várias interações Wolbachia-hospedeiros, a transferência horizontal de genes (THG) da Wolbachia para seus hospedeiros tem sido reportada, como em Drosophila ananassae, Nasonia vitripentis, N. longicornis, N. giraulti, Brugia malayi, Dirofilaria immits (Dunning-Hotopp et al., 2007), Aedes aegypt, Ae. mascarensis (Klasson et al., 2009), Acanthocheilonema viteae, Onchocerca flexuosa (McNulty et al. 2010). O genoma quase completo de Wolbachia foi encontrado no segundo cromossomo de $D$. ananassae, sendo que quase $2 \%$ dos genes transferidos podem ser transcritos (Dunning-Hotopp et al., 2007). No genoma de vespas parasitódes do gênero Nasonia e nos nemátodas do gênero Onchocerca, Brugia e Dirofilaria um pequeno número de genes da Wolbachia foi detectado (Dunning-Hotopp et al., 2007). No besouro Monochanus alternatus ao menos $14 \%$ do genoma da Wolbachia é localizado em um cromossomo do hospedeiro (Aikawa et al., 2009). Evento de THG foi observado em Ae. aegypt, sendo classificado como transcricionalmente ativo em suas glândulas salivares (Klasson et al., 2009). Em Anastrepha, Marcon et al. (2011b) identificaram transposons do tipo mariner nas linhagens de Wolbachia que infectam três espécies destas moscas, sugerindo que há troca de fragmentos de DNA entre a bactéria e seus hospedeiros. As inserções dos fragmentos de DNA da Wolbachia no hospedeiro podem resultar em novas funções aos genes, a aquisição destes novos genes poderia ocasionar um rearranjo cromossômico no hospedeiro, o que poderia resultar em isolamento reprodutivo (Werren et al., 2008; Marcon, 2009).

No Brasil, Selivon et al. (1996) observaram a presença de grande população de bactérias no vitelo e células polares de embriões Anastrepha sp.2 aff. fraterculus. Posteriormente, com o sequenciamento do gene $\mathrm{fts} Z$ do ciclo celular bacteriano, foi demonstrado que tais bactérias pertencem ao gênero Wolbachia e que são encontradas nas células germinativas dos embriões e em todas etapas do desenvolvimento da linhagem germinativa das fêmeas, inclusive nos ovos maduros das fêmeas adultas, indicando uma transmissão vertical desta bactéria nesta espécie (Selivon et al., 2002). A presença da bactéria Wolbachia também foi observada em uma amostra de população natural e em duas colônias de laboratório de Ceratitis capitata (Rocha et al., 2005) e em diversas espécies de Anastrepha (Coscrato et al., 2009). Mascarenhas (2007) observou a presença de Wolbachia em sete espécies de Anastrepha e quatro espécies de Braconídeos associados.

Em moscas-das-frutas, diversos estudos com Wolbachia foram feitos, demonstrando incompatibilidade citoplasmática em Bactrocera ascita (Jamnongluk et al., 2002), Rhagoletis cerasi (Riegler et al., 2002; Zabalou et al., 2004; Charlat et al., 2004), Ceratitis capitata (Zabalou et al., 2004). Ribeiro (2009) demonstrou a ocorrência 
de incompatibilidade citoplasmática mediada pela bactéria em Anastrepha sp.1 aff. fraterculus e Anastrepha obliqua.

A família Tephritidae congrega espécies que caracteristicamente se desenvolvem em tecidos vegetais vivos. Várias espécies utilizam frutos como substrato alimentar no estágio de larva, adquirindo o status de inseto-praga quando esses frutos são de valor comercial. As espécies-praga pertencem aos gêneros Anastrepha, Bactrocera, Ceratitis, Dacus, Rhagoletis e Toxotrypana (White \& ElsonHarris, 1992). No Brasil as espécies mais importantes pertencem aos gêneros Anastrepha e Ceratitis capitata (Malavasi et al., 2000).

O gênero Anastrepha é endêmico do Continente Americano e compreende 215 espécies descritas distribuídas por toda região Neotropical e parte da Neártica, das quais 112 ocorrem no Brasil (Zucchi, 2007; 2008). Norrbom et al. (1999) com base em características morfológicas, agruparam as espécies de Anastrepha em dezessete grupos infragenéricos. Posteriormente, os resultados obtidos por Norrbom et al.(1999), foram corroborados através das análises do gene ribossomal $16 \mathrm{~S}$ mitocondrial (McPheron et al. 1999) e da região hipervariável do gene period (Barr et al., 2005). As espécies registradas no país pertencem a 12 grupos, sendo que os grupos com maior número de espécies são: fraterculus e mucronota com 17 espécies cada, pseudoparallella (9), robusta e spatulata (5), serpentina (5), daciformis (4), dentata, grandis e punctata (4), leptozona (3) e benjamini (1) (Zucchi, 2007, 2008).

As espécies de importância econômica no Brasil são: $A$. fraterculus (Wiedemann), A. obliqua (Macquart), A. sororcula Zucchi, A. zenildae Zucchi e $A$. distincta Greene, que pertencem ao grupo fraterculus; $A$. grandis (Macquart) (grupo grandis); A. pseudoparallella (Loew) (grupo pseudoparallella); e A. bistrigata Bezzi, $A$. serpentina (Wiedemann) e A. striata Schiner (grupo serpentina) (Zucchi, 2007).

Dentre os grupos, um dos que tem recebido bastante atenção nos últimos anos é o grupo fraterculus por congregar muitas das espécies-praga (White \& Elson-Harris, 1992; Aluja, 1994), incluindo A. fraterculus (sensu lato). Existem várias espécies morfologicamente similares a Anastrepha fraterculus, o que pode ser um indicativo de que o grupo infragenérico fraterculus, que inclui cerca de 27 espécies, tenha uma história evolutiva recente (Aluja, 1994; McPheron et al., 1999; Norrbom et al., 1999; Smith-Caldas et al., 2001, Selivon et al., 2005).

Dentre estas, a espécie de maior importância econômica é $A$. fraterculus s.l. (Wiedemann), distribuída nas Américas entre as latitudes $35^{\circ} \mathrm{N}$ e $35^{\circ} \mathrm{S}$ (Malavasi et al., 2000), abrangendo desde o norte do México ao centro da Argentina e norte do 
Chile (Basso et al., 2003) e ilhas do Caribe, ocupando ambientes bastante distintos. É uma espécie generalista sendo que mais de 90 de frutos hospedeiros são conhecidos (Malavasi, 2000; Zucchi, 2007). Como sugerido por Selivon et al. (2004b), é possível que esta extensa lista de hospedeiros deva estar relacionada com a dificuldade de reconhecer as diferentes espécies crípticas que integram a espécie nominal $A$. fraterculus.

A possibilidade da existência de espécies crípticas em $A$. fraterculus s.l. foi aventada na década de 1940, quando Stone (1942) reconheceu uma extensa variação na morfologia das asas em amostras desta espécie, mas preferiu considerá-las como raças geográficas. Em 1944, Baker et al., sugeriram que, na verdade, um complexo de espécies crípticas poderia estar envolvido. Estudos posteriores corroboraram estes resultados utilizando diversas características biológicas, como cariótipo (Mendes, 1958; Bush, 1962; Solferini \& Morgante, 1987; Morgante et al., 1993); isozimas (Morgante et al., 1980; Steck 1991; Amaral, 1994; Alberti et al., 1999, 2002; Basso et al., 2003); RFLP do DNA mitocondrial (Steck \& Sheppard, 1993; Santos, 1994); RNA 16S mitocondrial (McPheron et al., 1999), COI mitocondrial (Smith-Caldas et al., 2001) e o gene nuclear period (Barr et al., 2005).

No Brasil, diversos estudos encontraram diferenças nos cariótipos (Selivon et al., 2004a, 2005, Goday et al., 2006), na estrutura dos ovos (Selivon \& Perondini, 1998, Selivon et al., 2004a, Figueiredo et al., 2011), em isozimas (Selivon, 1996; Selivon et al., 2005), na morfometria de estruturas dos adultos (Selivon et al., 2004b, 2005), isolamento reprodutivo (Selivon et al., 1999, 2005), no ITS1 (Prezotto, 2008), caracterizando a existência de três espécies no complexo que foram denominadas, provisoriamente por Anastrepha sp. 1 affinis fraterculus, A. sp. 2 aff. fraterculus e $A$. sp. 3 aff. fraterculus. Além dessas, Selivon et al. (2004b) caracterizou outra entidade, Anastrepha sp. 4 affinis fraterculus, encontrada em Guayaquil, Equador. HernándezOrtiz et al. (2004) utilizando análise morfométrica (acúleo, asas e mesonoto) e Prezotto (2008) através da caracterização do ITS1, analisando amostras de diversas localidades do México, Peru, Equador, Colômbia, Brasil e Argentina, mostraram que outras espécies devem existir no complexo de espécies crípticas de $A$. fraterculus. Vera e colaboradores (2006) encontraram isolamento reprodutivo entre populações de diversas localidades do Peru e Colômbia e Brasil/Argentina, mas compatibilidade entre Brasil e Argentina. Amostras de A. fraterculus s.l. de populações da Argentina e do Peru apresentaram diferenças comportamentais, químicas, citológicas e genéticas, indicando pertencerem a diferentes entidades biológicas (Cáceres et al., 2009). Recentemente, Hernández-Ortiz et al. (2012) demonstraram a presença de, ao menos, 
sete morfotipos distintos dentro deste complexo de espécies. De acordo com as áreas biogeográficas das Américas, as populações que ocorrem no domínio Mesoamericano (México, Guatemala e Panamá) foram agrupadas em uma única entidade, rotuladas como morfotipo "Mexicano". No noroeste do domínio Sul-americano, as amostras caíram em três grupos distintos: o morfotipo "Venezuelano", com uma única população das planícies do Caribe venezuelano; o "Andino", morfotipo das terras altas da Venezuela e da Colômbia, e o terceiro grupo ou morfotipo "Peruano", compreendendo as amostras das planícies costeiras do Pacifico no Equador ( $A$. sp.4) e Peru. Três grupos adicionais foram identificados nas sub-regiões do Chaco e Paranaense correspondentes às três entidades caracterizadas por Selivon et al. (2004a, 2005): o morfotipo "Brasileiro-1" (A. sp.1) foi reconhecido como o mais comum ao Brasil, incluindo as amostras da Argentina, e amplamente distribuído nessas regiões biogeográficas; o morfotipo "Brasileiro-2" (A. sp.2), incluindo duas amostras do estado de São Paulo (Ilhabela e São Sebastião) e o morfotipo "Brasileiro-3" ( $A$. sp.3) incluiu uma única população de Botucatu (estado de São Paulo) (Hernández-Ortiz et al., 2012). Com base em dados publicados anteriormente (acima citados) que mostram diferenciação genética e cariotípica, bem como isolamento reprodutivo entre alguns desses grupos, Hernández-Ortiz et al. (2012) concluíram que esses morfotipos de fato representam grupos naturais e entidades taxonômicas distintas. Várias espécies de Anastrepha, inclusive as três entidades do complexo fraterculus no Brasil, estão infectadas pela bactéria Wolbachia, como acima apresentado. Além disso, Cáceres e colaboradores (2009) encontraram contaminação com a bactéria Wolbachia pertencente ao supergrupo "A" em amostras de populações do Brasil, Argentina e Peru. Uma amostra de região desconhecida apresentou dupla infecção, com cepas do supergrupo "A" e cepas do supergrupo "B" de Wolbachia. Recentemente, Martínez et al. (2012) encontraram infecção de Wolbachia pertencentes ao supergrupo "B" em Anastrepha striata do México.

Estudos que sequenciaram o genoma da $W$. pipientis mostraram que esta bactéria possui recombinação gênica (Wu et al., 2004) e que várias espécies de artrópodes estão infectados por Wolbachia dos supergrupos "A" e "B" (Werren et al., 1995; Werren \& Windsor, 2000), o que poderia causar fluxo gênico entre as espécies (Paraskevopoulos et al., 2006). Foi claramente demonstrado que recombinação no gene wsp é elevada entre os supergrupos "A" e "B" (Jiggins et al., 2001; Werren \& Bartos, 2001; Baldo et al., 2005). Assim, este gene deve ser evitado quando se procura identificar e compreender as relações entre cepas de $W$. pipentis (Paraskevopoulos et al., 2006). Desta forma, uma identificação confiável de cepas 
requer uma abordagem do tipo MLST (do inglês, Multilocus Sequence Typing). Uma ampla abordagem utilizando essa metodologia foi desenvolvida para $W$. pipientis utilizando cinco "genes de manutenção" (standard house-keeping genes): gatB, $\operatorname{cox} A$, hcpA, fbpA, e ftsZ (Baldo et al., 2006a; Paraskevopoulos et al., 2006). Os resultados revelaram frequente recombinação e uma notável diversidade entre $W$. pipientis, na qual 35 de 37 haplótipos eram únicos (Baldo et al., 2006a). Recombinação frequente entre cepas intimamente relacionadas é consistente com o fato dessas cepas serem membros de uma única espécie, a W. pipientis (Paraskevopoulos et al., 2006).

Um sistema de tipagem suplementar utilizando as regiões hipervariáveis da proteína de superfície Wsp da Wolbachia foi também desenvolvido (Wsp-Typing). A estrutura do gene wsp consiste em quatro regiões hipervariáveis (HVR) intercaladas por regiões conservadas (CR). Porções do gene englobando HVRs e CRs têm sido extensivamente embaralhadas entre as linhagens, gerando haplótipos e sequencias extremamente divergentes da proteína (Baldo \& Werren, 2007). Segundo esses autores, o gene wsp pode ser utilizado para a identificação de haplótipos, mas não seria indicado para a identificação dos supergrupos a que esses haplótipos estariam associados.

Como a Wolbachia induz a IC em diversos organismos, foi proposto o seu emprego em programas de erradicação ou supressão de populações de insetos-praga, (Beard et al., 1993; Zabalou et al., 2004). Nessa metodologia, Técnica do Inseto Incompatível (TII), a IC pode ser utilizada para controlar populações naturais de pragas de insetos de uma maneira análoga à Técnica do Inseto Estéril (TIE) (Zabalou et al., 2009; Bredsforard \& Dobson, 2011). Para a aplicação bem-sucedida do TII (com base em uma abordagem IC unidirecional) contra a espécie-alvo, é essencial que as linhagens ou cepas da Wolbachia sejam rigorosamente identificadas para que sejam somente liberados machos portadores de uma linhagem de Wolbachia distinta da linhagem existente na população alvo.

Como existe a indicação de que a Wolbachia pode estar envolvida em efeitos de IC entre populações de Anastrepha e no isolamento reprodutivo entre as espécies do complexo (Selivon et al., 2005; Ribeiro, 2009) e também existem evidências que diferentes estirpes de Wolbachia podem estar envolvidas (Coscrato, 2009; Mascarenhas, 2007), há a necessidade de uma identificação mais precisas das cepas de Wolbachia existentes nessas espécies para que programas de controle populacional dessas espécies-praga possam ser eventualmente efetivados. 


\section{Objetivos}

Objetivo Geral:

Utilizar as análises pelas metodologias do MLST e do Wsp Typing em buscando a caracterização de diferentes linhagens da Wolbachia presentes em amostras do complexo $A$. fraterculus da região Neotropical e realizar experimentos para corroborar a existência de incompatibilidade citoplasmática causada por essa bactéria em linhagens destas espécies.

Objetivos específicos:

- Amplificação e sequenciamento dos genes gatB, $\operatorname{coxA}, h c p A$, fbpA, ftsZ de Wolbachia nas diferentes amostras do complexo $A$. fraterculus

- Caracterizar as linhagens e Wolbachia pelo MLST.

- Deteç̧ão de Wolbachia nas diferentes amostras por amplificação e sequenciamento do gene wsp.

- Caracterização das linhagens pelo Wsp-Typing.

- Estabelecer as relações filogenéticas entre as diferentes estirpes de Wolbachia comparando as metodologias MLST e Wsp-Typing.

- Obter linhagens de A. sp.1 e A. obliqua isentas de Wolbachia por tratamento térmico.

- Descrever os resultados de cruzamentos intraespecíficos envolvendo as espécies $A$. sp.1 e A. obliqua isentas e não isentas de Wolbachia quanto as taxas de eclosão.

- Observar possíveis diferenças nos ovários e testículos de indivíduos tratados e não tratados de ambas as espécies. 


\section{Material e Métodos}

\section{Amostras utilizadas}

Amostras populacionais de espécies do complexo fraterculus (A. sp.1, A. sp.2 e A. sp.3) coletadas no Vale do Paraíba, litoral norte e região central do estado de São Paulo, sul de Minas Gerais, litoral e parte central do Paraná e norte de Santa Catarina (Tabela I, Figura 1).

Tabela I. Localidade, coordenadas geográficas e hospedeiros das amostras populacionais do complexo A. fraterculus coletados em diferentes localidades do Brasil.

\begin{tabular}{|c|c|c|c|c|}
\hline Código & Localidade & $\begin{array}{c}\text { Coordenadas } \\
\text { Geográficas }\end{array}$ & Hospedeiro & Entidade \\
\hline Ara & Araraquara (SP) & $\begin{array}{l}21^{\circ} 47^{\prime} 38^{\prime \prime S} \mathrm{~S} \\
48^{\circ} 10^{\prime} 33^{\prime \prime O}\end{array}$ & $\begin{array}{c}\text { Goiaba } \\
\text { (Psidium guajava) }\end{array}$ & A. sp.1 \\
\hline Ber & Bertioga (SP) & $\begin{array}{l}23^{\circ} 51^{\prime} 14^{\prime \prime} \mathrm{S} \\
46^{\circ} 08^{\prime} 20^{\prime \prime} \mathrm{O}\end{array}$ & $\begin{array}{c}\text { Chapéu-de-sol } \\
\text { (Terminalia cattapa) }\end{array}$ & $\begin{array}{l}\text { A. sp. } 2 \\
\text { A. sp.3 }\end{array}$ \\
\hline Bot & Botucatu (SP) & $\begin{array}{l}22^{\circ} 56^{\prime} 18^{\prime \prime} \mathrm{S} \\
48^{\circ} 18^{\prime} 25^{\prime \prime} \mathrm{O}\end{array}$ & Goiaba & A. sp.1 \\
\hline Ilbi & Ibiúna (SP) & $\begin{array}{l}23^{\circ} 39^{\prime} 21^{\prime \prime S} \\
47^{\circ} 13^{\prime} 22^{\prime \prime O}\end{array}$ & Goiaba & A. sp.1 \\
\hline Ilb & Ilhabela (SP) & $\begin{array}{l}23^{\circ} 48^{\prime} 22^{\prime \prime} \mathrm{S} \\
45^{\circ} 21^{\prime} 54^{\prime \prime} \mathrm{O}\end{array}$ & Goiaba & A. sp. 2 \\
\hline Ilc & Ilha Comprida (SP) & $\begin{array}{l}24^{\circ} 44^{\prime} 27^{\prime \prime} \mathrm{S} \\
47^{\circ} 32^{\prime} 24^{\prime \prime} \mathrm{O}\end{array}$ & Chapéu-de-sol & $\begin{array}{l}\text { A. sp. } 2 \\
\text { A. sp. } 3\end{array}$ \\
\hline Ita & Itapetininga (SP) & $\begin{array}{c}23^{\circ} 35^{\prime} 31^{\prime \prime S} \\
48^{\circ} 3^{\prime} 10^{\prime \prime} \mathrm{O} \\
\end{array}$ & Goiaba & A. sp.1 \\
\hline Ite & Itanhaém (SP) & $\begin{array}{l}24^{\circ} 10^{\prime} 58^{\prime \prime} \mathrm{S} \\
46^{\circ} 47^{\prime} 20^{\prime \prime} \mathrm{O}\end{array}$ & Chapéu-de-sol & A. sp. 2 \\
\hline Itr & Itararé (SP) & $\begin{array}{c}24^{\circ} 6^{\prime} 54^{\prime \prime S} \\
49^{\circ} 20^{\prime} 27^{\prime \prime O}\end{array}$ & Goiaba & A. sp.1 \\
\hline Jac & Jacareí (SP) & $\begin{array}{l}23^{\circ} 18^{\prime} 18^{\prime \prime S} \mathrm{~S} \\
45^{\circ} 41^{\prime \prime} 16^{\prime \prime} \mathrm{O}\end{array}$ & Goiaba & A. sp.1 \\
\hline Jam & Jambeiro (SP) & $\begin{array}{l}23^{\circ} 15^{\prime} 14^{\prime \prime} \mathrm{S} \\
45^{\circ} 07^{\prime} 30^{\prime \prime} \mathrm{O}\end{array}$ & Goiaba & $\begin{array}{l}\text { A. sp.1 } \\
\text { A. sp. } 3\end{array}$ \\
\hline Lor & Lorena (SP) & $\begin{array}{l}22^{\circ} 43^{\prime} 51^{\prime \prime S} \\
45^{\circ} 07^{\prime} 30^{\prime \prime} \mathrm{O}\end{array}$ & Goiaba & A. sp.1 \\
\hline Mir & Mirassol (SP) & $\begin{array}{c}20^{\circ} 49^{\prime} 7 " \mathrm{~S} \\
49^{\circ} 30^{\prime} 30^{\prime \prime O} \\
\end{array}$ & Goiaba & A. sp.1 \\
\hline Pet & Pedro de Toledo (SP) & $\begin{array}{l}24^{\circ} 16^{\prime} 30^{\prime \prime S} \\
47^{\circ} 13^{\prime} 58^{\prime \prime O} \mathrm{O}\end{array}$ & Goiaba & $\begin{array}{l}\text { A. sp. } 2 \\
\text { A. sp. } 3\end{array}$ \\
\hline Per & Peruíbe (SP) & $\begin{array}{l}24^{\circ} 19^{\prime} 12^{\prime \prime} \mathrm{S} \\
46^{\circ} 59^{\prime} 52^{\prime \prime} \mathrm{O} \\
\end{array}$ & Chapéu-de-sol & $\begin{array}{l}\text { A. sp. } 2 \\
\text { A. sp. } 3\end{array}$ \\
\hline Pir & Piracicaba (SP) & $\begin{array}{l}22^{\circ} 43^{\prime} 30^{\prime \prime} \mathrm{S} \\
47^{\circ} 38^{\prime} 56^{\prime \prime} \mathrm{O} \\
\end{array}$ & Goiaba & A. sp.1 \\
\hline \multirow[b]{2}{*}{ Sal } & \multirow[b]{2}{*}{ Salesópolis (SP) } & \multirow{2}{*}{$\begin{array}{l}23^{\circ} 31^{\prime} 51^{\prime \prime S} \\
45^{\circ} 50^{\prime} 30^{\prime \prime} \mathrm{O}\end{array}$} & Goiaba & A. sp.1 \\
\hline & & & $\begin{array}{c}\text { Laranja } \\
\text { (Citrus sinensis) } \\
\end{array}$ & A. sp. 3 \\
\hline \multirow{2}{*}{ Sis } & \multirow{2}{*}{ Santa Isabel (SP) } & \multirow{2}{*}{$\begin{array}{l}23^{\circ} 19^{\prime} 00^{\prime \prime} \mathrm{S} \\
46^{\circ} 13^{\prime} 25^{\prime \prime} \mathrm{O}\end{array}$} & Goiaba & A. sp.1 \\
\hline & & & Laranja & A. sp. 2 \\
\hline SIp & São Luís do Paraitinga (SP) & $\begin{array}{l}23^{\circ} 13^{\prime} 24^{\prime \prime S} \\
45^{\circ} 18^{\prime} 47^{\prime \prime O} \\
\end{array}$ & Goiaba & $\begin{array}{l}\text { A. sp.1 } \\
\text { A. sp.3 } \\
\end{array}$ \\
\hline \multirow[t]{2}{*}{ Sse } & \multirow[t]{2}{*}{ São Sebastião (SP) } & \multirow{2}{*}{$\begin{array}{l}23^{\circ} 45^{\prime} 22^{\prime \prime} \mathrm{S} \\
45^{\circ} 24^{\prime} 54^{\prime \prime} \mathrm{O}\end{array}$} & Laranja & A. $\mathrm{sp} .2$ \\
\hline & & & Chapéu-de-sol & A. sp. 3 \\
\hline
\end{tabular}




\begin{tabular}{|c|c|c|c|c|}
\hline \multirow{2}{*}{ Tau } & \multirow{2}{*}{ Taubaté (SP) } & \multirow{2}{*}{$\begin{array}{c}23^{\circ} 01^{\prime} 33^{\prime \prime} \mathrm{S} 45^{\circ} 33^{\prime} \\
31^{\prime \prime} \mathrm{O}\end{array}$} & Laranja & A. sp. 2 \\
\hline & & & Goiaba & A. sp. 3 \\
\hline Uba & Ubatuba (SP) & $\begin{array}{l}22^{\circ} 46^{\prime} 24^{\prime \prime} \mathrm{S} \\
45^{\circ} 41^{\prime} 52^{\prime \prime} \mathrm{O}\end{array}$ & Chapéu-de-sol & $\begin{array}{l}\text { A. sp. } 2 \\
\text { A. sp. } 3\end{array}$ \\
\hline Tri & Três Rios (RJ) & $\begin{array}{l}22^{\circ} 07^{\prime} 24^{\prime \prime} \mathrm{S} \\
43^{\circ} 12^{\prime} 47^{\prime \prime} \mathrm{O}\end{array}$ & Goiaba & A. sp.1 \\
\hline Ube & Uberlândia (MG) & $\begin{array}{l}18^{\circ} 56^{\prime} 46^{\prime \prime} \mathrm{S} \\
48^{\circ} 13^{\prime} 55^{\prime \prime} \mathrm{O}\end{array}$ & Goiaba & A. sp.1 \\
\hline Cai & Caiobá (PR) & $\begin{array}{l}25^{\circ} 49^{\prime} 04^{\prime \prime} \mathrm{S} \\
48^{\circ} 32^{\prime} 34^{\prime \prime} \mathrm{O}\end{array}$ & Chapéu-de-sol & $\begin{array}{l}\text { A. sp. } 2 \\
\text { A. sp. } 3\end{array}$ \\
\hline Gua & Guarapuava (PR) & $\begin{array}{l}25^{\circ} 23^{\prime} 42^{\prime \prime} \mathrm{S} \\
51^{\circ} 27^{\prime} 28^{\prime \prime O}\end{array}$ & Goiaba & A. sp.1 \\
\hline Gut & Guaratuba (PR) & $\begin{array}{l}25^{\circ} 52^{\prime} 58^{\prime \prime S} \\
48^{\circ} 34^{\prime} 30^{\prime \prime O}\end{array}$ & Chapéu-de-sol & $\begin{array}{l}\text { A. sp. } 2 \\
\text { A. sp. } 3\end{array}$ \\
\hline Imb & Imbituva (PR) & $\begin{array}{l}25^{\circ} 13^{\prime} 48^{\prime \prime} \mathrm{S} \\
50^{\circ} 36^{\prime} 16^{\prime \prime} \mathrm{O}\end{array}$ & Goiaba & A. sp.1 \\
\hline Ira & Irati (PR) & $\begin{array}{l}25^{\circ} 28^{\prime} 10^{\prime \prime S} \\
50^{\circ} 39^{\prime} 30^{\prime \prime O}\end{array}$ & Goiaba & A. sp.1 \\
\hline Par & Paranaguá (PR) & $\begin{array}{l}25^{\circ} 31^{\prime} 12^{\prime \prime S} \\
48^{\circ} 30^{\prime} 32^{\prime \prime O}\end{array}$ & Chapéu-de-sol & A. sp. 2 \\
\hline Sen & Sengés (PR) & $\begin{array}{c}24^{\circ} 6^{\prime} 46^{\prime \prime S} \\
49^{\circ} 27^{\prime} 50^{\prime \prime} \mathrm{O}\end{array}$ & Goiaba & A. sp.1 \\
\hline Gum & Guaramirim (SC) & $\begin{array}{l}26^{\circ} 28^{\prime} 23^{\prime \prime S} \\
49^{\circ} 00^{\prime} 10^{\prime \prime O}\end{array}$ & Goiaba & A. sp.1 \\
\hline Rne & Rio Negrinho (SC) & $\begin{array}{l}26^{\circ} 15^{\prime} 14^{\prime \prime S} \\
49^{\circ} 31^{\prime} 4 " 0\end{array}$ & Goiaba & $\begin{array}{l}\text { A. sp. } 1 \\
\text { A. sp. } 3\end{array}$ \\
\hline
\end{tabular}

Além disso, foram utilizadas amostras de outras áreas da Região Neotropical cedidas pelo Dr. Vicente Hernández-Ortiz, do Instituto de Ecología A.C.(Conacyt), Xalapa, Veracruz, México, que estavam conservadas em etanol e mantidas a -20ํ․ A amostra de Guayaquil (Equador) estava disponível no laboratório e congelada em nitrogênio líquido (Selivon et al., 2004b) (Tabela II, Figura 1). 
Tabela II. Localidade, coordenadas geográficas e hospedeiros das amostras populacionais do complexo A. fraterculus s.l. e A. sp.4 coletados em diferentes localidades da América do Sul, Central e do México.

\begin{tabular}{|c|c|c|c|c|}
\hline Código & Localidade & Coordenadas & Frutos & Entidade \\
\hline Mis & Argentina: Misiones, Posadas & $\begin{array}{l}27^{\circ} 23^{\prime} 59^{\prime \prime} \mathrm{S} \\
55^{\circ} 56^{\prime} 01^{\prime \prime} \mathrm{O}\end{array}$ & Goiaba & A. fraterculus s.l. \\
\hline Con & Argentina: Entre Ríos, Concordia & $\begin{array}{l}31^{\circ} 23^{\prime} 13^{\prime \prime S} \\
58^{\circ} 01^{\prime} 12^{\prime \prime} \mathrm{O}\end{array}$ & Goiaba & A. fraterculus s.l. \\
\hline Tuc & Argentina: Tucumán & $\begin{array}{l}27^{\circ} 02^{\prime} 18^{\prime \prime} \mathrm{S} \\
65^{\circ} 19^{\prime} 13^{\prime \prime} \mathrm{O} \\
\end{array}$ & Goiaba & A. fraterculus s.l. \\
\hline Hmo & Argentina: Tucumán, Horco Molle & $\begin{array}{l}26^{\circ} 46^{\prime} 37^{\prime \prime} \mathrm{S} \\
65^{\circ} 19^{\prime} 49^{\prime \prime} \mathrm{O}\end{array}$ & Goiaba & A. fraterculus s.l. \\
\hline Lmo & $\begin{array}{c}\text { Peru: La Molina, colônia de } \\
\text { laboratório }\end{array}$ & $\begin{array}{l}12^{\circ} 14^{\prime} 15^{\prime \prime S} \\
76^{\circ} 31^{\prime} 50^{\prime \prime} \mathrm{O}\end{array}$ & $\begin{array}{c}\text { Cherimoia } \\
\text { (Annona cherimola) }\end{array}$ & A. fraterculus s.l. \\
\hline Piu & Peru: Piura, colonia de laboratório & $\begin{array}{l}7^{\circ} 40^{\prime} 23^{\prime \prime} \mathrm{S} \\
79^{\circ} 12^{\prime} 40^{\prime \prime} \mathrm{O}\end{array}$ & Goiaba & A. fraterculus s.l. \\
\hline Guy & Equador: Guayaquil & $\begin{array}{l}\text { 2012'13"S } \\
79-53^{\prime} 50^{\prime \prime} \mathrm{O}\end{array}$ & Goiaba & A. $s p .4$ \\
\hline Tol & $\begin{array}{l}\text { Colombia: Ibagué, Tolimá, colônia de } \\
\text { laboratório }\end{array}$ & $\begin{array}{r}4^{\circ} 26^{\prime} 11^{\prime \prime} \mathrm{N} \\
75^{\circ} 11^{\prime} 29^{\prime \prime} \mathrm{O} \\
\end{array}$ & $\begin{array}{c}\text { café } \\
\text { (Coffe arabica) }\end{array}$ & A. fraterculus s.l. \\
\hline Guc & Guatemala: Guatemala City & $\begin{array}{l}14^{\circ} 36^{\prime} 51^{\prime \prime} \mathrm{N} \\
90^{\circ} 32^{\prime} 22^{\prime \prime} \mathrm{O}\end{array}$ & Goiaba & A. fraterculus s.l. \\
\hline Tap & Mexico: Chiapas, Tapachula & $\begin{array}{l}14^{\circ} 53^{\prime} 47^{\prime \prime} \mathrm{N} \\
92^{\circ} 10^{\prime} 30^{\prime \prime} \mathrm{O}\end{array}$ & $\begin{array}{l}\text { Goiaba e } \\
\text { Nêspera } \\
\text { (Eriobotrya } \\
\text { japônica) }\end{array}$ & A. fraterculus s.l. \\
\hline Chi & $\begin{array}{l}\text { Mexico: Chiapas, San Vicente L. } \\
\text { Montebello }\end{array}$ & $\begin{array}{l}16^{\circ} 24^{\prime} 36^{\prime \prime} \mathrm{N} \\
92^{\circ} 24^{\prime} 31^{\prime \prime} \mathrm{O}\end{array}$ & Goiaba & A. fraterculus s.l. \\
\hline Qur & Mexico: Quintana Roo, Chunhuhub & $\begin{array}{l}19^{\circ} 37^{\prime} 39^{\prime \prime} \mathrm{N} \\
88^{\circ} 38^{\prime} 56^{\prime \prime} \mathrm{O}\end{array}$ & Armadilha McPhail & A. fraterculus s.l. \\
\hline Teo & Mexico: Veracruz, Teocelo & $\begin{array}{l}19^{\circ} 23^{\prime} 14^{\prime \prime} \mathrm{N} \\
96^{\circ} 57^{\prime} 23^{\prime \prime} \mathrm{O}\end{array}$ & Goiaba & A. fraterculus s.l. \\
\hline Apa & $\begin{array}{l}\text { Mexico: Veracruz, Apazapan, } \\
\text { Apazapan }\end{array}$ & $\begin{array}{l}19^{\circ} 17^{\prime} \mathrm{O}^{\prime \prime} \mathrm{N} \\
96^{\circ} 36^{\prime} 59^{\prime \prime} \mathrm{O}\end{array}$ & Armadilha McPhail & A. fraterculus s.l. \\
\hline Jic & $\begin{array}{l}\text { Mexico: Veracruz, E. Zapata La } \\
\text { Jicayna }\end{array}$ & $\begin{array}{l}19^{\circ} 21^{\prime} 44^{\prime \prime} \mathrm{N} \\
96^{\circ} 39^{\prime} 23^{\prime \prime} \mathrm{O}\end{array}$ & Goiaba & A. fraterculus s.l. \\
\hline
\end{tabular}

Para efeito de comparação com outras espécies de moscas-das-frutas, foram obtida amostras de Anastrepha obliqua, coletadas em manga, nas localidades de Bariri

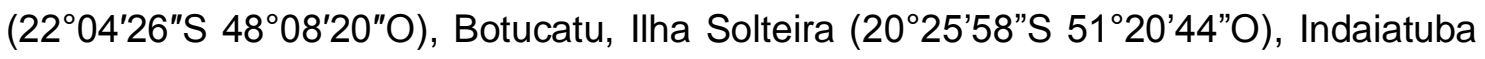

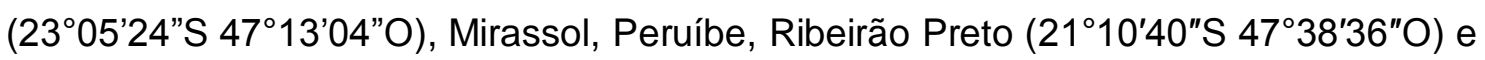
Taubaté (SP), Foi também, utilizada amostra de Ceratitis capitata obtida de seriguela (Spondias purpurea) coletada em Mirassol. 


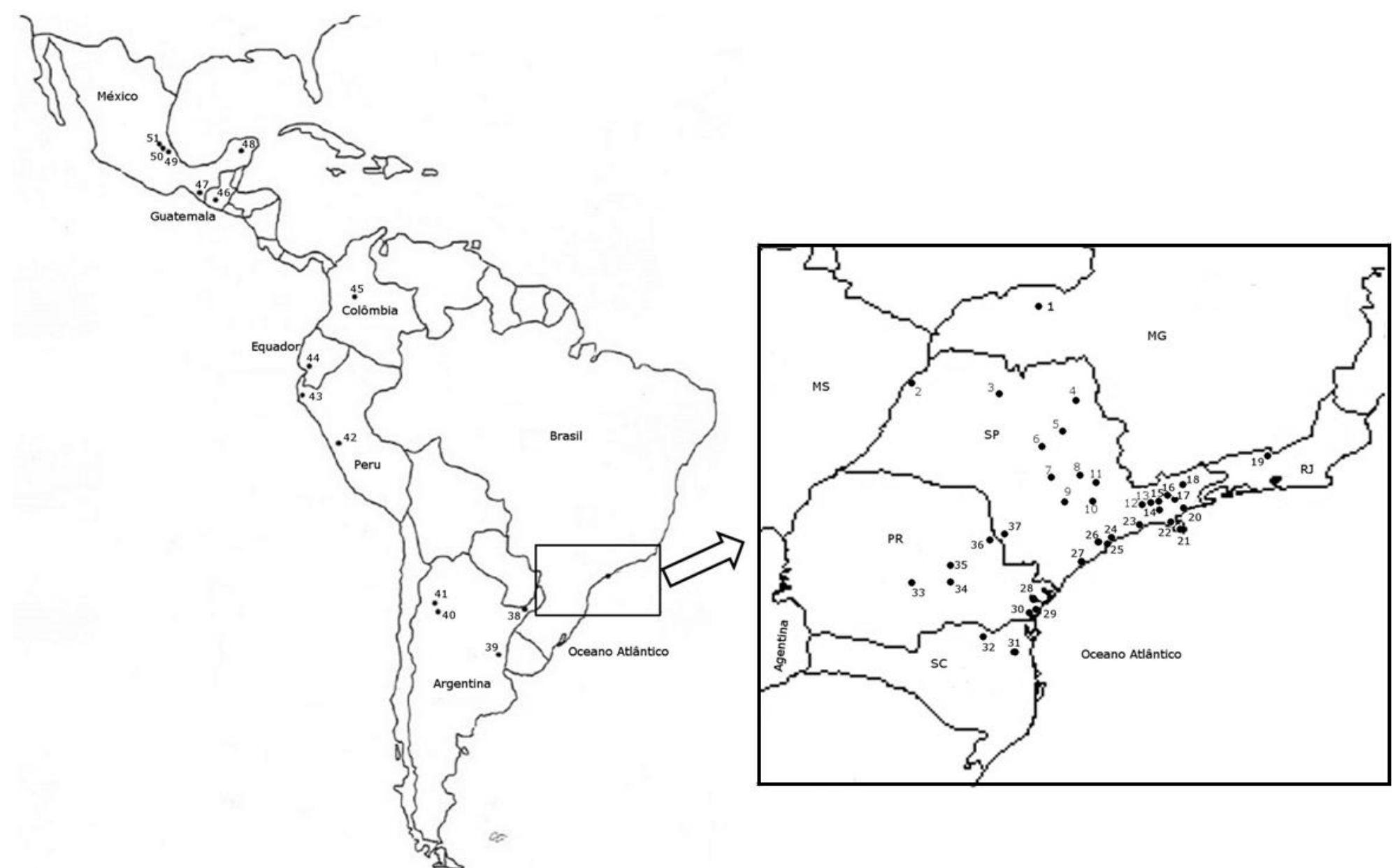

Figura1: Localidades das amostras coletadas. 1. Uberlândia (MG); 2. Ilha Solteira; 3. Mirassol (SP); 4. Ribeirão Preto (SP); 5. Araraquara (SP); 6. Bariri (SP); 7. Botucatu (SP); 8. Piracicaba (SP); 9. Itapetininga (SP); 10. Ibiúna (SP): 11. Indaiatuba (SP); 12. Santa Isabel (SP); 13. Jacareí (SP); 14. Salesópolis (SP); 15. Jambeiro (SP); 16. Taubaté (SP); 17. São Luís do Paraitinga (SP); 18. Lorena (SP); 19. Três Rios (RJ); 20. Ubatuba (SP); 21. Ilhabela (SP); 22. São Sebastião (SP); 23. Bertioga (SP); 24. Itanhaém (SP); 25. Peruíbe (SP); 26. Pedro de Toledo (SP); 27. Ilha Comprida (SP); 28. Paranaguá (PR); 29. Caiobá (PR); 30. Guaratuba (PR); 31 Guaramirim (SC); 32. Rio Negrinho (SC); 33. Guarapuava (PR); 34. Irati (PR); 35. Imbituva (PR); 36. Sengés (PR); 37. Itararé (SP); 38. Misiones (Ar); 39. Concórdia (AR); 40. Tucumán (AR); 41. Horco Molle (AR); 42. La Molina (Pe); 43. Piura (Pe); 44. Guayaquil (Eq); 45. Tolima (Co); 46. Guatemala City (Gu); 47. Tapachula (Mx); 48. Quitana Roo (Mx); 49. Teocelo (Mx); 50. Apazapan (Mx); Jicayna (Mx). 


\section{Extração de DNA}

As extrações de DNA foram realizadas seguindo o método adaptado a partir do protocolo para extração de DNA de Drosophila sp. "Single fly DNA extraction" (Jowett et al., 1986). Para cada extração foi utilizado o tórax de um indivíduo, que foi macerado em solução [Tris- $\mathrm{HCl} 10 \mathrm{mM}(\mathrm{pH}=7,5), \mathrm{NaCl} 60$ mM, EDTA 50 mM], seguida da adição de solução de lise [SDS 1,25\%, Tris- $\mathrm{HCl} 0,3 \mathrm{M}(\mathrm{pH}=9,0)$, EDTA $0,1 \mathrm{M}$, sacarose $5 \%$, proteinase $\mathrm{K}$ a $100 \mu \mathrm{g} / \mathrm{ml}$.] e a mistura foi incubada a $65{ }^{\circ} \mathrm{C}$ por 1 hora. Após, o material foi incubado a $4{ }^{\circ} \mathrm{C}$ por $45 \mathrm{~min}$, seguido de centrifugação a $12.000 \mathrm{~g} \mathrm{a} 4{ }^{\circ} \mathrm{C}$. O precipitado foi descartado e o sobrenadante transferido para outro tubo contendo etanol $100 \%$ com o dobro de seu volume para a precipitação do DNA. Após cinco minutos de incubação à temperatura ambiente, as amostras foram novamente centrifugadas a $12.000 \mathrm{~g}$ à temperatura ambiente. $O$ precipitado foi seco e re-suspendido em $20 \mu$ de $\mathrm{H} 2 \mathrm{O}$ milli-Q (Millipore) para cada amostra, que foi armazenada a $-20^{\circ} \mathrm{C}$. As amostras de DNA recém-extraído foram tratadas com RNAase (Ribonuclease A, Sigma) a uma concentração final $100 \mu \mathrm{g} / \mathrm{ml}$ por 1 hora a $37^{\circ} \mathrm{C}$, para eliminar o RNA.

\section{Amplificação dos fragmentos de genes}

Os seguintes iniciadores foram utilizados para amplificação dos genes utilizados no MLST: gatB, $\operatorname{cox} A, h c p A, f b p A$, ftsZ (Baldo et al., 2006a):

- gatB:

F1 (5'-GAK TTA AAY CGY GCA GGB GTT-3')

R1 (5'-TGG YAA YTC RGG YAA AGA TGA-3');

- $\operatorname{COxA}$ :

F1 (5'-TTG GRG CRA TYA ACT TTA TAG-3')

R1(5'- CT AAA GAC TTT KAC RCC AGT-3');

- $h c p A$ :

F1 (5'-GAA ATA RCA GTT GCT GCA AA-3')

R1 (5'- GAA AGT YRA GCA AGY TCT G-3');

- $f t s Z:$

F1 (5'-ATY ATG GAR CAT ATA AAR GAT AG-3')

R1 (5'-TCR AGY AAT GGA TTR GAT AT-3'),

- $f b p A$ :

F1 (5'-GCT GCT CCR CTT GGY WTG AT-3')

R1 (5'-CCR CCA GAR AAA AYY ACT ATT C-3') 
O ciclo de amplificação utilizado foi de 2 minutos a $94^{\circ} \mathrm{C}, 37$ ciclos $(30$ segundos a $94^{\circ} \mathrm{C}, 45$ segundos de hibridação a $54^{\circ} \mathrm{C}$ para $h c p A$, gat $B$, fts $Z$, e cox $A$, e $59^{\circ} \mathrm{C}$ para fbp $A, 1$ minuto e 30 segundos a $\left.72^{\circ} \mathrm{C}\right), 10$ minutos a $72^{\circ} \mathrm{C}$.

Para o gene wsp os iniciadores foram (Zhou et al., 1998):

wsp 81F (5'TGG TCC AAT AAG TGA TGA AGA AAC3') wsp 691R (5'AAA AAT TAA ACG CTA CTC CA3').

Os ciclos de amplificação foram de 2 minutos a 95ํㅡ, seguido de 35 ciclos (1 minuto a $95^{\circ} \mathrm{C}, 1$ minuto a $55^{\circ} \mathrm{C}, 1$ minuto a $75^{\circ} \mathrm{C}$ ) e mais 10 minutos a $72^{\circ}$. Em caso de resultado negativo de amplificação para Wolbachia, as mesmas amostras de DNA foram amplificadas com os inciadores do ITS-1 (Prezotto, 2008).

\section{Eletroforese}

Alíquotas do DNA foram analisadas por eletroforese em géis de agarose a 1,0\% em tampão TAE. A eletroforese foi realizada em cubas horizontais contendo solução TAE 1X como tampão de corrida, por 30 minutos sob tensão elétrica de $60 \mathrm{~V}$ e corrente de $60 \mathrm{~mA}$ constantes, conforme recomendado por Sambrook et al (1989). Os géis foram corados com brometo de etídio a $5 \mu \mathrm{g} / \mathrm{ml}$, visualizados em um transiluminador UV com filtro vermelho. As imagens dos géis foram digitalizadas em uma câmera digital (Vilber Loumart) e transferidas para computador para análise.

\section{Sequenciamento de DNA}

O sequenciamento dos fragmentos amplificados foi feito com os iniciadores DF2 e DR2 (que sequenciam as extremidades 5' e 3' respectivamente) e o "kit" para sequenciamento automático BigDye 2.0 (Applied Biosystems). Gerando, desta forma, uma sequência foward e outra reverse. Em cada reação de sequenciamento foram usados $200 \mathrm{ng}$ de fragmento amplificado purificado, 1 pmol de um dos iniciadores e 2 $\mu \mathrm{l}$ de BigDye. O programa de reações utilizado no aparelho termociclador Eppendorf foi 2 min a $94{ }^{\circ} \mathrm{C}, 25$ ciclos de $30 \mathrm{~s}$ de desnaturação a $94{ }^{\circ} \mathrm{C}, 30 \mathrm{~s}$ de anelamento a 60 ${ }^{\circ} \mathrm{C}$ e 2 min de elongação a $68^{\circ} \mathrm{C}$. A leitura do sequenciamento foi feita em aparelho de sequenciamento automático ABI-377 (Applied Biosystems), e os eletroferogramas foram analisados pelo programa Sequence Navigator (para Macintosh), para comparação das réplicas, eliminação de erros de leitura do sequenciamento e também 
para obtenção de alinhamentos entre sequências das amostras de populações de $A$. fraterculus.

\section{Análise das sequências}

As sequências obtidas foram analisadas utilizando o programa BioEdit Sequence Alignment Editor versão 7.0.9.0., no qual verificou-se a qualidade das sequências. Em seguida, as sequências obtidas foram alinhadas utilizando o programa ClustalW (Thompson et al., 1994) e para análises dos haplótipos foi utilizado o programa DNAsp versão 5.10 (Rozas \& Librado, 2009). As sequências que eram similares, indicadas pelo programa, foram eliminadas exceto uma, que foi utilizada como representante daquele conjunto. As análises segundo a metodologia do MLST foram feitas de acordo com Baldo et al. (2006a, 2007). Os haplótipos obtidos foram comparados com as sequências depositadas nos banco de dados do MLST (http://www.pubmlst.org/wolbachia/) para verificar a qual supergrupo pertenciam e se haviam sequências iguais já depositadas. Nos casos de haplótipos inéditos, as sequências foram enviadas ao banco de dados de Wolbachia para obtenção do código de identificação. Os diferentes genes que formam o MLST, foram analisados e concatenados pela ordem - gatB, coxA, hcpA, ftsZ e fbpA - para formar o ST ("Strain Type") que define a linhagem da bactéria (Baldo et al. 2007).

As análises do gene wsp foram feitas pela metodologia do "Wsp Typing", como proposto por Baldo et al. (2006a). As sequências do wsp foram submetidas ao banco de dados do wsp, também existente no banco de dados do MLST de Wolbachia, para identificação de sequências já anteriormente descritas e para obtenção de novos códigos para as sequências inéditas.

Além do sequenciamento dos cinco genes que formam o MLST e do gene wsp de Wolbachia, foram incluídas sequências depositadas no banco de dados do MLST de alelos encontrados em diferentes hospedeiros de diferentes regiões (Tabelas III e IX).

As análises filogenéticas foram feitas após a escolha do melhor modelo de substituição determinado pela ferramenta "Procura do Melhor Modelo" (Find Best Models) do programa Mega 5.1 (Tamura et al., 2011). Segundo os valores de AICc (Akaike Information Criterion, corrected), o melhor modelo foi o GTR (General Time Reversible) (Tavaré, 1986), tanto para os cinco genes do MLST quanto para o gene wsp. A matrizes de distâncias entre as diferentes sequências dos genes do MLST e para o gene wsp, foram geradas no programa Mega 5.1. Para cada gene, três metodologias de análises filogenéticas foram empregadas, a Máxima Verossimilhança, a Neighbor-Joining e o método de parcimônia. As árvores filogenéticas foram 
construídas utilizando o método de parcimônia no programa Phylip 3.67: dnapars (Felsenstein, 1989), padrão default e com 1000 réplicas de bootstrap.

Para o gene wsp também foram realizadas algumas análises para evidenciar possíveis eventos de recombinação entre os distintos haplótipos, seguindo-se as recomendações de Baldo et al. (2006a, 2007). Para tanto, foi feita (1) a tradução conceitual dos haplótipos obtidos pelo programa BioEdit e procedeu-se o exame visual das sequência de aminoácidos, (2) análises filogenética individualizadas de regiões hipervariáveis e (3) teste de recombinação pelo método do MAXCHI (Maynard-Smith, 1992) implementado no programa RDP3-4.1 ("Recombination Detection Program", Heath et al. (2006).

\section{Estabelecimento de linhagens de Anastrepha isentas (curadas) de Wolbachia}

A eliminação de bactérias em $A$. sp.1 e em $A$. obliqua foi feita por tratamento térmico, método já estabelecido para Anastrepha (Pires, 2005; Ribeiro, 2007). Para tanto, pupas logo após a ecdise pupal, provenientes das colônias mantidas no laboratório, foram colocadas em caixas de plástico contendo vermiculita e transferidas para estufa cuja temperatura fora previamente fixada em $30^{\circ} \mathrm{C}$, cuidado tendo sido tomado para evitar a desidratação. As pupas foram mantidas nessa temperatura até a emergência dos adultos. Estes foram separados pelo sexo em caixas de populações $(15 \times 15 \times 20 \mathrm{~cm})$ e mantidos em sala com temperatura $\left(25^{\circ} \mathrm{C}\right)$, umidade $(60-70 \%)$ e fotoperíodos (12L:12E) controlados. Para verificação da eficácia do tratamento, foi feita a extração do DNA e reação de sequenciamento com o gene wsp. Com esses indivíduos foram estabelecidas colônias não infectadas pela Wolbachia para ambas as espécies de hospedeiros.

\section{Análise de efeitos da Wolbachia em A. sp.1 e em A. obliqua}

Para uma análise de possíveis efeitos da Wolbachia nos hospedeiros, foram estudadas quatro características biológicas das duas espécies hospedeiras em indivíduos infectados e curados: análise morfológica dos ovários; produção de espermatozoides; análise da fecundidade das fêmeas e da fertilidade dos ovos.

Essas análises foram feitas utilizando-se indivíduos infectados e outros curados, isentos das bactérias. Como existe descrições de efeitos da temperatura em algumas relações da Wolbachia com seus hospedeiros (ver Snook et al. 2000), em todos os experimentos realizados neste trabalho, os indivíduos não infectados 
(curados) derivaram da geração $\mathrm{F} 1$ das colônias não infectadas, de ambas as espécies. Os cruzamentos foram feitos em caixas de populações $(15 \times 15 \times 20 \mathrm{~cm})$, contendo cinco casais cada uma (Selivon et al., 2005) e mantidas sob condições controladas, como acima descrito. Para cada espécie, foram feitos quatro tipos de cruzamentos: (1) entre machos e fêmeas infectados; (2) entre machos e fêmeas não infectados; (3) entre fêmeas infectadas e machos não infectados e (4) entre fêmeas não infectadas e machos infectados.

A análise morfológica dos ovários foi feita isoladamente para cada espécie. Fêmeas infectadas e fêmeas não infectadas (cruzamentos 1 e 2 acima), foram coletadas entre os dias 10 a 25 após a emergência. Os ovários foram dissecados em tampão KNT (183mM KCl; 47mM NaCl, 10mM Tris-HCl, pH6,8) (Esteban et al., 1997), colocados entre lâmina e lamínula siliconizada e ligeiramente pressionados. As preparações foram congeladas em nitrogênio líquido, as lamínulas retiradas com o auxílio de uma gilete e a preparação fixada em $100 \%$ metanol a $-10^{\circ} \mathrm{C}$ por $15 \mathrm{mim}$. Após secagem ao ar, as preparações foram coradas pelo 4',6-diamino-2-fenil-indol (DAPI) a $1,5 \mu \mathrm{g} / \mathrm{ml}$ em tampão 2x SSC. Algumas preparações foram coradas pela "Acridina alaranjada" ("Acridine Orange") a 0,25 $\mu \mathrm{g} / \mathrm{ml}$ em tampão fosfato, $\mathrm{pH}$ 6,8 por 5 mim (mod. de Pannebakker et al., 2007). Após imersão nos tampões respectivos, as preparações foram montadas sob lamínula em uma solução de tampão e glicerol (1:1) contendo $n$-propilgalato para maior durabilidade da fluorescência. As preparações foram examinadas em microscópio Olympus BX-60 equipado com epifluorescência e as imagens digitalizadas por câmera CCD Leica D100 acoplada ao microscópio. As imagens foram editadas pelo progama PhotoShop 7.0.

A análise da produção de espermatozóides foi feita segundo o protocolo descrito por Snook et al. (2000) para Drosophila sumulans, com pequenas modificações. Como esses autores descrevem, os testículos são organizados em cistos de espermatogônias cujas células desenvolvem-se sincronicamente e a meiose ocorre sequêncialmente, em ondas a partir da extremidade distal do testículo em direção à base, onde os espermatozóides maduros são expulsos para os canais deferentes. Os espermatozóides maduros são muito longos e a contagem precisa do número produzido é difícil e trabalhosa. Assim, utilizaram um índice, referente ao número de espermatozóides produzidos, contando o número de conjuntos de espermatozóides em determinado estágio da espermiogênese. Os estágios da espermiogênese, de cada conjunto de espermátides (de cada cisto), podem ser facilmente identificados em uma preparação de testículos por leve esmagamento entre lâmina e lamínula. Como a espermatogênese ocorre linearmente ao longo dos testículos, cada cisto passa necessariamente pelos estágios da espermiogênese. 
Assim, a contagem de cistos em um desses estágios, fornece um índice confiável do número de espermatozoides produzidos. Como em Anastrepha a espermatogênese também ocorre sequencialmente, em ondas ao longo dos testículos (Bartolucci et al., 2008), esse método foi utilizado no presente trabalho para análise da produção de espermatozoides nas duas espécies de Anastrepha (Figura 2), comparando-se indivíduos infectados e curados. Para tanto, machos foram coletados em dias sucessivos após a emergência e dissecados em tampão KNT. Os testículos foram transferidos para lâmina histológicas, cobertos por lamínula siliconizadas e ligeiramente esmagados. Após congelamento em nitrogênio líquido, remoção da lamínula, fixação em metanol a $-10^{\circ} \mathrm{C}$ por $15 \mathrm{mim}$ e secagem ao ar, as preparações foram coradas pelo DAPI (ver acima) ou então, pelo Giemsa a 5\% em tampão fosfato, $\mathrm{pH}$ 6,8, por 5 mim. As preparações foram montadas em solução de tampão:glicerina com n-propilgalato para a coloração por DAPI (ver acima) ou com bálsamo do Canadá, para a coloração pelo Giemsa. As preparaçôes coradas pelo DAPI foram examinadas em microscópio de fluorescência como descrito para a análise dos ovários e as preparações coradas pelo Giemsa, examinadas em microscópio Zeiss sob microscopia de luz e cistos, em determinado estágio da espermiogênese, contados com o auxílio de um contador de colônias de bactérias e um tudo de desenho da Zeiss (Perondini, 1971). Os dados obtidos sobre a produção de espermatozoides foram analisados por Análise de variância com dois parâmetros, tratamento (infectados e curados) e dias de amostragens, utilizando o programa Statistica 7.0 (StatSoft, Inc).
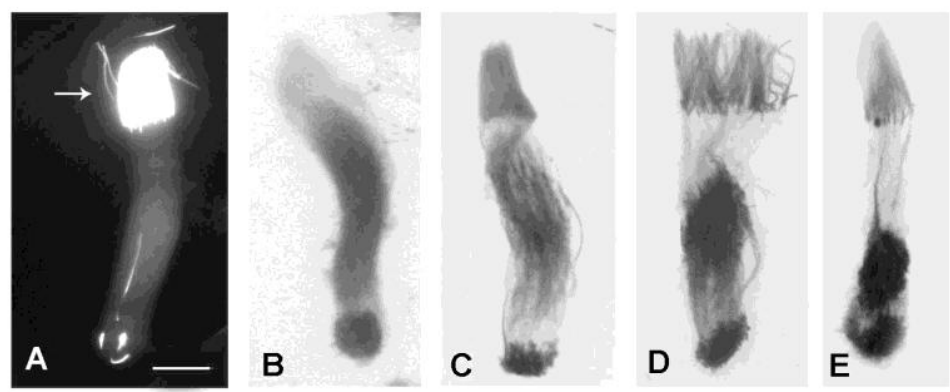

Figura 2. Estágios da espermiogênese de $A$. sp.1. (A) Cisto Corado pelo DAPI onde a seta indica os núcleos dos espermatozoides; (B-E) Estágios sucessivos da espermiogênese corados pelo Giemsa e mostrando a retração do citoplasma das espermátides; (D) Um cisto com núcleos dos espermatozoides separados durante a preparação do material. Barra em $A=50$ um e válida para as demais figuras.

As análises da fecundidade das fêmeas e fertilidade dos ovos foram feitas para cada espécie utilizando-se indivíduos derivados dos quatro tipos de cruzamentos acima referidos. De cada tipo de cruzamento foram coletadas amostras de ovos a cada 2-3 dias, durante um mês (15 amostras). Para coleta de ovos, em cada tipo de 
cruzamento, foram disponibilizadas semiesferas de ágar a 4\%, coloridas com anilina vermelha e recobertas com Parafilm ${ }^{\circledR}$ "M". Os ovos foram retirados destas semiesferas e transferidos para placas de Petri contendo camada de ágar a $4 \%$ e mantidos a temperatura de $25^{\circ} \mathrm{C}$, quando foram, então, contados. Cada placa foi monitorada por seis dias seguidos e a eclosão de larvas, registradas (Selivon et al. 2005). Assim, a fecundidade foi estimada pelo número de ovos botados e a fertilidade pela taxa de eclosão dos ovos, expressa como a porcentagem de larvas eclodidas a partir do número de ovos botados.

Os dados obtidos quanto ao número de ovos nos diferentes cruzamentos e amostras, foram analisados por testes não paramétricos (Kruskal-Wallis; MannWhitney), utilizando o programa GraphPad InStat 2.0 (GraphPad Software, DF Johnson, Rutgers University, 1993). Os dados porcentuais das taxas de eclosão foram transformados em arcosen $\sqrt{P}$ e analisados por análise de variância, seguida do teste de Student-Newman-Keuls e testes t de Student, utilizando-se o programa GraphPad InStat 2.0.

Além disso, para as duas espécies de hospedeiros, foi estimado o índice de incompatibilidade citoplasmática (\% IC corrigida) utilizando-se a fórmula de Poinsot et al. (1998):

$\% \mathrm{IC}_{\text {cor }}=\left[\left(\mathrm{IC}_{\text {obs }}-\mathrm{CCM}\right) /(100-\mathrm{CCM})\right] \times 100$

onde, $\mathrm{IC}_{\mathrm{obs}}$ é a porcentagem de ovos não eclodidos observada nos cruzamentos incompatíveis (cruzamento 4, fêmeas não infectadas cruzadas com machos infectados) e CCM é a mortalidade dos cruzamento compatíveis (cruzamento 3, fêmeas infectadas $X$ machos não infectados). 


\section{Resultados}

\section{Caracterização de linhagens de Wolbachia}

A caracterização das linhagens da Wolbachia foi feita pela amplificação dos cinco genes que formam o MLST ( $g a t B, \operatorname{cox} A, h c p A, f b p A$, fts $Z$ ) e pelo gene wsp, tendo sido analisadas amostras dos hospedeiros $A$. sp.1, A. sp.2, A. sp.3 do Brasil (Tabela I) e amostras de Anastrepha fraterculus s.l. e A. sp.4 originárias de diferentes regiões do México, América Central e do Sul (Tabela II). Também foram analisadas amostras de A. obliqua e Ceratitis capitata do Brasil. Foram analisados 292 indivíduos no total e todos estavam infectados pela Wolbachia, exceto os espécimens de $C$. capitata (três indivíduos analisados), um indivíduo de cada população de Chiapas, Jicayna, Tapachula e Teocelo (México) e um de Concórdia (Argentina) cuja amplificação foi negativa para Wolbachia.

\section{2. "Multilocus Sequence Typing" (MLST)}

Foram testados os iniciadores para amplificação dos fragmentos dos genes gatB, $\operatorname{cox} A, h c p A, f b p A, f t s Z$, obtendo-se a amplificação de todas amostras testadas (Tabelas II e III), como exemplificados na Figura 3. Os fragmentos amplificados com os cinco genes continham cerca de $500 \mathrm{pb}$, em todas essas amostras, sendo este resultado semelhante ao encontrado por Baldo e colaboradores (2006a) para outras espécies de insetos. Além disso, não houve diferenças significativas no tamanho entre os fragmentos amplificados das diferentes espécies para os genes que formam o MLST.

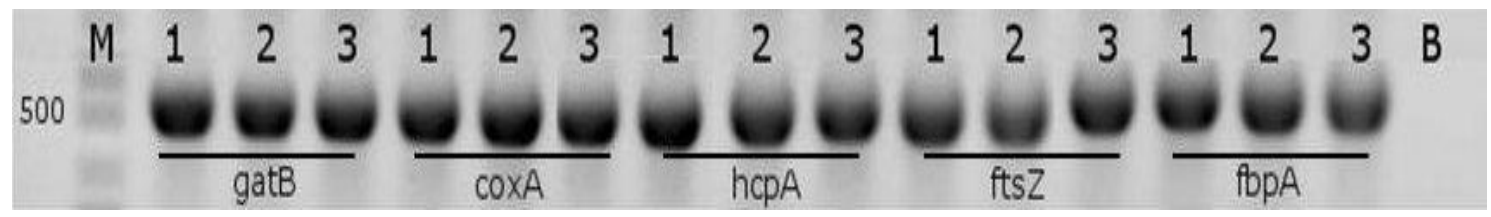

Figura 3: Fragmentos amplificados dos cinco genes. Marcador GeneRuler ${ }^{\mathrm{TM}}$ DNA Ladder. 1: $A$. sp.1 Salesópolis; 2: A. sp.2 Taubaté; 3: A. sp.3 Ubatuba; B: controle negativo. Abaixo os genes que formam o MLST, gatB, coxA, hcpA, ftsZ e fbpA.

A seguir serão apresentados os resultados das análises filogenéticas dos cinco genes. As árvores geradas pelos três métodos foram semelhantes, e a árvore de máxima verossimilhança foi à escolhida para representar as filogenias. Os valores de bootstrap dos três métodos estão indicados nas árvores, sendo o primeiro da máxima verossimilhança, o segundo do neighbor joining e o terceiro de parcimônia. 


\subsection{Gene gatB}

As sequências obtidas foram comparadas com sequências depositadas no banco de dados de MLST de Wolbachia. As sequências possuíam 369 bases. Os alelos encontrados nos hospedeiros $A$. sp.1 na população de Araraquara, Botucatu, Ibiúna, Itapetininga, Itararé, Jacareí, Jambeiro, Lorena, Mirassol, Piracicaba, Salesópolis, Santa Isabel, São Luís do Paraitinga (SP), Três Rios (RJ), Uberlândia (MG), Guarapuava, Imbituva, Irati, Sengés (PR), Guaramirim e Rio Negrinho (SC); de A. sp.2 de Bertioga, Ilhabela, Ilha Comprida, Itanhaém, Pedro de Toledo, Peruíbe, São Sebastião, Taubaté, Ubatuba (SP), Caiobá, Guaratuba e Paranaguá (PR); de A. sp.3 de Bertioga, Ilha Comprida, Jambeiro, Pedro de Toledo, Peruíbe, Salesópolis, São Luís do Paraitinga, Taubaté, Ubatuba (SP), Caiobá, Guaratuba (PR) e Rio Negrinho (SC); de A. sp.4 de Guayaquil; de A. fraterculus s.I. de Apazapan, Chiapas, de Quitana Roo, Tapachula e Teocelo no México; de La Molina e Piura no Peru; Concórdia, Horco Molle e Tucumán na Argentina; de A. obliqua de Bariri, Botucatu, Ilha Solteira, Indaiatuba, Mirassol, Peruíbe, Ribeirão Preto e Taubaté (SP) foram iguais ao alelo 1, descrito para o hospedeiro $D$. melanogaster (melEu). O alelo 23 , encontrado em Tolima na Colômbia (fraCoTol), é similar ao encontrado nos hospedeiros Acromis sparsa do Panamá e em Odontomachus clarus dos EUA. Além disso, foram encontrados outros alelos distintos no hospedeiro $A$. sp.1 de Jacareí e Salesópolis, um no hospedeiro $A$. fraterculus de Apazapan e Jicayna no México, um na amostra da Guatemala e um em Misiones na Argentina (Tabela III).

Tabela III: Hospedeiros, localidade, número de indivíduos e alelos analisados para os genes

\begin{tabular}{|c|c|c|c|c|c|c|c|c|c|c|}
\hline Hospedeiro & População & Código & $\begin{array}{c}\text { Número } \\
\text { de } \\
\text { indivíduos }\end{array}$ & gatB & $\operatorname{cox} A$ & hсpA & $f t s Z$ & $f b p A$ & ST & $\begin{array}{c}\text { Código Banco de } \\
\text { dados MLST }\end{array}$ \\
\hline \multirow{5}{*}{ A. sp.1 } & $\begin{array}{c}\text { Brasil-Botucatu } \\
\text { (SP) }\end{array}$ & sp1BrBot & 5 & 1 & 1 & 1 & 1 & 1 & 1 & Afra_A_wB14 \\
\hline & $\begin{array}{c}\text { Brasil- } \\
\text { Itapetininga }\end{array}$ & sp1Brlta & 5 & 1 & 1 & 1 & 3 & 1 & 13 & Afra_A_wB15 \\
\hline & $\begin{array}{c}\text { Brasil-Itararé } \\
\text { (SP) } \\
\end{array}$ & sp1Brltr & 5 & 1 & 1 & 1 & 1 & 1 & 1 & Afra_A_wB14 \\
\hline & $\begin{array}{c}\text { Brasil-Lorena } \\
\text { (SP) } \\
\end{array}$ & sp1BrLor & 2 & 1 & 1 & 1 & 1 & 1 & 1 & Afra_A_wB14 \\
\hline & Brasil-Mirassol & sp1BrMir & 3 & 1 & 1 & 1 & 3 & 1 & 13 & Afra_A_wB15 \\
\hline
\end{tabular}




\begin{tabular}{|c|c|c|c|c|c|c|c|c|c|c|}
\hline & (SP) & & & & & & & & & \\
\hline & $\begin{array}{c}\text { Brasil- } \\
\text { Piracicaba (SP) }\end{array}$ & sp1BrPir & 5 & 1 & 1 & 1 & 1 & 1 & 1 & Afra_A_wB14 \\
\hline & Brasil- & sp1BrSal & 4 & 1 & 1 & 1 & 3 & 1 & 13 & Afra_A_wB15 \\
\hline & Salesópolis (SP) & sp1BrSal & 1 & 200 & 190 & 1 & 3 & 257 & 330 & Afra_A_wB12 \\
\hline & $\begin{array}{c}\text { Brasil-Santa } \\
\text { Isabel (SP) }\end{array}$ & sp1BrSis & 5 & 1 & 1 & 1 & 1 & 1 & 1 & Afra_A_wB14 \\
\hline & $\begin{array}{c}\text { Brasil-São Luís } \\
\text { do Paraitinga } \\
\text { (SP) }\end{array}$ & sp1BrSlp & 5 & 1 & 1 & 1 & 1 & 1 & 1 & Afra_A_wB14 \\
\hline & $\begin{array}{c}\text { Brasil-Três Rios } \\
\text { (RJ) }\end{array}$ & sp1BrTri & 3 & 1 & 1 & 1 & 1 & 1 & 1 & Afra_A_wB14 \\
\hline & $\begin{array}{l}\text { Brasil- } \\
\text { Uberlândia } \\
\text { (MG) }\end{array}$ & sp1BrUbe & 4 & 1 & 1 & 1 & 1 & 1 & 1 & Afra_A_wB14 \\
\hline & $\begin{array}{c}\text { Brasil- } \\
\text { Guarapuava } \\
\text { (PR) }\end{array}$ & sp1BrGua & 5 & 1 & 1 & 1 & 1 & 1 & 1 & Afra_A_wB14 \\
\hline & $\begin{array}{c}\text { Brasil-Imbituva } \\
\text { (PR) }\end{array}$ & sp1Brlmb & 5 & 1 & 1 & 1 & 1 & 1 & 1 & Afra_A_wB14 \\
\hline & Brasil-Irati (PR) & sp1BrIra & 5 & 1 & 1 & 1 & 1 & 1 & 1 & Afra_A_wB14 \\
\hline & $\begin{array}{l}\text { Brasil-Sengés } \\
\text { (PR) }\end{array}$ & sp1BrSen & 5 & 1 & 1 & 1 & 162 & 1 & 331 & Afra_A_wB13 \\
\hline & $\begin{array}{c}\text { Brasil- } \\
\text { Guaramirim } \\
\text { (SC) } \\
\end{array}$ & sp1BrGum & 5 & 1 & 1 & 1 & 1 & 1 & 1 & Afra_A_wB14 \\
\hline & $\begin{array}{c}\text { Brasil-Rio } \\
\text { Negrinho (SC) } \\
\end{array}$ & sp1BrRne & 5 & 1 & 1 & 1 & 1 & 1 & 1 & Afra_A_wB14 \\
\hline \multirow{12}{*}{ A. sp. 2} & $\begin{array}{c}\text { Brasil-Bertioga } \\
\text { (SP) }\end{array}$ & sp2BrBer & 5 & 1 & 1 & 1 & 1 & 1 & 1 & Afra_A_wB21 \\
\hline & $\begin{array}{c}\text { Brasil- } \\
\text { Ilhabela(SP) }\end{array}$ & sp2Brllb & 4 & 1 & 1 & 1 & 1 & 1 & 1 & Afra_A_wB21 \\
\hline & $\begin{array}{c}\text { Brasil-Ilha } \\
\text { Comprida (SP) }\end{array}$ & sp2Brllc & 5 & 1 & 1 & 1 & 1 & 1 & 1 & Afra_A_wB21 \\
\hline & $\begin{array}{c}\text { Brasil- } \\
\text { Itanhaém (SP) }\end{array}$ & sp2Brlte & 5 & 1 & 1 & 1 & 1 & 1 & 1 & Afra_A_wB21 \\
\hline & $\begin{array}{c}\text { Brasil-Pedro de } \\
\text { Toledo (SP) }\end{array}$ & sp2BrPet & 5 & 1 & 1 & 1 & 1 & 1 & 1 & Afra_A_wB21 \\
\hline & $\begin{array}{c}\text { Brasil-Peruíbe } \\
\text { (SP) } \\
\end{array}$ & sp2BrPer & 3 & 1 & 1 & 1 & 1 & 1 & 1 & Afra_A_wB21 \\
\hline & $\begin{array}{c}\text { Brazil-São } \\
\text { Sebastião (SP) } \\
\end{array}$ & sp2BrSse & 1 & 1 & 1 & 1 & 1 & 1 & 1 & Afra_A_wB21 \\
\hline & $\begin{array}{c}\text { Brazil-Taubaté } \\
\text { (SP) }\end{array}$ & sp2BrTau & 4 & 1 & 1 & 1 & 3 & 1 & 13 & Afra_A_wB22 \\
\hline & $\begin{array}{c}\text { Brazil-Ubatuba } \\
\text { (SP) }\end{array}$ & sp2BrUba & 5 & 1 & 1 & 1 & 1 & 1 & 1 & Afra_A_wB21 \\
\hline & $\begin{array}{c}\text { Brasil-Caiobá } \\
\text { (PR) }\end{array}$ & sp2BrCai & 5 & 1 & 1 & 1 & 1 & 1 & 1 & Afra_A_wB21 \\
\hline & $\begin{array}{c}\text { Brasil- } \\
\text { Guaratuba (PR) }\end{array}$ & sp2BrGut & 5 & 1 & 1 & 1 & 1 & 1 & 1 & Afra_A_wB21 \\
\hline & $\begin{array}{c}\text { Brasil- } \\
\text { Paranaguá (PR) }\end{array}$ & sp2BrPar & 5 & 1 & 1 & 1 & 1 & 1 & 1 & Afra_A_wB21 \\
\hline \multirow{9}{*}{ A. sp.3 } & $\begin{array}{c}\text { Brasil-Bertioga } \\
\text { (SP) }\end{array}$ & sp3BrBer & 4 & 1 & 1 & 1 & 1 & 1 & 1 & Afra_A_wB33 \\
\hline & $\begin{array}{c}\text { Brasil- Ilha } \\
\text { Comprida (SP) }\end{array}$ & sp3Brllc & 5 & 1 & 1 & 1 & 1 & 1 & 1 & Afra_A_wB33 \\
\hline & $\begin{array}{c}\text { Brasil-Jambeiro } \\
\text { (SP) }\end{array}$ & sp3BrJam & 5 & 1 & 1 & 1 & 1 & 1 & 1 & Afra_A_wB33 \\
\hline & $\begin{array}{c}\text { Brasil-Pedro de } \\
\text { Toledo (SP) }\end{array}$ & sp3BrPet & 5 & 1 & 1 & 1 & 1 & 1 & 1 & Afra_A_wB33 \\
\hline & $\begin{array}{c}\text { Brasil-Peruíbe } \\
\text { (SP) }\end{array}$ & sp3BrPer & 5 & 1 & 1 & 1 & 1 & 1 & 1 & Afra_A_wB33 \\
\hline & \multirow{2}{*}{$\begin{array}{c}\text { Brasil- } \\
\text { Salesópolis (SP) }\end{array}$} & sp3BrSal & 4 & 1 & 1 & 1 & 1 & 1 & 1 & Afra_A_wB33 \\
\hline & & sp3BrSal & 1 & 1 & 1 & 1 & 162 & 258 & 332 & Afra_A_wB31 \\
\hline & $\begin{array}{c}\text { Brasil-São Luís } \\
\text { do Paraitinga } \\
\text { (SP) }\end{array}$ & sp3BrSlp & 4 & 1 & 191 & 1 & 1 & 1 & 333 & Afra_A_wB32 \\
\hline & $\begin{array}{c}\text { Brasil-Taubaté } \\
\text { (SP) }\end{array}$ & sp3BrTau & 2 & 1 & 1 & 1 & 1 & 1 & 1 & Afra_A_wB33 \\
\hline
\end{tabular}




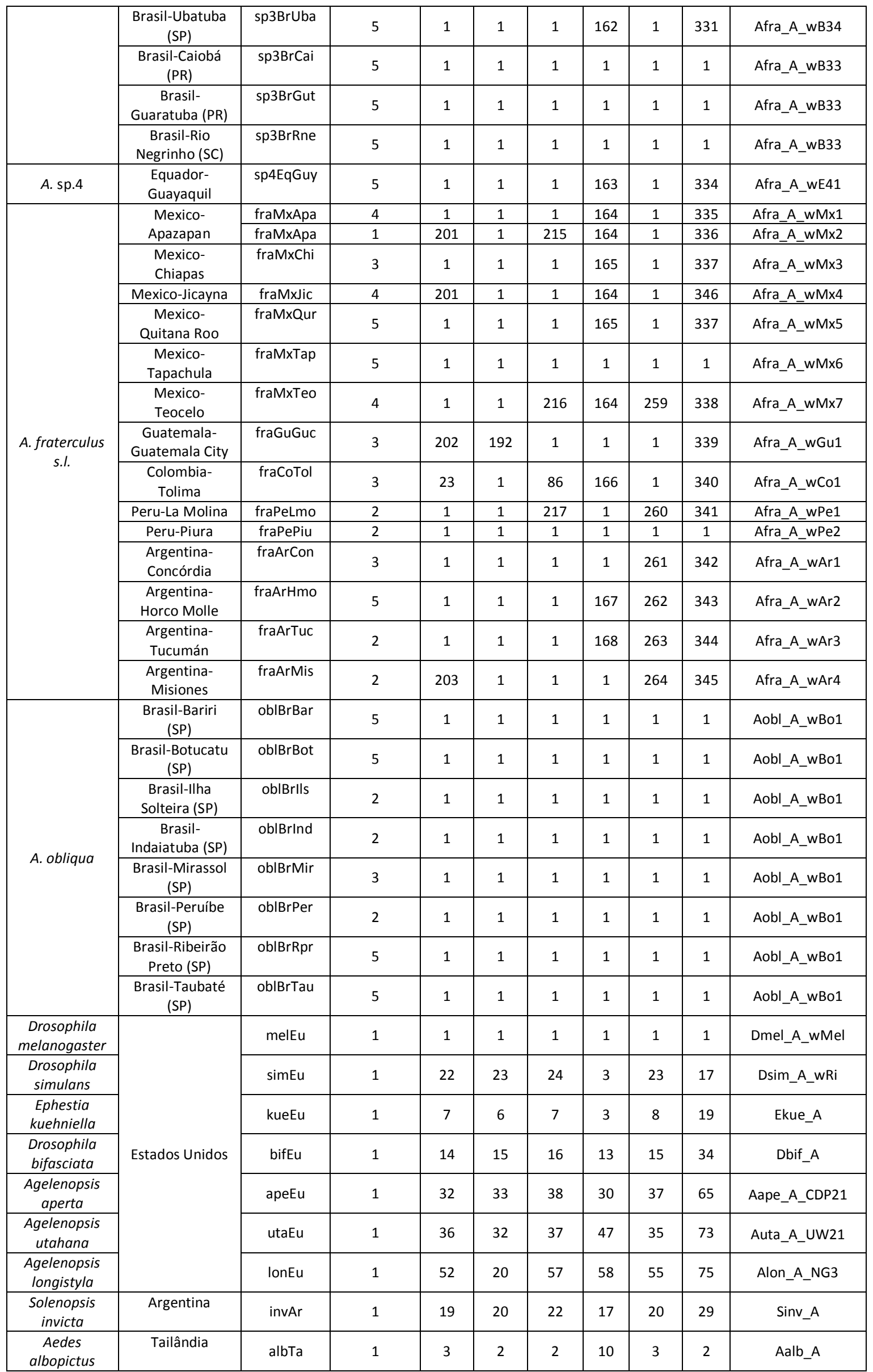




\begin{tabular}{|c|c|c|c|c|c|c|c|c|c|c|}
\hline $\begin{array}{c}\text { Drosophila } \\
\text { orientacea }\end{array}$ & Japão & oriJa & 1 & 10 & 10 & 11 & 14 & 11 & 12 & Dori_A \\
\hline $\begin{array}{c}\text { Acraea } \\
\text { encedon }\end{array}$ & EUA & encEu & 1 & 9 & 11 & 12 & 11 & 12 & 3 & Aenc_B_Ugardan \\
\hline
\end{tabular}

Comparação das distâncias genéticas mostrou que a menor (0.001) foi encontrada entre os alelos 201 (fraMxApa /fraMxJic) do México e 202 (fraGuGuc) da Guatemala. A maior distância (0.069) foi encontrada entre os alelos 199 (sp1BrJac) e 52 (lonEu) (Tabela IV).

Tabela IV: Matriz de distância entre alelos do gene gatB.

\begin{tabular}{|c|c|c|c|c|c|c|c|c|c|c|c|c|c|c|c|c|}
\hline Código & Alelo & 1 & 199 & 200 & 201 & 202 & 203 & 23 & 22 & 7 & 14 & 32 & 36 & 52 & 19 & 3 \\
\hline sp1BrJac & 199 & .0 .014 & & & & & & & & & & & & & & \\
\hline sp1BrSal & 200 & .005 & .020 & & & & & & & & & & & & & \\
\hline fraMxApa /fraMxJic & 201 & .008 & .022 & .014 & & & & & & & & & & & & \\
\hline fraGuGuc & 202 & .003 & .017 & .008 & .001 & & & & & & & & & & & \\
\hline fraArMis & 203 & .003 & .017 & .008 & .011 & .005 & & & & & & & & & & \\
\hline fraCoTol & 23 & .014 & .028 & .020 & .022 & .017 & .014 & & & & & & & & & \\
\hline simEu & 22 & .026 & .040 & .031 & .034 & .028 & .028 & .041 & & & & & & & & \\
\hline kueEu & 7 & .017 & .031 & .022 & .025 & .020 & .020 & .032 & .026 & & & & & & & \\
\hline bifEu & 14 & .023 & .037 & .028 & .031 & .025 & .025 & .026 & .025 & .023 & & & & & & \\
\hline apeEu & 32 & .028 & .043 & .034 & .037 & .031 & .031 & .032 & .032 & .035 & .023 & & & & & \\
\hline utaEu & 36 & .026 & .040 & .031 & .034 & .028 & .028 & .029 & .028 & .026 & .003 & .026 & & & & \\
\hline IonEu & 52 & .053 & .069 & .060 & .063 & .057 & .057 & .064 & .038 & .034 & .035 & .035 & .038 & & & \\
\hline invAr & 19 & .020 & .034 & .025 & .028 & .022 & .022 & .029 & .022 & .020 & .014 & .031 & .017 & .038 & & \\
\hline albTa & 3 & .020 & .034 & .025 & .028 & .022 & .020 & .023 & .017 & .020 & .014 & .038 & .017 & .044 & .011 & \\
\hline orija & 10 & .032 & .046 & .037 & .041 & .035 & .035 & .041 & .023 & .032 & .031 & .020 & .035 & .044 & .041 & .041 \\
\hline
\end{tabular}

A análise filogenética do gatB (Figura 4.I) mostrou que o alelo 52 (lonEu) mostrou ser o mais basal. O alelo 10 (oriJa) ficou próximo ao 32 (apeEu). Próximo a estes, ficou o alelo 7 (kueEu), formando um ramo distinto. Outro ramo é formado pelos alelos 23 (fraCoTol) e 36 (utaEu), que ficaram próximos. Neste ramo, encontra-se a única linhagem de Wolbachia presente em $A$. fraterculus que ficou mais distante das demais. Outro ramo é formado pelos alelos 3 (albTa) e 19 (invAr). Os alelos 14 (bifEu) forma um ramo distinto, assim como o 22 (simEu). Os alelos de Wolbachia encontrados nos hospedeiros $A$. fraterculus e $A$. obliqua formam um clado distinto, onde o alelo 203 (fraArMis) é o mais basal. O alelo 1 (sp1Br: Ara, Bot, Ibi, Ita, Itr, Jac, Jam, Lor, Mir, Pir, Sal, Sis, Slp, Tri, Ube, Gua, Imb, Ira, Sem, Gum, Rne; sp2Br: Ber, llb, Ilc, Ite, Pet, Per, Sse, Tau, Uba, Cai, Gut, Par; sp3Br: Ber, Ilc, Jam, Pet, Per, Sal, Slp, Tau, Uba, Cai, Gut, Rne; sp4EqGuy; fraMx: Apa, Chi, Qur, Tap, Teo; fraPe: Lmo, Piu; fraAr: Com, Hmo, Tuc; oblBr: Bar, Bot, Ils, Ind, Mir, Per, Rpr, Tau; melEu) ficou próximo ao 199 (sp1BrJac), formando um clado distinto. Os alelos 200 (sp1BrSal), 201 (fraMxApa, fraMxJic) e 202 (fraGuGuc) ficaram próximos, formando um clado distinto, sendo o 200 mais basal. 


\subsection{Gene $\operatorname{cox} A$}

As sequências obtidas foram comparadas com sequências depositadas no banco de dados de MLST de Wolbachia. As sequências possuíam 402 bases. Os alelos encontrados nos hospedeiros $A$. sp.1 na população de Araraquara, Botucatu, Ibiúna, Itapetininga, Itararé, Jacareí, Jambeiro, Lorena, Mirassol, Piracicaba, Salesópolis, Santa Isabel, São Luís do Paraitinga (SP), Três Rios (RJ), Uberlândia (MG), Guarapuava, Imbituva, Irati, Sengés (PR), Guaramirim e Rio Negrinho (SC); de A. sp.2 de Bertioga, Ilhabela, Ilha Comprida, Itanhaém, Pedro de Toledo, Peruíbe, São Sebastião, Taubaté e Ubatuba (SP), Caiobá, Guaratuba e Paranaguá (PR); de A. sp.3 de Bertioga, Ilha Comprida, Jambeiro, Pedro de Toledo, Peruíbe, Salesópolis, Taubaté e Ubatuba (SP), Caiobá, Guaratuba (PR), Rio Negrinho (SC); de A. sp.4 de Guayaquil; de A. fraterculus s.I. de Apazapan, Chiapas, Jicayna, Quitana Roo, Tapachula e Teocelo no México; de Tolima, Colômbia; de La Molina e Piura no Peru; Concordia, Horco Molle e Tucumán na Argentina; de A. obliqua de Bariri, Botucatu, Ilha Solteira, Indaiatuba, Mirassol, Peruíbe, Ribeirão Preto e Taubaté (SP) foram muito similares ao alelo descrito para o hospedeiro $D$. melanogaster (melEu). Além disso, foram encontrados outros alelos distintos no hospedeiro A. sp.1 de Salesópolis, em A. sp.3 de São Luís do Paraitinga, um no hospedeiro A. fraterculus s.l. de da Guatemala (Tabela III).

A menor distância genética foi de 0.005 encontrada entre os alelos 6 (Ekue_A) e 33 (apeEu) e a maior foi de 0.039 entre os alelos 23 (simEu) e 32 (utaEu) (Tabela V).

Tabela V: Matriz de distância entre alelos do gene coxA.

\begin{tabular}{|c|c|c|c|c|c|c|c|c|c|c|c|c|}
\hline Código & Alelo & 1 & 190 & 191 & 192 & 23 & 6 & 15 & 33 & 32 & 20 & 2 \\
\hline sp1BrSal & 190 & . 010 & & & & & & & & & & \\
\hline sp3BrSlp & 191 & .008 & .013 & & & & & & & & & \\
\hline fraGuGuc & 192 & .015 & .020 & .018 & & & & & & & & \\
\hline simEu & 23 & .015 & .013 & .018 & .023 & & & & & & & \\
\hline kueEu & 6 & .005 & .010 & .008 & .015 & .015 & & & & & & \\
\hline bifEu & 15 & .008 & .013 & .010 & .018 & .018 & .008 & & & & & \\
\hline apeEu & 33 & .005 & .010 & .008 & .015 & .015 & .005 & .008 & & & & \\
\hline utaEu & 32 & .028 & .033 & .031 & .038 & .039 & .028 & .031 & .028 & & & \\
\hline lonEu/ invar & 20 & .015 & .018 & .018 & .025 & .026 & .015 & .018 & .015 & .039 & & \\
\hline albTa & 2 & .018 & .023 & .020 & .028 & .028 & .018 & .020 & .018 & .031 & .028 & \\
\hline orija & 10 & .010 & .015 & .013 & .020 & .02 & .010 & .013 & .01 & .018 & .020 & .013 \\
\hline
\end{tabular}

1: alelos sp1Br: Ara, Bot, Ibi, Ita, Itr, Jac, Jam, Lor, Mir, Pir, Sal, Sis, Slp, Tri, Ube, Gua, Imb, Ira, Sem, Gum, Rne; sp2Br: Ber, Ilb, Ilc, Ite, Pet, Per, Sse, Tau, Uba, Cai, Gut, Par; sp3Br: Ber, Ilc, Jam, Pet, Per, Sal, Tau, Uba, Cai, Gut, Rne; sp4EqGuy; fraMx: Apa, Chi, Jic, Qur, Tap, Teo; fraCoTol; fraPe: Lmo, Piu; fraAr: Com, Hmo, Mis, Tuc; oblBr: Bar, Bot, Ils, Ind, Mir, Per, Rpr, Tau; melEu. 
Os alelos do gene coxA encontrados nos diferentes hospedeiros de Wolbachia formam ramos distintos. Os alelos 10 (oriJa) e 32 (utaEu) ficaram próximos, com o 33 (apeEu) mais basal e formando um grupo distinto. Outro ramo é formado pelos alelos 2 (albTa) e 20 (lonEu, invAr) próximos e o 15 (bifEu) mais basal. Os alelos 6 (kueEu) e 23 (simEu) ficaram próximos, formando um ramo distinto. Os alelos de Wolbachia encontrados em Anastrepha ficaram juntos, formando um grupo distinto. Nele o alelo 1 (sp1Br: Ara, Bot, Ibi, Ita, Itr, Jac, Jam, Lor, Mir, Pir, Sal, Sis, Slp, Tri, Ube, Gua, Imb, Ira, Sem, Gum, Rne; sp2Br: Ber, Ilb, Ilc, Ite, Pet, Per, Sse, Tau, Uba, Cai, Gut, Par; sp3Br: Ber, Ilc, Jam, Pet, Per, Sal, Tau, Uba, Cai, Gut, Rne; sp4EqGuy; fraMx: Apa, Chi, Jic, Qur, Tap, Teo; fraCoTol; fraPe: Lmo, Piu; fraAr: Com, Hmo, Mis, Tuc; oblBr: Bar, Bot, Ils, Ind, Mir, Per, Rpr, Tau; melEu) é o mais basal. O 190 (sp1BrSal) ficou próximo e os 191 (sp3BrSlp) e 192 (fraGuGuc) ficaram próximos (Figura 4.II).

\subsection{Gene hcpA}

As sequências obtidas foram comparadas com sequências depositadas no banco de dados de MLST de Wolbachia. As sequências possuíam 444 bases. Os alelos encontrados nos hospedeiros $A$. sp.1 na população de Araraquara, Botucatu, Ibiúna, Itapetininga, Itararé, Jacareí, Jambeiro, Lorena, Mirassol, Piracicaba, Salesópolis, Santa Isabel, São Luís do Paraitinga (SP), Três Rios (RJ), Uberlândia (MG), Guarapuava, Imbituva, Irati, Sengés (PR), Guaramirim e Rio Negrinho (SC); de A. sp.2 de Bertioga, Ilhabela, Ilha Comprida, Itanhaém, Pedro de Toledo, Peruíbe, São Sebastião e Ubatuba (SP), Caiobá, Guaratuba e Paranaguá (PR); de A. sp.3 de Bertioga, Ilha Comprida, Jambeiro, Pedro de Toledo, Peruíbe, Salesópolis, Taubaté e Ubatuba (SP), Caiobá, Guaratuba (PR), Rio Negrinho (SC); de A. sp.4 de Guayaquil; de A. fraterculus s.l. de Apazapan, Chiapas, Jicayna, Quitana Roo, e Tapachula no México; de Guatemala City na Guatemala; de Piura no Peru; Concordia, Horco Molle, Misiones e Tucumán na Argentina; de A. obliqua de Bariri, Botucatu, Ilha Solteira, Indaiatuba, Mirassol, Peruíbe, Ribeirão Preto e Taubaté (SP) foram iguais ao alelo descrito para o hospedeiro $D$. melanogaster. Foram encontrados outros alelos no hospedeiro $A$. sp.1 da população de Jacareí, outros alelos no hospedeiro $A$. fraterculus s.I. das populações de Apazapan, Teocelo, e La Molina. No hospedeiro A. fraterculus s.l. de Tolima, Colômbia, o alelo da Wolbachia era o mesmo encontrado em um drosofilideo do Panamá e de outro hospedeiro desconhecido depositado no banco de dados do MLST de Wolbachia. (Tabela III). 
A menor distância foi de 0.001, encontrada entre os alelo 1 (sp1Br: Ara, Bot, Ibi, Ita, Itr, Jac, Jam, Lor, Mir, Pir, Sal, Sis, SIp, Tri, Ube, Gua, Imb, Ira, Sem, Gum, Rne; sp2Br: Ber, Ilb, Ilc, Ite, Pet, Per, Sse, Tau, Uba, Cai, Gut, Par; sp3Br: Ber, Ilc, Jam, Pet, Per, Sal, Slp, Tau, Uba, Cai, Gut, Rne; sp4EqGuy; fraMx: Apa, Chi, Qur, Tap; fraPePiu; fraAr: Com, Hmo, Tuc, Mis; oblBr: Bar, Bot, Ils, Ind, Mir, Per, Rpr, Tau; melEu) e 214 (sp1BrJac). A maior foi de 0.052 entre os alelos 22 (invAr) e 24 (simEu) (Tabela VI).

Tabela VI: Matriz de distância entre alelos do gene hcpA.

\begin{tabular}{|c|c|c|c|c|c|c|c|c|c|c|c|c|c|c|c|}
\hline Código & Alelo & 1 & 214 & 215 & 216 & 86 & 217 & 24 & 7 & 16 & 38 & 37 & 57 & 22 & 2 \\
\hline sp1BrJac & 214 & .001 & & & & & & & & & & & & & \\
\hline fraMxApa & 215 & .002 & .005 & & & & & & & & & & & & \\
\hline fraMxTeo & 216 & .002 & .005 & .005 & & & & & & & & & & & \\
\hline fraCoTol & 86 & .009 & .011 & .007 & .011 & & & & & & & & & & \\
\hline fraPeLmo & 217 & .005 & .007 & .002 & .007 & .009 & & & & & & & & & \\
\hline simEu & 24 & .009 & .011 & .007 & .011 & .014 & .009 & & & & & & & & \\
\hline kueEu & 7 & .037 & .04 & .035 & .039 & .042 & .037 & .042 & & & & & & & \\
\hline bifEu & 16 & .045 & .047 & .042 & .047 & .049 & .045 & .05 & .054 & & & & & & \\
\hline apeEu & 38 & .028 & .03 & .025 & .03 & .033 & .028 & .033 & .042 & .025 & & & & & \\
\hline utaEu & 37 & .033 & .035 & .03 & .035 & .037 & .033 & .037 & .018 & .05 & .037 & & & & \\
\hline IonEu & 57 & .035 & .037 & .032 & .037 & .04 & .035 & .04 & .049 & .028 & .011 & .042 & & & \\
\hline invAr & 22 & .047 & .05 & .045 & .05 & .052 & .047 & .052 & .035 & .04 & .028 & .033 & .035 & & \\
\hline albTa & 2 & .045 & .047 & .042 & .047 & .05 & .045 & .05 & .028 & .042 & .03 & .025 & .037 & .007 & \\
\hline orija & 11 & .021 & .023 & .018 & .023 & .025 & .021 & .025 & .035 & .028 & .016 & .03 & .014 & .04 & .037 \\
\hline
\end{tabular}

1: alelos sp1Br: Ara, Bot, Ibi, Ita, Itr, Jac, Jam, Lor, Mir, Pir, Sal, Sis, SIp, Tri, Ube, Gua, Imb, Ira, Sem, Gum, Rne; sp2Br: Ber, Ilb, Ilc, Ite, Pet, Per, Sse, Tau, Uba, Cai, Gut, Par; sp3Br: Ber, Ilc, Jam, Pet, Per, Sal, Slp, Tau, Uba, Cai, Gut, Rne; sp4EqGuy; fraMx: Apa, Chi, Qur, Tap; fraPePiu; fraAr: Com, Hmo, Tuc, Mis; oblBr: Bar, Bot, Ils, Ind, Mir, Per, Rpr, Tau; melEu.

$\mathrm{Na}$ árvore formada pelo gene hcpA (Figura 4. III), os alelos formaram três grupos distintos. Em um deles, o alelo 2 (albTa) é mais basal. Os alelos 22 (invAr) e 57 (lonEu) ficaram próximos e o alelo 86 (fraCoTol) é mais basal, sendo esta a única linhagem de Wolbachia encontrada em Anastrepha que ficou distante das demais encontradas no mesmo hospedeiro em diferentes localidades, de forma semelhante a ao ocorrido com o gene gatB. No outro grupo, os alelos 24 (simEu) e 7 (kueEu) são mais basais, o 16 (bifEu) ficou próximo aos alelos 11 (oriJa) e 37 (utaEu). No terceiro grupo encontram-se as linhagens de Wolbachia encontradas no hospedeiro Anastrepha. Neste grupo, os alelos 214 e 215 ficaram próximos, formando um ramo. Em outro ramo, os alelos 1 (sp1Br: Ara, Bot, Ibi, Ita, Itr, Jac, Jam, Lor, Mir, Pir, Sal, Sis, SIp, Tri, Ube, Gua, Imb, Ira, Sem, Gum, Rne; sp2Br: Ber, Ilb, Ilc, Ite, Pet, Per, Sse, Tau, Uba, Cai, Gut, Par; sp3Br: Ber, Ilc, Jam, Pet, Per, Sal, Slp, Tau, Uba, Cai, Gut, Rne; sp4EqGuy; fraMx: Apa, Chi, Qur, Tap; fraPePiu; fraAr: Com, Hmo, Tuc, Mis; oblBr: Bar, Bot, Ils, Ind, Mir, Per, Rpr, Tau; melEu) e 217 (fraPeLmo) ficaram próximos e o 216 (fraMxTeo) ficou mais basal perante estes. 


\subsection{Gene ftsZ}

As sequências obtidas foram comparadas com sequências depositadas no banco de dados de MLST de Wolbachia. As sequências possuíam 435 bases. Os alelos encontrados nos hospedeiros $A$. sp.1 na população de Araraquara, Botucatu, Ibiúna, Itararé, Jacareí, Jambeiro, Lorena, Piracicaba, Santa Isabel, São Luís do Paraitinga (SP), Três Rios (RJ), Uberlândia (MG), Guarapuava, Imbituva, Irati (PR), Guaramirim e Rio Negrinho (SC); de A. sp.2 de Bertioga, Ilhabela, Ilha Comprida, Itanhaém, Pedro de Toledo, Peruíbe, São Sebastião e Ubatuba (SP), Caiobá, Guaratuba e Paranaguá (PR); de A. sp.3 de Bertioga, Ilha Comprida, Jambeiro, Pedro de Toledo, Peruíbe, Salesópolis, São Luis do Paraitinga e Taubaté (SP), Caiobá, Guaratuba (PR), Rio Negrinho (SC); de A. fraterculus s.l. de Tapachula no México; de Guatemala City na Guatemala; de La Molina e Piura no Peru; Concordia e Misiones na Argentina; de $A$. obliqua de Bariri, Botucatu, Ilha Solteira, Indaiatuba, Mirassol, Peruíbe, Ribeirão Preto e Taubaté (SP) foram iguais ao alelo descrito para o hospedeiro $D$. melanogaster (melEu). O alelo encontrado em $A$. sp.1 da população de Itapetininga, Mirassol e Salesópolis e A. sp.2 de Taubaté são semelhantes aos encontrados em Drosophila simulans, D. innubila, D. munda, D. recens, Leucophenga maculosa, Ragholetis cingulata, Suilia e Ephestia kuehniella dos EUA; Technomirmex albipes das Filipinas; Leptomirmex da Austrália; Ornipholidotos peucetia da África do Sul; Pheidole plagiara e P. sauberi da Tailândia; Ceutorhynchus neglectus do Canadá. Além desses, foram encontrados outro alelo de Wolbachia no hospedeiro $A$. sp.1 de Sengés (SC) e $A$. sp.3 de Salesópolis e Ubatuba. Outro alelo foi encontrado em $A$. sp.4 de Guayaquil; em A. fraterculus s.l. de Apazapan, Chiapas, Quitana Roo e Teocelo, no México; Tolima, na Colômbia; Horco Molle e Tucumán, na Argentina (Tabela III).

A menor distância foi de 0.002, encontrada entre os alelos 3 (sp1Br: Ita, Mir, Sal; sp2BrTau; simEu; kueEu) e 162 (Afra_A: sp1BrSen; sp3Br: sal, Uba) e 3 e 163 (sp4EqGuy). A maior foi de 0.036, entre os alelos 1 (sp1Br: Ara, Bot, Ibi, Itr, Jac, Jam, Lor, Pir, Sis, Slp, Tri, Ube, Gua, Imb, Ira, Gum, Rne; sp2Br: Ber, Ilb, Ilc, Ite, Pet, Per, Sse, Uba, Cai, Gut, Par; sp3Br: Ber, Ilc, Jam, Pet, Per, Sal, Slp, Tau, Cai, Gut, Rne; fraMxTap; fraGuGuc ; fraPe: Lmo, Piu; fraAr: Com, Mis; oblBr: Bar, Bot, Ils, Ind, Mir, Per, Rpr, Tau; melEu) e 167 (fraArHmo) (Tabela VII). 
Tabela VII: Matriz de distância entre alelos do gene ftsZ.

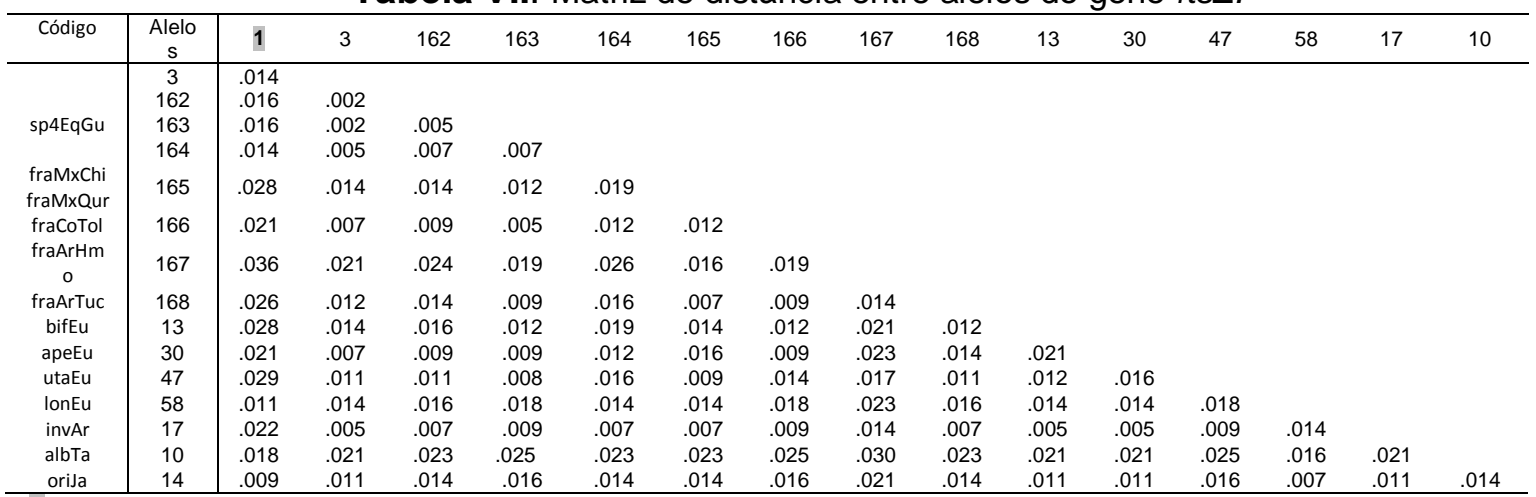

1: alelos sp1Br: Ara, Bot, Ibi, Itr, Jac, Jam, Lor, Pir, Sis, Slp, Tri, Ube, Gua, Imb, Ira, Gum, Rne; sp2Br: Ber, Illb, Ilc, Ite, Pet, Per, Sse, Uba, Cai, Gut, Par; sp3Br: Ber, Ilc, Jam, Pet, Per, Sal, Slp, Tau, Cai, Gut, Rne; fraMxTap; fraGuGuc; fraPe: Lmo, Piu; fraAr: Com, Mis; oblBr: Bar, Bot, Ils, Ind, Mir, Per, Rpr, Tau; melEu. 3: sp1Br: Ita, Mir, Sal; sp2BrTau; simEu; kueEu. 162: Afra_A: sp1BrSen; sp3Br: sal, Uba. 164: fraMx: Apa, Jic, Teo.

A árvore formada pelo gene ftsZ (Figura 4.IV) não agrupou todos alelos encontrados em Anastrepha. Os alelos 17 (invAr) e 58 (lonEu) ficaram próximos, mais basal a estes ficou o 30 (apeEu), os três alelos formando um grupo. O alelo 10 (albTa) formou um ramo separado. O alelo 1 (sp1Br: Ara, Bot, Ibi, Itr, Jac, Jam, Lor, Pir, Sis, Slp, Tri, Ube, Gua, Imb, Ira, Gum, Rne; sp2Br: Ber, llb, Ilc, Ite, Pet, Per, Sse, Uba, Cai, Gut, Par; sp3Br: Ber, Ilc, Jam, Pet, Per, Sal, Slp, Tau, Cai, Gut, Rne; fraMxTap; fraGuGuc ; fraPe: Lmo, Piu; fraAr: Com, Mis; oblBr: Bar, Bot, Ils, Ind, Mir, Per, Rpr, Tau; melEu) formou um ramo separado, ficando, este alelo de Wolbachia, distante dos demais encontrados em Anastrepha. Os alelos 14 (oriJa) e 47 (utaEu) ficaram próximos, formando um clado distinto. Outro ramo é formado pelos alelos "mexicanos" 164 (fraMx: Apa, Jic, Teo) e 165 (fraMxChi, fraMxQur). O alelo 13 (bifEu) forma um ramo distinto. Outro clado é formado pelos alelos 3 (sp1Br: Ita, Mir, Sal; sp2BrTau; simEu; kueEu) e 162 (Afra_A: sp1BrSen; sp3Br: sal, Uba). Outro grupo é formado pelos alelos 168 (fraArTuc), mais basal, 166 (fraCoTol) e 163 (sp4EqGuy) e 167 (fraArHmo) próximos.

\subsection{Gene $f b p A$}

As sequências obtidas foram comparadas com sequências depositadas no banco de dados de MLST de Wolbachia. As sequências possuíam 429 bases. Os alelos encontrados nos hospedeiros $A$. sp.1 na população de Araraquara, Botucatu, Ibiúna, Itapetininga, Itararé, Jacareí, Jambeiro, Lorena, Mirassol, Piracicaba, Salesópolis, Santa Isabel, São Luís do Paraitinga (SP), Três Rios (RJ), Uberlândia 
(MG), Guarapuava, Imbituva, Irati, Sengés (PR), Guaramirim e Rio Negrinho (SC); de A. sp.2 de Bertioga, Ilhabela, Ilha Comprida, Itanhaém, Pedro de Toledo, Peruíbe, São Sebastião, Taubaté e Ubatuba (SP), Caiobá, Guaratuba e Paranaguá (PR); de A. sp.3 de Bertioga, Ilha Comprida, Jambeiro, Pedro de Toledo, Peruíbe, Salesópolis, Taubaté e Ubatuba (SP), Caiobá, Guaratuba (PR), Rio Negrinho (SC); de A. sp.4 de Guayaquil; de A. fraterculus s.I. de Apazapan, Chiapas, Jicayna, Quitana Roo e Tapachula, no México; de Guatemala City, de Tolima, Colômbia e de Piura, no Peru; de A. obliqua de Bariri, Botucatu, Ilha Solteira, Indaiatuba, Mirassol, Peruíbe, Ribeirão Preto e Taubaté (SP) foram iguais ao alelo descrito para o hospedeiro $D$. melanogaster (melEu). Foram encontrados outros alelos em $A$. sp1 de Salesópolis, $A$. sp.3 de Salesópolis, $A$. fraterculus s.l. de Teocelo, no México, La Molina, no Peru, Concórdia, Horco Molle, Tucumán e Misiones, na Argentina (Tabela III).

A menor distância foi de 0.002, encontrada entre os alelos 257 (sp1BrSal) e 259 (fraMxTeo) e entre os alelos 257 e 260 (fraPeLmo). A maior (0.086) foi encontrada entre os alelos 1 (sp1Br: Ara, Bot, Ibi, Ita, Itr, Jac, Jam, Lor, Mir, Pir, Sal, Sis, Slp, Tri, Ube, Gua, Imb, Ira, Sem, Gum, Rne; sp2Br: Ber, Ilb, Ilc, Ite, Pet, Per, Sse, Tau, Uba, Cai, Gut, Par; sp3Br: Ber, Ilc, Jam, Pet, Per, Sal, Slp, Tau, Uba, Cai, Gut, Rne; sp4EqGuy; fraMx: Apa, Chi, Jic, Qur, Tap; fraGuGuc ; fraPePiu; oblBr: Bar, Bot, Ils, Ind, Mir, Per, Rpr, Tau; melEu) e 15 (bifEu) (Tabela VIII).

Tabela VIII: Matriz de distância entre alelos do gene $f b p A$.

\begin{tabular}{|c|c|c|c|c|c|c|c|c|c|c|c|c|c|c|c|c|c|c|}
\hline Código & Alelo & 1 & 257 & 258 & 259 & 260 & 261 & 262 & 263 & 264 & 23 & 8 & 15 & 37 & 35 & 55 & 20 & 3 \\
\hline sp1BrSal & 257 & .022 & & & & & & & & & & & & & & & & \\
\hline fraMxTeo & 259 & .024 & .002 & .014 & & & & & & & & & & & & & & \\
\hline fraPelmo & 260 & .024 & .002 & .014 & .005 & & & & & & & & & & & & & \\
\hline fraArHmo & 262 & .041 & .019 & .031 & .021 & .021 & .021 & & & & & & & & & & & \\
\hline fraArTuc & 263 & .070 & .046 & .054 & .048 & .048 & .029 & .031 & & & & & & & & & & \\
\hline fraArMis & 264 & .081 & .059 & .067 & .061 & .061 & .046 & .054 & .031 & & & & & & & & & \\
\hline simEu & 23 & .075 & .051 & .059 & .054 & .053 & .033 & .036 & .005 & .036 & & & & & & & & \\
\hline apeEu & 37 & .072 & .051 & .059 & .054 & .053 & .038 & .046 & .024 & .012 & .029 & .009 & .021 & & & & & \\
\hline utaEu & 35 & .072 & .048 & .056 & .051 & .051 & .031 & .033 & .002 & .034 & .007 & .031 & .044 & .026 & & & & \\
\hline IonEu & 55 & .040 & .014 & .021 & .018 & .017 & .006 & .014 & .006 & .003 & .011 & .010 & .009 & .025 & .018 & & & \\
\hline invAr & 20 & .078 & .056 & .064 & .059 & .059 & .043 & .051 & .029 & .012 & .034 & .046 & .054 & .048 & .048 & .029 & & \\
\hline albTa & 3 & .081 & .059 & .067 & .061 & .061 & .046 & .054 & .031 & .018 & .017 & .006 & .014 & .006 & .003 & .011 & .009 & \\
\hline oriJa & 11 & .081 & .059 & .067 & .061 & .061 & .046 & .054 & .031 & .041 & .021 & .034 & .024 & .024 & .024 & .002 & .014 & .056 \\
\hline
\end{tabular}

1: alelos sp1Br: Ara, Bot, Ibi, Ita, Itr, Jac, Jam, Lor, Mir, Pir, Sal, Sis, Slp, Tri, Ube, Gua, Imb, Ira, Sem, Gum, Rne; sp2Br: Ber, Ilb, Ilc, Ite, Pet, Per, Sse, Tau, Uba, Cai, Gut, Par; sp3Br: Ber, Ilc, Jam, Pet, Per, Sal, Slp, Tau, Uba, Cai, Gut, Rne; sp4EqGuy; fraMx: Apa, Chi, Jic, Qur, Tap; fraGuGuc ; fraPePiu; oblBr: Bar, Bot, Ils, Ind, Mir, Per, Rpr, Tau;melEu.

$\mathrm{Na}$ árvore do $f b p A$ três grandes grupos são encontrados (Figura 4. V). Em um deles, o alelo 3 (albTa) é mais basal. O alelo 37 (apeEu) ficou próximo aos alelos 20 (invAr) e 55 (lonEu). Outro grupo é formado pelos alelos 15 (bifEu), mais basal e pelos alelos 11 (oriJa) e 35 (utaEu) próximos. O terceiro grupo é formado pelos demais alelos, nos quais o alelo 23 (simEu) forma um ramo mais basal. $O$ alelo 8 (kueEu) 
forma um ramo distinto. Outro ramo é formado pelo alelo 259 (fraMxTeo). O alelo 1 (sp1Br: Ara, Bot, Ibi, Ita, Itr, Jac, Jam, Lor, Mir, Pir, Sal, Sis, Slp, Tri, Ube, Gua, Imb, Ira, Sem, Gum, Rne; sp2Br: Ber, Ilb, Ilc, Ite, Pet, Per, Sse, Tau, Uba, Cai, Gut, Par; sp3Br: Ber, Ilc, Jam, Pet, Per, Sal, Slp, Tau, Uba, Cai, Gut, Rne; sp4EqGuy; fraMx: Apa, Chi, Jic, Qur, Tap; fraGuGuc ; fraPePiu; oblBr: Bar, Bot, Ils, Ind, Mir, Per, Rpr, Tau; melEu) forma um ramo distinto. Os alelo 258 (sp3BrSal) e 260 (fraPeLmo) ficaram próximos, formando um clado distinto. Outro clado é formado pelos alelos 264 (fraArMis), mais basal. O alelo 262 (fraArHmo) forma um ramo distinto. O alelo 261 (fraArCon) ficou próximo aos alelos 257 (sp1BrSal) e 263 (fraArTuc)

\subsection{Comparação entre as filogenias dos cinco genes do MLST}

Existem discrepâncias entre as filogenias dos cinco genes quanto às posições relativas das amostras nas árvores, muito embora os alelos de Wolbachia obtidos de A. fraterculus se agrupam em todas elas (Figuras 4. I a V). As comparações foram feitas tomando-se a filogenia do gene gatB como base.

Nota-se que na árvore do gene coxA (Figuras 4.I e 4.II), os alelos 36 (utaEu) e 23 (fraCoTol), que formavam um ramo em gatB, separam-se agora. Os alelos 7 (kueEu), 10 (oriJa) e 32 (apeEu), que formavam um ramo distinto, separam-se na árvore do gene $\operatorname{cox} A$, na qual o alelo kueEu fica mais distante. Os alelos 3 (albTa) e 19 (inAr) permanecem juntos, formando um ramo em ambas filogenias. O grupo formado pelas linhagens de Wolbachia encontradas na Anastrepha permanece formando um grupo distinto, embora, internamente, hajam mudanças.

$\mathrm{Na}$ árvore do gene $h c p A$, em relação aos grupos formados no gene gat $B$, nota-se que o grupo formado as linhagens invAr e albTa separou-se. O mesmo ocorrendo com a linhagem apeEu, que se separou das linhagens oriJa e kueEu. Também ficaram separadas as linhagens fraCoTol e utaEu. As linhagens encontradas em Anastrepha permanecem juntas (Figuras 4. I e 4.III).

$\mathrm{Na}$ árvore do gene $f s t Z$, os grupos encontrados no gene gat $B$ separaram-se. As linhagens invAr e albTa ficaram distantes. Assim como apeEu, oriJa e kueEu. O grupo formado pelas linhagens fraCoTol e utaEu ficou separado (Figuras 4.I e 4.IV).

Em relação aos grupos formados na árvore do gene gatB, nota-se que no gene $f p b A$ as linhagens invAr e albTa ficaram separadas, porém dentro de um mesmo grupo. O grupo formado pelas linhagens apeEu, oriJa e kueEu separou-se. O mesmo ocorrendo pelo formado pelas linhagens fraCoTol e utaEu. O grupo formado pelas linhagens encontradas em Anastrepha permaneceu junto (Figuras 4.I e 4.V). 


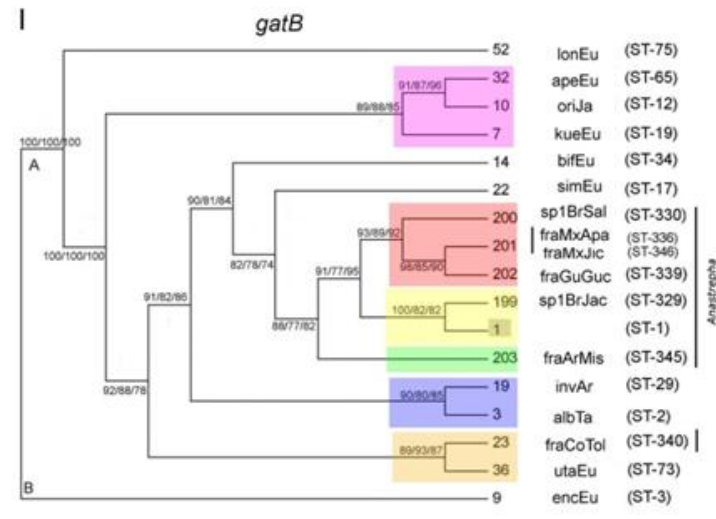

II

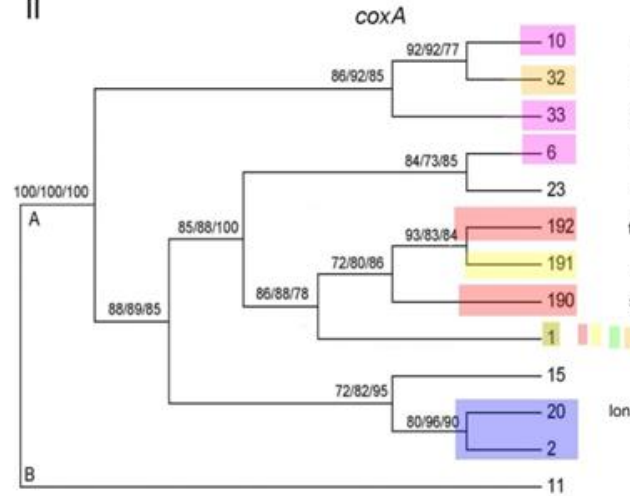

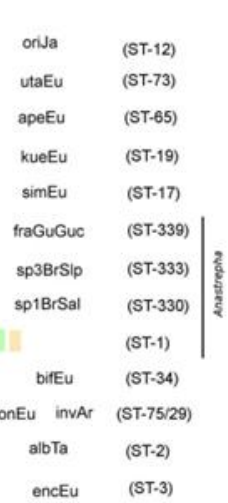

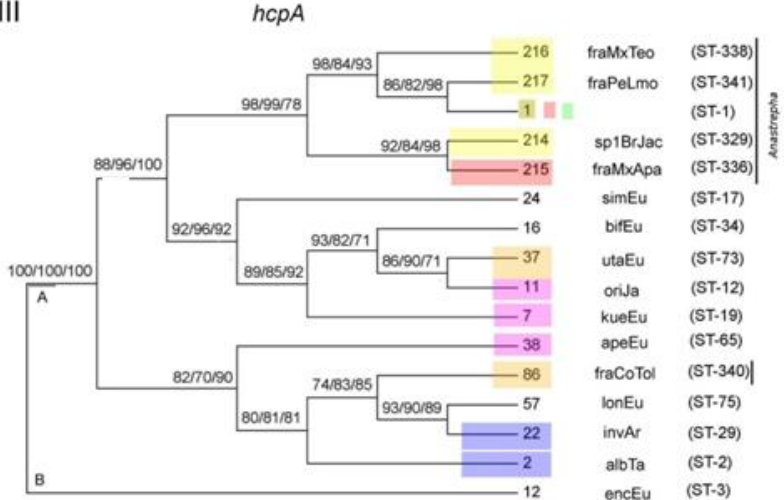

IV fts
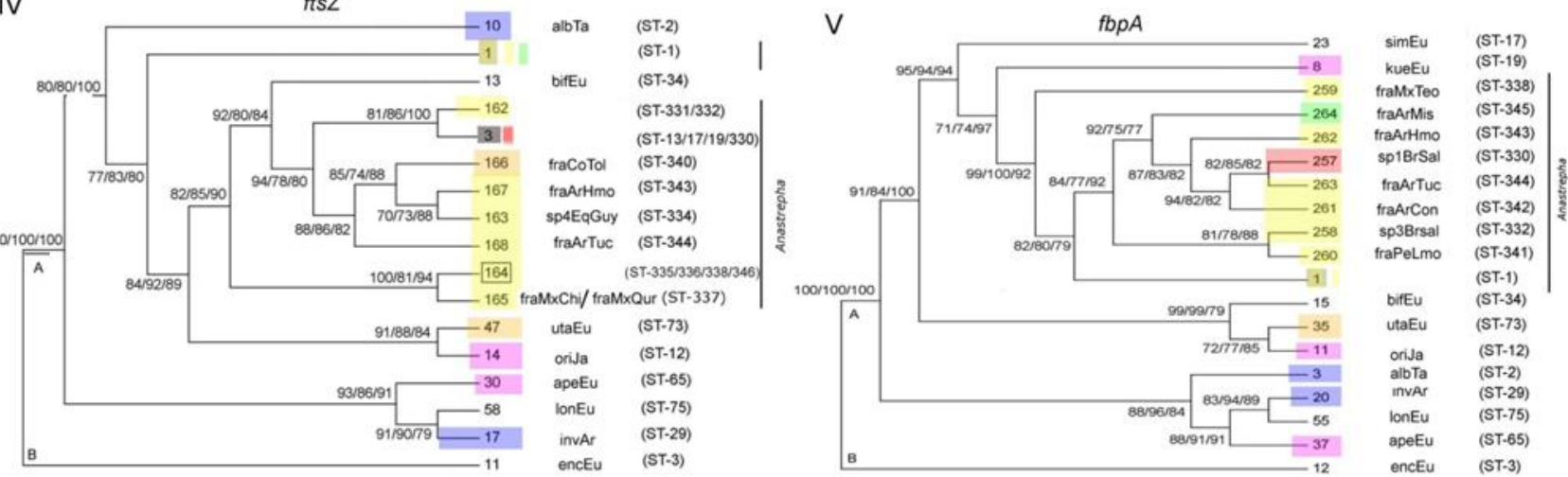

Figura 4: Filogenia dos genes do MLST. I: Árvore filogenética do gene gatB. II. Árvore filogenética do gene coxA. III: árvore filogenética do gene hcpA. IV: Árvore filogenética do gene ftsZ. V: Árvore filogenética do gene fbpA. Em colorido, os grupos formados relativos à filogenia do gene gatB. Por exempo, em lilás, o grupo com os alelos 7 (kueEu), 10 (oriJa) e 32 (ageEu) em gatB estão separados nas demais filogenias. A: alelos do supergrupo " $A$ ". B: alelo do supergrupo "B". 


\subsection{Sequências dos cinco genes concatenadas}

As sequências obtidas de cada gene foram concatenadas pela ordem dos genes, gat $B, \operatorname{cox} A, h c p A, f t s Z$ e $f b p A$, gerando sequências com 2.079 bases, de acordo com Baldo et al. (2006). Estas foram analisadas pelo programa DnaSP 5.10 (Rozas et al., 2009) definindo os haplótipos encontrado na Wolbachia (Tabela III). De acordo com os resultados obtidos, o haplótipo 1 é encontrado em: $A$. sp.1 das populações de Araraquara, Botucatu, Ibiuna, Itararé, Jacareí, Jambeiro, Lorena, Piracicaba, Santa Isabel, São Luís do Paraitinga (SP), Três Rios (RJ), Uberlândia (MG), Guarapuava, Imbituva, Irati (PR), Guaramirim, Rio Negrinho (SC); em A. sp.2 das populações de Bertioga, Ilhabela, Ilha Comprida, Itanhaém, Pedro de Toledo, Peruíbe, São Sebastião, Ubatuba (SP), Caiobá, Guaratuba, Paranaguá (PR); em $A$. sp.3 das populações de Bertioga, Ilha Comprida, Jambeiro, Pedro de Toledo, Peruíbe, Salesópolis, Taubaté, Ubatuba (SP), Caiobá, Guaratuba (PR), Rio Negrinho (SC); em A. fraterculus s.l. das populações de Tapachula, no México, Piura, no Peru e nas populações de $A$. obliqua de Bariri, Botucatu, Ilha Solteira, Indaiatuba, Mirassol, Peruíbe, Ribeirão Preto e Taubaté (SP). Este haplótipo é similar ao Dmel_A_wMel encontrado em Drosophila melanogaster. Além deste, foi encontrado o haplótipo 13 em $A$. sp.1 de Itapetininga, Mirassol e Salesópolis e em $A$. sp.2 de Taubaté. Este haplótipo é encontrado também nos hospedeiros Drosophila recens, Leucophenga maculosa, Siullia dos Estados Unidos; em Rhagoletis cingulata, da Alemanha, em um díptero não especificado do Japão, em Sphaeroceridae, Tabanidae e Phoridae dos EUA, drosofilideo do Panamá e EUA e em Calyptrate do Panamá. Outros haplótipo distintos foram encontrados A. sp.1 de Jacareí, Salesópolis (SP), Sengés (PR); em $A$. sp.3 de Salesópolis, São Luís do Paraitinga e Ubatuba (SP); $A$. sp.4 de Guayaquil, no Equador; A. fraterculus s.l. de populações de Apazapan, Chiapas, Jicayna, Quitana Roo e Teocelo, no México; de Guatemala City; Tolima, Colômbia; La Molina, no Peru e em Concórdia, Horco Molle, Tucumán e Misiones, na Argentina.

$\mathrm{Na}$ comparação das divergências entre os haplótipos, encontrou-se que a menor distância foi entre os haplótipos 330 (sp1BrSal) e 333 (sp3BrSlp) (0.001) e a maior, entre os haplótipos 13 (sp1Br: Ita, Mir, Sal; sp2BrTau) e 65 (apeEu) (0.058) (Tabela IX). 
Tabela IX: Matriz de distância entre haplótipos das sequencias dos genes concatenados

\begin{tabular}{|c|c|c|c|c|c|c|c|c|c|c|c|c|c|c|c|c|c|c|c|c|c|c|c|c|c|c|c|c|c|}
\hline Código & Haplótipos & 1 & $13^{*}$ & 329 & 330 & 331 & 332 & 333 & 334 & 335 & 336 & 337 & 346 & 338 & 339 & 340 & 341 & 342 & 343 & 344 & 345 & 17 & 19 & 34 & 65 & 73 & 75 & 29 & 2 \\
\hline & $13^{*}$ & \begin{tabular}{|c|}
.019 \\
\end{tabular} & & & & & & & & & & & & & & & & & & & & & & & & & & & \\
\hline sp1BrJac & 329 & .023 & .007 & & & & & & & & & & & & & & & & & & & & & & & & & & \\
\hline sp1BrSal & 330 & .019 & .003 & .007 & & & & & & & & & & & & & & & & & & & & & & & & & \\
\hline $\begin{array}{l}\text { sp1BrSen } \\
\text { sp3Bruba }\end{array}$ & 331 & .023 & .007 & .012 & .005 & & & & & & & & & & & & & & & & & & & & & & & & \\
\hline sp3BrSal & 332 & .020 & .004 & .009 & .003 & .007 & & & & & & & & & & & & & & & & & & & & & & & \\
\hline sp3BrSlp & 333 & .018 & .002 & .008 & .001 & .004 & .003 & & & & & & & & & & & & & & & & & & & & & & \\
\hline sp4EqGuy & 334 & .021 & .005 & .010 & .004 & .008 & .005 & .004 & & & & & & & & & & & & & & & & & & & & & \\
\hline fraM×Apa & 335 & .021 & .005 & .009 & .004 & .008 & .003 & .003 & .005 & & & & & & & & & & & & & & & & & & & & \\
\hline fraMхАра & 336 & .028 & .012 & .017 & .011 & .015 & .012 & .011 & .013 & .012 & & & & & & & & & & & & & & & & & & & \\
\hline $\begin{array}{l}\text { fraMxChi } \\
\text { fraMxOur }\end{array}$ & 337 & .047 & .031 & .035 & .030 & .034 & .030 & .029 & .030 & .030 & .031 & & & & & & & & & & & & & & & & & & \\
\hline & 346 & .028 & .012 & .016 & .011 & .015 & .011 & .010 & .012 & .011 & .009 & .032 & & & & & & & & & & & & & & & & & \\
\hline fraMxTeo & 338 & .027 & .010 & .014 & .010 & .014 & .010 & .009 & .011 & .011 & .014 & .030 & .014 & & & & & & & & & & & & & & & & \\
\hline fraGuGuc & 339 & .020 & .004 & .008 & .003 & .007 & .003 & .002 & .004 & .004 & .011 & .030 & .011 & .010 & & & & & & & & & & & & & & & \\
\hline fracotol & 340 & .018 & .001 & .006 & .002 & .006 & .003 & .002 & .004 & .003 & .011 & .029 & .010 & .008 & .002 & & & & & & & & & & & & & & \\
\hline fraPeLmo & 341 & .027 & .011 & .016 & .010 & .014 & .011 & .010 & .012 & .011 & .015 & .035 & .014 & .010 & .010 & .010 & & & & & & & & & & & & & \\
\hline fraArCon & 342 & .030 & .014 & .019 & .013 & .017 & .014 & .013 & .014 & .014 & .017 & .033 & .016 & .010 & .011 & .013 & .014 & & & & & & & & & & & & \\
\hline fraArHmo & 343 & .019 & .003 & .007 & .002 & .006 & .002 & .001 & .003 & .003 & .010 & .029 & .010 & .009 & .002 & .001 & .009 & .012 & & & & & & & & & & & \\
\hline fraArTuc & 344 & .029 & .015 & .019 & .014 & .018 & .014 & .013 & .015 & .015 & .018 & .038 & .018 & .014 & .014 & .013 & .011 & .017 & .013 & & & & & & & & & & \\
\hline fraArMis & 345 & .037 & .021 & .026 & .020 & .024 & .021 & .020 & .022 & .021 & .024 & .040 & .023 & .017 & .019 & .020 & .018 & .013 & .019 & .018 & & & & & & & & & \\
\hline simEu & 17 & $\mid .039$ & .024 & .028 & .023 & .027 & .024 & .023 & .025 & .024 & .027 & .045 & .027 & .020 & .023 & .023 & .023 & .025 & .022 & .017 & .020 & & & & & & & & \\
\hline kueEu & 19 & .046 & .031 & .035 & .030 & .034 & .031 & .030 & .032 & .031 & .029 & .051 & .028 & .032 & .030 & .030 & .034 & .036 & .028 & .028 & .034 & .029 & & & & & & & \\
\hline bifEu & 34 & .045 & .029 & .033 & .028 & .032 & .029 & .027 & .030 & .029 & .033 & .049 & .032 & .022 & .028 & .027 & .028 & .029 & .026 & .020 & .025 & .015 & .027 & & & & & & \\
\hline apeЕu & 65 & .055 & .058 & .043 & .039 & .042 & .039 & .038 & .040 & .040 & .038 & .059 & .037 & .037 & .039 & .038 & .040 & .039 & .037 & .036 & .033 & .026 & .021 & .029 & & & & & \\
\hline utaEu & 73 & .048 & .033 & .037 & .032 & .036 & .033 & .032 & .034 & .033 & .030 & .052 & .029 & .031 & .032 & .032 & .034 & .034 & .030 & .030 & .031 & .025 & .020 & .026 & .014 & & & & \\
\hline IOnEu & 75 & $\mid .045$ & .030 & .033 & .029 & .032 & .029 & .028 & .030 & .030 & .022 & .049 & .026 & .032 & .029 & .028 & .030 & .034 & .027 & .024 & .029 & .023 & .018 & .026 & .022 & .016 & & & \\
\hline invar & 29 & .046 & .030 & .033 & .029 & .032 & .029 & .028 & .030 & .030 & .033 & .049 & .033 & .022 & .029 & .028 & .028 & .029 & .027 & .022 & .022 & .014 & .026 & .011 & .030 & .031 & .030 & & \\
\hline albTa & 2 & .039 & .021 & .024 & .019 & .022 & .020 & .019 & .021 & .020 & .021 & .021 & .022 & .019 & .019 & .019 & .022 & .022 & .017 & .019 & .017 & .017 & .016 & .017 & .018 & .017 & .012 & .019 & \\
\hline orija & 12 & .019 & .003 & .007 & .002 & .006 & .002 & .001 & .003 & .003 & .010 & .029 & .010 & .009 & .002 & .001 & .009 & .012 & .047 & .031 & .035 & .030 & .034 & .030 & .029 & .030 & .030 & .031 & .028 \\
\hline
\end{tabular}


$\mathrm{Na}$ árvore filogenética da Figura 5, nota-se o haplótipo 2 (albTa) formando um clado distinto, mais basal e o 65 (apeEu) próximo aos haplótipos 29 (invAr) e 75 (lonEu). Outro grupo é formado pelos haplótipos 34 (bifEu), que forma um ramo mais basal, e os haplótipos 12 (oriJa) e 73 (utaEu) próximos. O haplótipo 19 (kueEu) forma um ramo distinto. Assim como o 17 (simEu). Os haplótipos de Wolbachia encontrados nas diferentes espécies de Anastrepha formam um grupo distinto. O haplótipo 340 (fraCoTol) forma um ramo mais basal. O haplótipo 344 (fraArTuc) ficou próximo aos 334 (sp4EqGuy) e 343 (fraArHmo), formando um clado distinto dentro deste grupo. Outro ramo é formado pelos haplótipos 330 (sp1BrSal), mais basal e 333 (sp3BrSlp) e 339 (fraGuGuc) próximos. Outro ramo é formado pelos haplótipos 1 (sp1Br: Ara, Bot, Ibi, Itr, Jac, Jam, Lor, Pir, Sis, SIp, Tri, Ube, Gua, Imb, Ira, Gum, Rne; sp2Br: Ber, Ilb, Ilc, Ite, Pet, Per, Sse, Uba, Cai, Gut, Par; sp3Br: Ber, Ilc, Jam, Pet, Per, Sal, Tau, Cai, Gut, Rne; fraMxTap; fraPePiu; oblBr: Bar, Bot, Ils, Ind, Mir, Per, Rpr, Tau; melEu) e 329 (sp1BrJac) próximos e 345 (fraArMis) mais basal. Os haplótipos 341 (fraPeLmo) e 342 (fraArCon) formam um ramo distinto. Outro clado é formado pelos haplótipos 331 (sp1BrSen, sp3BrUba) e 332 (sp3BrSal) próximos e pelo 13 (sp1Br: Ita, Mir, Sal; sp2BrTau) mais basal. Os haplótipos encontrados no México formam um grupo distinto, no qual o haplótipo 337 (fraMxChi, fraMxQur) é mais basal. Outro ramo é formado pelos haplótipos 335 (fraMxApa) e 338 (fraMxTeo) próximos. Os haplótipos 336 (fraMxApa) e 346 (fraMxJic) formam outro ramo. 


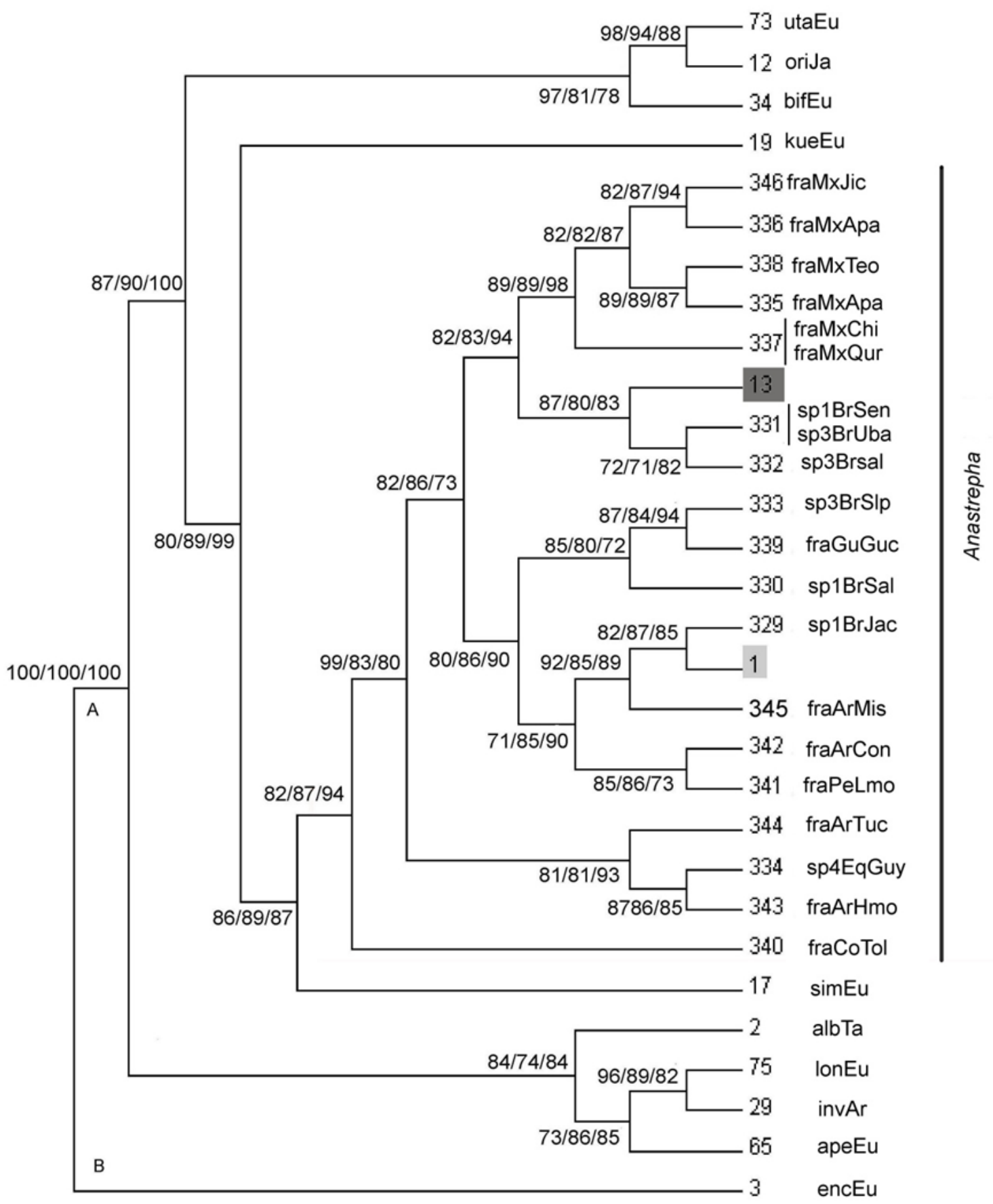

Figura 5. Árvore filogenética dos genes concatenados. A: alelos do supergrupo "A". B: alelo do supergrupo "B". 1: alelos sp1Br: Ara, Bot, Ibi, Itr, Jac, Jam, Lor, Pir, Sis, Slp, Tri, Ube, Gua, Imb, Ira, Gum, Rne; sp2Br: Ber, Ilb, Ilc, Ite, Pet, Per, Sse, Uba, Cai, Gut, Par; sp3Br: Ber, Ilc, Jam, Pet, Per, Sal, Tau, Cai, Gut, Rne; fraMxTap; fraPePiu; oblBr: Bar, Bot, Ils, Ind, Mir, Per, Rpr, Tau; melEu. 13: sp1Br: Ita, Mir, Sal; sp2BrTau. 


\section{Análise do gene wsp}

A análise do gene wsp foi feita a partir das amostras do complexo fraterculus e de $A$. obliqua que foram utilizadas para a identificação das linhagens de Wolbachia pela metodologia do MLST (Tabela I), como descritas no item 2 deste trabalho. Foram estudados 292 indivíduos distribuídos pelas 22 amostras, como mostra a Tabela X e a amplificação resultou em fragmentos de $\approx 600$ pb para todos os espécimens (Figura 6).

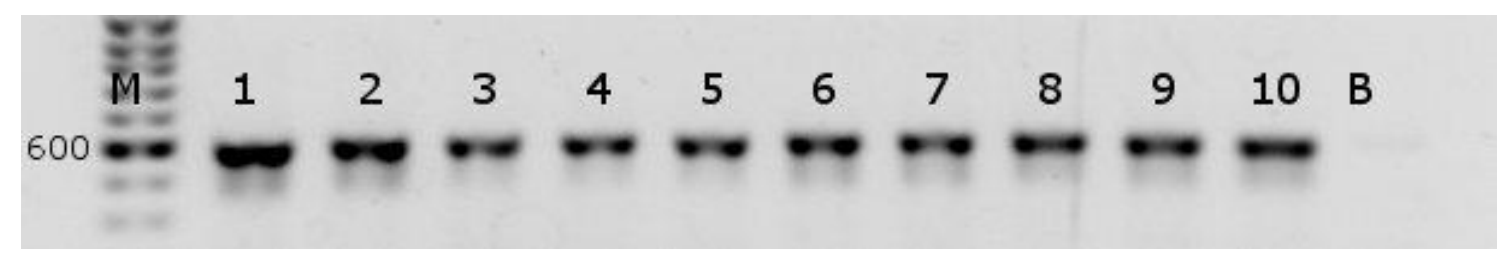

Figura 6: Fragmento amplificado genes wsp. Marcador GeneRuler ${ }^{\mathrm{TM}}$ DNA Ladder. 1: $A$. sp.1 Salesópolis; 2: A. sp.2 Taubaté; 3: A. sp.3 Ubatuba; 4: A. sp.4 Guayaquil; 5: A. fraterculus Apazapan; 6: A. fraterculus Chiapas; 7: $A$. fraterculus Guatemala City; 8: A. fraterculus Tolima; $A$. fraterculus Piura; 9: $A$. fraterculus Concórdia; 10: $A$. fraterculus Tucumán; B: controle negativo.

A comparação das sequências obtidas com os dados depositados no banco de sequências do gene wsp de Wolbachia (http://pubm/st.org/wolbachia), mostrou que todas eram sequências do gene wsp dessa bactéria. As sequências do wsp tinham cerca de $500 \mathrm{pb}$ e foram analisadas pelo programa DnaSP 5.0, que identificou a existência de 22 haplótipos distintos (Tabelas X e XI).

A Figura 7 mostra que o nível de variabilidade de nucleotídeos não é uniforme ao longo do gene, formando um padrão com quatro regiões hipervariáveis, "HVRs" (sigla em inglês) separadas por regiões conservadas, "CRs", como ocorre usualmente com esse gene em linhagens de Wolbachia de outros hospedeiros (Baldo et al., 2006). Este padrão se repete na variabilidade observada nas sequências de aminoácidos, obtidas pela tradução conceitual das sequências de nucleotídeos e mostradas na Figura 8: as maiores diferenças entre as sequências ocorrem nas HVRs e são espaçadas por regiões conservadas (CRs) nas proteínas. 


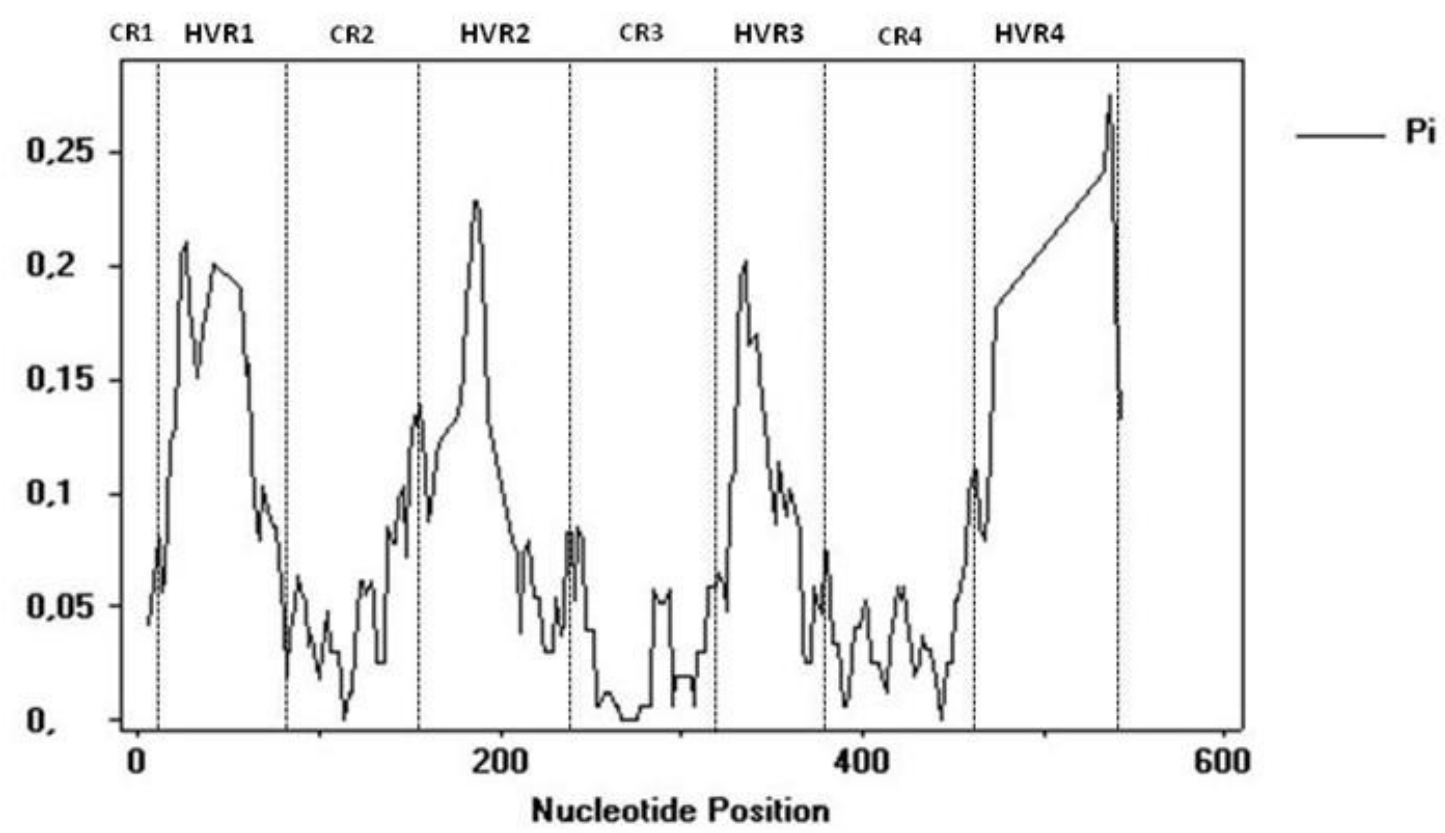

Figura 7. Divergência de nucleotídeos $(\mathrm{Pi})$ do alinhamento das sequências do WSP. Quatro picos são identificados, correspondendo aos quatro HVRs.

Pela metodologia do "Wsp Typing" a caracterização dos diferentes haplótipos e dos supergrupos da Wolbachia é feita pela análise de cada HVR isoladamente (Baldo et al., 2006a). Assim, os dados de cada HVR das sequências de Anastrepha foram submetidos ao "Wsp gene GeneBank" que identificou as quatro HVRs de cada sequência atribuindo um código numérico a cada uma, como mostrado na Tabela X. $O$ conjunto desses quatro números, por sua vez, identifica o haplótipo (ou linhagem) da Wolbachia e sugere a qual supergrupo a linhagem tem maior afinidade. Por exemplo, na sequência obtida de $A$. sp.1 coletada em Araraquara, as quatro HVRs foram identificadas com os códigos, HVR1 = 1, HVR2 = 12, HVR3 = 21 e HVR4 = 24. Assim, este conjunto 1, 12, 21 e 24, define o haplótipo 31 que corresponde ao wsp da Wolbachia do grupo A encontrada em Drosophila melanogaster (melEu). A Tabela X lista os 22 haplótipos encontrados no complexo fraterculus e os dois de $A$. obliqua, indicando que todas as sequências encontradas pertencem ao supergrupo $A$ da Wolbachia.

O haplótipo 31 (melEu) é o mais comum e foi encontrado na maioria das amostras de Wolbachia: no hospedeiro A. sp.1 das populações coletadas em Araraquara, Botucatu, Ibiúna, Itararé, Jacareí, Jambeiro, Lorena, Mirassol, Piracicaba, Salesópolis, Santa Isabel, São Luís do Paraitinga (SP), Três Rios (RJ), Guarapuava (PR) e Guaramirim (SC); em A. sp.2 de Bertioga, Ilhabela, Ilha Comprida, Itanhaém, Peruíbe, São Sebastião, Taubaté, Ubatuba (SP) e Paranaguá (PR); A. sp.3 de Bertioga, llha Comprida, Jambeiro, Peruíbe, Salesópolis, São Luís do Paraitinga, Taubaté, Ubatuba 
(SP) e Caiobá (PR); A. sp.4 de Guayaquil, Equador; $A$ fraterculus s.l. de Chiapas, Quitana Roo, Tapachula, no México; Guatemala City; Tolima, na Colômbia; La Molina e Piura, no Peru; Concórdia, Horco Molle e Tucumán na Argentina; A. obliqua de Bariri, Botucatu, Ilha Solteira, Indaiatuba, Peruíbe, Ribeirão Preto e Taubaté.

O haplótipo 23 foi encontrado nas populações do hospedeiro $A$. sp.2 de Pedro de Toledo, Ubatuba (SP), Guaratuba (PR) e em A. sp.3 de Pedro de Toledo (SP), este haplótipo também é descrito para Nasonia longicornis, para Sphaeroceridae, Suillia, Leucophenga maculosa dos EUA, em Rhagoletis cingulata da Alemanha, entre outros. Além desses, foram encontrados haplótipos únicos, que não haviam sido descritos para Wolbachia, nas populações de A. sp.1 de Itapetininga (SP), Uberlândia (MG), Imbituva, Irati, Sengés (PR), Rio Negrinho (SC); em A. sp.2 de Pedro de Toledo (SP), Caiobá (PR); em A. sp.3 de Pedro de Toledo, Salesópolis (SP), Guaratuba (PR), Rio Negrinho (SC); em A. fraterculus s.l. de Apazapan, Chiapas, Jicayna, Tapachula e Teocelo (México), em Misiones (Argentina) e em A. obliqua de Mirassol (SP) (Tabela $\mathrm{X})$.

Tabela X: Hospedeiros, localidade, número de indivíduos e alelos analisados para o gene wsp.

\begin{tabular}{|c|c|c|c|c|c|c|c|c|c|}
\hline Hospedeiro & População & Código & $\begin{array}{c}\text { Número } \\
\text { de } \\
\text { indivíduos }\end{array}$ & wsp & HVR1 & HVR2 & HVR3 & HVR4 & Linhagem \\
\hline \multirow{14}{*}{ A. sp.1 } & $\begin{array}{c}\text { Brasil- } \\
\text { Araraquara (SP) }\end{array}$ & sp1BrAra & 3 & 31 & 1 & 12 & 21 & 24 & Afra_A_wB11 \\
\hline & $\begin{array}{c}\text { Brasil-Botucatu } \\
\text { (SP) }\end{array}$ & sp1BrBot & 5 & 31 & 1 & 12 & 21 & 24 & Afra_A_wB11 \\
\hline & $\begin{array}{c}\text { Brasil- } \\
\text { Itapetininga }\end{array}$ & sp1Brlta & 5 & 640 & 218 & 252 & 21 & 24 & Afra_A_wB12 \\
\hline & $\begin{array}{c}\text { Brasil-Itararé } \\
\text { (SP) } \\
\end{array}$ & sp1Brltr & 5 & 31 & 1 & 12 & 21 & 24 & Afra_A_wB11 \\
\hline & $\begin{array}{c}\text { Brasil-Jacareí } \\
\text { (SP) }\end{array}$ & sp1BrJac & 5 & 31 & 1 & 12 & 21 & 24 & Afra_A_wB11 \\
\hline & $\begin{array}{l}\text { Brasil-Lorena } \\
\text { (SP) }\end{array}$ & sp1BrLor & 2 & 31 & 1 & 12 & 21 & 24 & Afra_A_wB11 \\
\hline & $\begin{array}{c}\text { Brasil-Mirassol } \\
\text { (SP) }\end{array}$ & sp1BrMir & 3 & 31 & 1 & 12 & 21 & 24 & Afra_A_wB11 \\
\hline & $\begin{array}{c}\text { Brasil-Piracicaba } \\
\text { (SP) }\end{array}$ & sp1BrPir & 5 & 31 & 1 & 12 & 21 & 24 & Afra_A_wB11 \\
\hline & $\begin{array}{c}\text { Brasil- } \\
\text { Salesópolis (SP) }\end{array}$ & sp1BrSal & 5 & 31 & 1 & 12 & 21 & 24 & Afra_A_wB11 \\
\hline & $\begin{array}{c}\text { Brasil-Santa } \\
\text { Isabel (SP) }\end{array}$ & sp1BrSis & 5 & 31 & 1 & 12 & 21 & 24 & Afra_A_wB11 \\
\hline & $\begin{array}{c}\text { Brasil-São Luís } \\
\text { do Paraitinga } \\
\text { (SP) }\end{array}$ & sp1BrSlp & 5 & 31 & 1 & 12 & 21 & 24 & Afra_A_wB11 \\
\hline & $\begin{array}{c}\text { Brasil-Imbituva } \\
\text { (PR) }\end{array}$ & sp1Brlmb & 5 & 658 & 226 & 253 & 21 & 277 & Afra_A_wB14 \\
\hline & Brasil-Irati (PR) & sp1BrIra & 5 & 659 & 1 & 12 & 21 & 278 & Afra_A_wB15 \\
\hline & Brasil-Sengés & sp1BrSen & 5 & 642 & 1 & 255 & 21 & 278 & Afra_A_wB16 \\
\hline
\end{tabular}




\begin{tabular}{|c|c|c|c|c|c|c|c|c|c|}
\hline & (PR) & & & & & & & & \\
\hline & $\begin{array}{c}\text { Brasil- } \\
\text { Guaramirim (SC) }\end{array}$ & sp1BrGum & 5 & 31 & 1 & 12 & 21 & 24 & Afra_A_wB11 \\
\hline & $\begin{array}{c}\text { Brasil-Rio } \\
\text { Negrinho (SC) }\end{array}$ & sp1BrRne & 5 & 643 & 1 & 12 & 21 & 24 & Afra_A_wB17 \\
\hline \multirow{14}{*}{ A. sp. 2} & $\begin{array}{c}\text { Brasil-Bertioga } \\
\text { (SP) }\end{array}$ & sp2BrBer & 5 & 31 & 1 & 12 & 21 & 24 & Afra_A_wB21 \\
\hline & $\begin{array}{c}\text { Brasil- } \\
\text { Ilhabela(SP) }\end{array}$ & sp2Brllb & 4 & 31 & 1 & 12 & 21 & 24 & Afra_A_wB21 \\
\hline & $\begin{array}{c}\text { Brasil-Ilha } \\
\text { Comprida (SP) }\end{array}$ & sp2Brllc & 5 & 31 & 1 & 12 & 21 & 24 & Afra_A_wB21 \\
\hline & $\begin{array}{l}\text { Brasil-Itanhaém } \\
\text { (SP) }\end{array}$ & sp2Brlte & 5 & 31 & 1 & 12 & 21 & 24 & Afra_A_wB21 \\
\hline & \multirow{2}{*}{$\begin{array}{c}\text { Brasil-Pedro de } \\
\text { Toledo (SP) }\end{array}$} & sp2BrPet & 3 & 23 & 1 & 12 & 21 & 19 & Afra_A_wB22 \\
\hline & & sp2BrPet & 2 & 644 & 1 & 12 & 21 & 19 & Afra_A_wB23 \\
\hline & $\begin{array}{l}\text { Brasil-Peruíbe } \\
\text { (SP) }\end{array}$ & sp2BrPer & 3 & 31 & 1 & 12 & 21 & 24 & Afra_A_wB21 \\
\hline & $\begin{array}{c}\text { Brazil-São } \\
\text { Sebastião (SP) }\end{array}$ & sp2BrSse & 1 & 31 & 1 & 12 & 21 & 24 & Afra_A_wB21 \\
\hline & $\begin{array}{c}\text { Brazil-Taubaté } \\
\text { (SP) }\end{array}$ & sp2BrTau & 4 & 31 & 1 & 12 & 21 & 24 & Afra_A_wB21 \\
\hline & \multirow{2}{*}{$\begin{array}{c}\text { Brazil-Ubatuba } \\
\text { (SP) }\end{array}$} & sp2BrUba & 4 & 31 & 1 & 12 & 21 & 24 & Afra_A_wB21 \\
\hline & & sp2BrUba & 1 & 23 & 1 & 12 & 21 & 19 & Afra_A_wB22 \\
\hline & $\begin{array}{c}\text { Brasil-Caiobá } \\
\text { (PR) }\end{array}$ & sp2BrCai & 5 & 645 & 1 & 12 & 21 & 279 & Afra_A_wB23 \\
\hline & $\begin{array}{c}\text { Brasil- } \\
\text { Guaratuba (PR) }\end{array}$ & sp2BrGut & 5 & 23 & 1 & 12 & 21 & 19 & Afra_A_wB22 \\
\hline & $\begin{array}{c}\text { Brasil- } \\
\text { Paranaguá (PR) }\end{array}$ & sp2BrPar & 5 & 31 & 1 & 12 & 21 & 24 & Afra_A_wB21 \\
\hline \multirow{14}{*}{ A. sp.3 } & $\begin{array}{c}\text { Brasil-Bertioga } \\
\text { (SP) }\end{array}$ & sp3BrBer & 4 & 31 & 1 & 12 & 21 & 24 & Afra_A_wB31 \\
\hline & $\begin{array}{c}\text { Brasil- Ilha } \\
\text { Comprida (SP) }\end{array}$ & sp3Brllc & 5 & 31 & 1 & 12 & 21 & 24 & Afra_A_wB31 \\
\hline & $\begin{array}{c}\text { Brasil-Jambeiro } \\
\text { (SP) }\end{array}$ & sp3BrJam & 5 & 31 & 1 & 12 & 21 & 24 & Afra_A_wB31 \\
\hline & \multirow{2}{*}{$\begin{array}{c}\text { Brasil-Pedro de } \\
\text { Toledo (SP) }\end{array}$} & sp3BrPet & 3 & 23 & 1 & 12 & 21 & 19 & Afra_A_wB32 \\
\hline & & sp3BrPet & 2 & 646 & 1 & 12 & 21 & 280 & Afra_A_wB33 \\
\hline & $\begin{array}{l}\text { Brasil-Peruíbe } \\
\text { (SP) }\end{array}$ & sp3BrPer & 5 & 31 & 1 & 12 & 21 & 24 & Afra_A_wB31 \\
\hline & \multirow{2}{*}{$\begin{array}{c}\text { Brasil- } \\
\text { Salesópolis (SP) }\end{array}$} & sp3BrSal & 4 & 31 & 1 & 12 & 21 & 24 & Afra_A_wB31 \\
\hline & & sp3BrSal & 1 & 647 & 1 & 12 & 21 & 281 & Afra_A_wB34 \\
\hline & $\begin{array}{c}\text { Brasil-São Luís } \\
\text { do Paraitinga } \\
\text { (SP) }\end{array}$ & sp3BrSlp & 4 & 31 & 1 & 12 & 21 & 24 & Afra_A_wB31 \\
\hline & $\begin{array}{c}\text { Brasil-Taubaté } \\
\text { (SP) }\end{array}$ & sp3BrTau & 2 & 31 & 1 & 12 & 21 & 24 & Afra_A_wB31 \\
\hline & $\begin{array}{c}\text { Brasil-Ubatuba } \\
\text { (SP) }\end{array}$ & sp3BrUba & 5 & 31 & 1 & 12 & 21 & 24 & Afra_A_wB31 \\
\hline & $\begin{array}{c}\text { Brasil-Caiobá } \\
\text { (PR) }\end{array}$ & sp3BrCai & 5 & 31 & 1 & 12 & 21 & 24 & Afra_A_wB31 \\
\hline & $\begin{array}{c}\text { Brasil- } \\
\text { Guaratuba (PR) } \\
\end{array}$ & sp3BrGut & 5 & 648 & 220 & 12 & 21 & 24 & Afra_A_wB35 \\
\hline & $\begin{array}{c}\text { Brasil-Rio } \\
\text { Negrinho (SC) }\end{array}$ & sp3BrRne & 5 & 649 & 1 & 256 & 21 & 24 & Afra_A_wB36 \\
\hline A. sp.4 & $\begin{array}{l}\text { Equador- } \\
\text { Guayaquil }\end{array}$ & sp4EqGuy & 5 & 31 & 1 & 12 & 21 & 24 & Afra_A_wE41 \\
\hline \multirow{11}{*}{$\begin{array}{c}\text { A. fraterculus } \\
\text { s.l. }\end{array}$} & \multirow{2}{*}{$\begin{array}{c}\text { Mexico- } \\
\text { Apazapan }\end{array}$} & fraMxApa & 4 & 650 & 1 & 12 & 21 & 282 & Afra_A_wMx1 \\
\hline & & fraMxApa & 1 & 651 & 1 & 12 & 257 & 283 & Afra_A_wMx2 \\
\hline & \multirow{2}{*}{ Mexico-Chiapas } & fraMxChi & 2 & 31 & 1 & 12 & 21 & 24 & Afra_A_wMx3 \\
\hline & & fraMxChi & 1 & 652 & 221 & 12 & 21 & 284 & Afra_A_wMx4 \\
\hline & Mexico-Jicayna & fraMxJic & 4 & 653 & 222 & 257 & 21 & 285 & Afra_A_wMx5 \\
\hline & $\begin{array}{c}\text { Mexico-Quitana } \\
\text { Roo }\end{array}$ & fraMxQur & 5 & 31 & 1 & 12 & 21 & 24 & Afra_A_wMx3 \\
\hline & \multirow{2}{*}{$\begin{array}{l}\text { Mexico- } \\
\text { Tapachula }\end{array}$} & fraMxTap & 3 & 31 & 1 & 12 & 21 & 24 & Afra_A_wMx3 \\
\hline & & fraMxTap & 2 & 654 & 223 & 258 & 21 & 286 & Afra_A_wMx6 \\
\hline & Mexico-Teocelo & fraMxTeo & 4 & 655 & 224 & 12 & 21 & 19 & Afra_A_wMx7 \\
\hline & $\begin{array}{c}\text { Guatemala- } \\
\text { Guatemala City }\end{array}$ & fraGuGuc & 3 & 31 & 1 & 12 & 21 & 24 & Afra_A_wGu1 \\
\hline & Colombia- & fraCoTol & 3 & 31 & 1 & 12 & 21 & 24 & Afra_A_wCo1 \\
\hline
\end{tabular}




\begin{tabular}{|c|c|c|c|c|c|c|c|c|c|}
\hline & Tolima & & & & & & & & \\
\hline & Peru-La Molina & fraPelmo & 2 & 31 & 1 & 12 & 21 & 24 & Afra_A_wPe1 \\
\hline & Peru-Piura & fraPePiu & 2 & 31 & 1 & 12 & 21 & 24 & Afra_A_wPe1 \\
\hline & $\begin{array}{l}\text { Argentina- } \\
\text { Concórdia }\end{array}$ & fraArCon & 3 & 31 & 1 & 12 & 21 & 24 & Afra_A_wAr1 \\
\hline & $\begin{array}{c}\text { Argentina-Horco } \\
\text { Molle }\end{array}$ & fraArHmo & 5 & 31 & 1 & 12 & 21 & 24 & Afra_A_wAr1 \\
\hline & $\begin{array}{l}\text { Argentina- } \\
\text { Tucumán }\end{array}$ & fraArTuc & 2 & 31 & 1 & 12 & 21 & 24 & Afra_A_wAr1 \\
\hline & $\begin{array}{l}\text { Argentina- } \\
\text { Misiones }\end{array}$ & fraArMis & 2 & 656 & 225 & 12 & 21 & 19 & Afra_A_wAr2 \\
\hline \multirow{8}{*}{ A. obliqua } & Brasil-Bariri (SP) & oblBrBar & 5 & 31 & 1 & 12 & 21 & 24 & Aobl_A_wBo1 \\
\hline & $\begin{array}{c}\text { Brasil-Botucatu } \\
\text { (SP) }\end{array}$ & oblBrBot & 5 & 31 & 1 & 12 & 21 & 24 & Aobl_A_wBo1 \\
\hline & $\begin{array}{l}\text { Brasil-Ilha } \\
\text { Solteira (SP) }\end{array}$ & oblBrlls & 2 & 31 & 1 & 12 & 21 & 24 & Aobl_A_wBo1 \\
\hline & $\begin{array}{c}\text { Brasil- } \\
\text { Indaiatuba (SP) }\end{array}$ & oblBrInd & 2 & 31 & 1 & 12 & 21 & 24 & Aobl_A_wBo1 \\
\hline & $\begin{array}{c}\text { Brasil-Mirassol } \\
\text { (SP) }\end{array}$ & oblBrMir & 3 & 657 & 1 & 12 & 21 & 287 & Aobl_A_wBo2 \\
\hline & $\begin{array}{c}\text { Brasil-Peruíbe } \\
\text { (SP) }\end{array}$ & oblBrPer & 2 & 31 & 1 & 12 & 21 & 24 & Aobl_A_wBo1 \\
\hline & $\begin{array}{c}\text { Brasil-Ribeirão } \\
\text { Preto (SP) } \\
\end{array}$ & oblBrRpr & 5 & 31 & 1 & 12 & 21 & 24 & Aobl_A_wBo1 \\
\hline & $\begin{array}{c}\text { Brasil-Taubaté } \\
\text { (SP) }\end{array}$ & oblBrTau & 5 & 31 & 1 & 12 & 21 & 24 & Aobl_A_wBo1 \\
\hline $\begin{array}{c}\text { Drosophila } \\
\text { melanogaster }\end{array}$ & \multirow{7}{*}{ Estados Unidos } & melEu & 1 & 31 & 1 & 12 & 21 & 24 & Dmel_A_wMel \\
\hline $\begin{array}{c}\text { Drosophila } \\
\text { simulans }\end{array}$ & & simEu & 1 & 16 & 11 & 13 & 15 & 14 & Dsim_A_wRi \\
\hline $\begin{array}{c}\text { Ephestia } \\
\text { kuehniella }\end{array}$ & & kueEu & 1 & 18 & 13 & 15 & 17 & 14 & Ekue_A \\
\hline $\begin{array}{c}\text { Drosophila } \\
\text { bifasciata }\end{array}$ & & bifEu & 1 & 11 & 9 & 9 & 12 & 9 & Dbif_A \\
\hline $\begin{array}{c}\text { Agelenopsis } \\
\text { aperta }\end{array}$ & & apeEu & 1 & 38 & 28 & 29 & 33 & 32 & Aape_A_CDP21 \\
\hline $\begin{array}{c}\text { Agelenopsis } \\
\text { utahana }\end{array}$ & & utaEu & 1 & 39 & 29 & 30 & 32 & 31 & Auta_A_UW21 \\
\hline $\begin{array}{c}\text { Agelenopsis } \\
\text { longistyla }\end{array}$ & & lonEu & 1 & 45 & 31 & 33 & 37 & 34 & Alon_A_NG3 \\
\hline $\begin{array}{c}\text { Solenopsis } \\
\text { invicta }\end{array}$ & Argentina & invAr & 1 & 28 & 21 & 21 & 25 & 21 & Sinv_A \\
\hline $\begin{array}{c}\text { Aedes } \\
\text { albopictus }\end{array}$ & Tailândia & albTa & 1 & 1 & 1 & 1 & 1 & 1 & Aalb_A \\
\hline $\begin{array}{l}\text { Drosophila } \\
\text { orientacea }\end{array}$ & Japão & oriJa & 1 & 13 & 1 & 11 & 21 & 11 & Dori_A \\
\hline $\begin{array}{l}\text { Acraea } \\
\text { encedon }\end{array}$ & EUA & encEu & 1 & 2 & 2 & 2 & 2 & 2 & Aenc_B_Ugardan \\
\hline
\end{tabular}

As distâncias genéticas entre os haplótipos (Tabela XI) mostrou uma variação de 0.001 entre os haplótipos 31 (sp1Br: Ara, Bot, Ibi, Itr, Itr, Jac, Jam, Lor, Mir, Pir, Sal, Sis, Slp, Tri, Gua, Gum; sp2Br: Ber, Ilb, Ilc, Ite, Per, Sse, Tau, Uba, Par; sp3Br: Ber, Ilc, Jam, Per, Sal, SIp, Tau, Uba, Cai; sp4EqGuy; fraMx: Chi, Qur, Tap; fraGuGuc; fraCoTol; fraPe: Lmo, Piu; fraAr: Com, Hmo, Tuc; oblBr: Bar, Bot, Ils, Ind, Per, Rpr, Tau; melEu) e o haplótipo 23 (sp2Br: Pet, Uba, Gut; sp3BrPet) a 0,038, entre os haplótipos 642 (sp1BrSen) e 653 (fraMxJic). Entre as amostras de Anastrepha e das outras espécies, as distâncias foram maiores, variando de 0.055 (várias amostras) a 0,235 entre os haplótipos 654 (fraMxTap) e o haplótipo 45 (lonEu). 
Tabela XI:Matriz de distância entre haplótipos das sequencias dos genes wsp

\begin{tabular}{|c|c|c|c|c|c|c|c|c|c|c|c|c|c|c|c|c|c|c|c|c|c|c|c|c|c|c|c|c|c|c|c|}
\hline Código & $\begin{array}{l}\text { Haplótipo } \\
\end{array}$ & 31 & $23^{*}$ & 640 & 641 & 658 & 659 & 642 & 643 & 644 & 645 & 646 & 647 & 648 & 649 & 650 & 651 & 652 & 653 & 654 & 655 & 655 & 657 & 16 & 18 & 11 & 38 & 39 & 45 & 28 & 1 \\
\hline & $\begin{array}{l}23 \\
640\end{array}$ & $\begin{array}{l}.001 \\
.007\end{array}$ & & & & & & & & & & & & & & & & & & & & & & & & & & & & & \\
\hline splibrube & 641 & .005 & .005 & & & & & & & & & & & & & & & & & & & & & & & & & & & & \\
\hline sp1Brlmb & 658 & .009 & .009 & .016 & .014 & & & & & & & & & & & & & & & & & & & & & & & & & & \\
\hline sp1Brrira & 659 & .005 & .005 & .012 & .009 & .014 & & & & & & & & & & & & & & & & & & & & & & & & & \\
\hline sp1BrSen & 642 & .009 & .009 & .016 & .014 & .019 & .009 & & & & & & & & & & & & & & & & & & & & & & & & \\
\hline sp1BrRne & 643 & .005 & .005 & .012 & .009 & .014 & .009 & .014 & & & & & & & & & & & & & & & & & & & & & & & \\
\hline sp2Brpet & 644 & .002 & .002 & .009 & .007 & .012 & .007 & .012 & .002 & & & & & & & & & & & & & & & & & & & & & & \\
\hline sp2BrCai & 645 & .003 & .002 & & .005 & .009 & .005 & .009 & .005 & .002 & & & & & & & & & & & & & & & & & & & & & \\
\hline 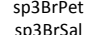 & $\begin{array}{l}646 \\
647\end{array}$ & $\begin{array}{l}.003 \\
002\end{array}$ & $\begin{array}{l}.002 \\
002\end{array}$ & $\begin{array}{l}.007 \\
007\end{array}$ & $\begin{array}{l}.005 \\
005\end{array}$ & .009 & $\begin{array}{l}.005 \\
.005\end{array}$ & .009 & .005 & .002 & .002 & & & & & & & & & & & & & & & & & & & & \\
\hline sp3BrGut & 648 & $\begin{array}{l}.002 \\
.002\end{array}$ & $\begin{array}{l}.002 \\
.002\end{array}$ & $\begin{array}{l}.007 \\
.009\end{array}$ & $\begin{array}{l}.005 \\
.007\end{array}$ & $\begin{array}{l}.009 \\
.012\end{array}$ & $\begin{array}{l}.005 \\
.007\end{array}$ & $\begin{array}{l}.009 \\
.012\end{array}$ & .007 .007 & . .005 & .002 & .002 .002 & .002 & & & & & & & & & & & & & & & & & & \\
\hline sp3BrRne & 649 & .002 & .002 & .009 & .007 & .012 & .007 & .012 & .007 & .005 & .002 & .002 & .002 & .005 & & & & & & & & & & & & & & & & & \\
\hline fram ХApa & 650 & .005 & .005 & .012 & .009 & .014 & .009 & .014 & .005 & .002 & .005 & .005 & .005 & .007 & .007 & & & & & & & & & & & & & & & & \\
\hline fraM ХApa & 651 & .002 & .002 & .009 & .007 & .012 & .007 & .012 & .007 & .005 & .002 & .002 & .002 & .005 & .005 & .007 & & & & & & & & & & & & & & & \\
\hline fram $\times$ Chi & 652 & .007 & .007 & .014 & .012 & .016 & .007 & .012 & .012 & .009 & .007 & .007 & .007 & .009 & .009 & .012 & .009 & & & & & & & & & & & & & & \\
\hline framxlic & 653 & .028 & .028 & .035 & .033 & .035 & .033 & .038 & .033 & .031 & .028 & .028 & .028 & .031 & .031 & .033 & .031 & .035 & & & & & & & & & & & & & \\
\hline 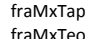 & $\begin{array}{l}654 \\
655\end{array}$ & $\begin{array}{l}.019 \\
002\end{array}$ & $\begin{array}{l}.019 \\
002\end{array}$ & $\begin{array}{l}.026 \\
009\end{array}$ & $\begin{array}{l}.023 \\
007\end{array}$ & $\begin{array}{l}.028 \\
012\end{array}$ & .023 & .028 & .023 & .021 & .019 & .019 & .019 & .021 & .021 & .023 & .021 & .026 & .035 & & & & & & & & & & & & \\
\hline 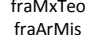 & $\begin{array}{l}655 \\
656\end{array}$ & .002 & .002 & .009 & .007 & .012 & .007 & .012 & .007 & .005 & .002 & .002 & .002 & .005 & .005 & . 007 & $\begin{array}{l}.005 \\
.005\end{array}$ & .009 & .031 & .021 & 005 & & & & & & & & & & \\
\hline $\begin{array}{l}\text { riaArryls } \\
\text { oblirMir }\end{array}$ & $\begin{array}{l}\text { b56 } \\
657\end{array}$ & $\begin{array}{l}.002 \\
.002\end{array}$ & $\begin{array}{l}.002 \\
.002\end{array}$ & $\begin{array}{l}.009 \\
.009\end{array}$ & .007 & $\begin{array}{l}.012 \\
.007\end{array}$ & .012 & .007 & .012 & .007 & .005 & .002 & $\begin{array}{l}.002 \\
.002\end{array}$ & .002 & .005 & .005 & .007 & .005 & .009 & .031 & .021 & .005 & & & & & & & & & \\
\hline simEu & 16 & .091 & .091 & .099 & .096 & .101 & .096 & .099 & .096 & .093 & .091 & .091 & .091 & .093 & .093 & .096 & .094 & .099 & .120 & .109 & .194 & .197 & .194 & & & & & & & & \\
\hline kueEu & 18 & .163 & .163 & .172 & .169 & .174 & .169 & .172 & .169 & .166 & .163 & .163 & .163 & .166 & .166 & .169 & .166 & .172 & .180 & .180 & .094 & .093 & .093 & .091 & & & & & & & \\
\hline bifEu & 11 & .055 & .055 & .062 & .060 & .065 & .060 & .062 & .060 & .057 & .055 & .055 & .055 & .057 & .057 & .060 & .058 & .062 & .085 & .072 & .166 & .166 & .166 & .174 & .166 & & & & & & \\
\hline ареЕи & 38 & .213 & .213 & .223 & .220 & .226 & .220 & .223 & .220 & .216 & .213 & .213 & .213 & .216 & .216 & .219 & .217 & .223 & .229 & .226 & .058 & .057 & .057 & .079 & .150 & .057 & & & & & \\
\hline utaEu & 39 & .188 & .188 & .197 & .194 & .200 & .194 & .197 & .194 & .191 & .188 & .188 & .188 & .191 & .191 & .194 & .191 & 197 & .218. & . 2066 & .217 & .216 & .216 & .254 & .182 & .227 & .227 & & & & \\
\hline IonEu & 45 & .204 & .204 & .214 & .210 & .216 & .216 & .211 & .217 & .210 & .207 & .204 & .204 & .204 & .207 & 207 & .210 & .208 & .214 & .235 & .191 & .191 & .188 & .188 & .238 & .192 & .229 & 192 & & & \\
\hline invar & 28 & .060 & .060 & .068 & .065 & .070 & .065 & .068 & .065 & .063 & .060 & .060 & .060 & .063 & .063 & .065 & .063 & .068 & .091 & & .223 & .208 & .207 & .204 & .214 & .252 & .214 & .261 & .252 & & \\
\hline albTa & 1 & .188 & .188 & .197 & .194 & .200 & .194 & .197 & .194 & 191 & 188 & .188 & .188 & .191 & .191 & .194 & .191 & .197 & .218 & .206 & .063 & .063 & .063 & .097 & .153 & .063 & .246 & .202 & .218 & .063 & \\
\hline orila & 13 & .055 & .055 & .062 & .060 & .065 & .060 & .062 & .060 & .057 & .055 & .055 & .055 & .057 & .057 & .060 & .058 & .062 & .085 & .072 & .191 & .191 & .188 & .188 & .238 & .192 & .229 & .192 & .207 & .204 & .214 \\
\hline
\end{tabular}

31: sp1Br: Ara, Bot, Ibi, Itr, Itr, Jac, Jam, Lor, Mir, Pir, Sal, Sis, Slp, Tri, Gua, Gum; sp2Br: Ber, Ilb, Ilc, Ite, Per, Sse, Tau, Uba, Par; sp3Br: Ber, Ilc, Jam, Per, Sal, Slp, Tau, Uba, Cai; sp4EqGuy; fraMx: Chi, Qur, Tap; fraGuGuc; fraCoTol; fraPe: Lmo, Piu; fraAr: Com, Hmo, Tuc; oblBr: Bar, Bot, Ils, Ind, Per, Rpr, Tau; melEu. 23*: sp2Br: Pet, Uba, Gut; sp3BrPet. 
O gene wsp é muito variável inclusive devido à ocorrência de recombinação intragênica frequente entre linhagens da Wolbachia, algumas pertencentes até a supergrupos distintos (Werren et al., 1995; Werren \& Windsor, 2000; Jiggins et al., 2001; Werren \& Bartos, 2001; Wu et al., 2004; Baldo et al., 2005). Embora não fosse objetivo do presente trabalho, as análises a seguir, como indicado em Material e Métodos, foram feitas na busca de evidências de recombinação entre os haplótipos encontrados em Anastrepha, segundo métodos utilizados por Baldo et al. (2007).

A Figura 8 mostra as sequências de aminoácidos dos polipeptídeos putativos alinhados com base na sequência da proteína de $D$. melanogaster (haplótipo 31). As sequências foram organizadas em grupos de acordo com a similaridade (identificados por cores diferentes), tomando-se a HVR1+ como base para o agrupamento. Por exemplo, na HVR1, as sequências de Anastrepha formam um grupo (motivo em amarelo) com pequenas diferenças entre elas, assim como as sequências 28,39 e 2 (motivo em azul), as sequências 18 e 38 (motivo em lilás), enquanto as quatro sequências restantes, 683, 11, 16 e 45, ficam isoladas cada uma com um motivo distinto, Esse mesmo padrão de agrupamento de sequências com motivos similares, ocorre também nas outras três HVRs, mas sequências de cada grupo que apresentam motivos similares na HVR1 podem exibir motivos similares ou motivos distintos nas demais HVRs. Por exemplo, a sequência 18, que apresenta motivo similar à sequência 38 na HVR1, mostra-se distinta da sequência 38 nas HVR2 e HVR3 enquanto que na HVR4, apresenta motivo similar à sequência 16. Na Figura 7, vários outros exemplos podem ser vistos de sequências apresentando uma mistura de motivos presentes nas distintas HVRs de diferentes sequências. De acordo com Baldo et al. (2007), que observaram situação semelhante em outros artrópodes, o "embaralhamento" entre as HVRs resulta de processos de recombinação entre diferentes linhagens da Wolbachia. 


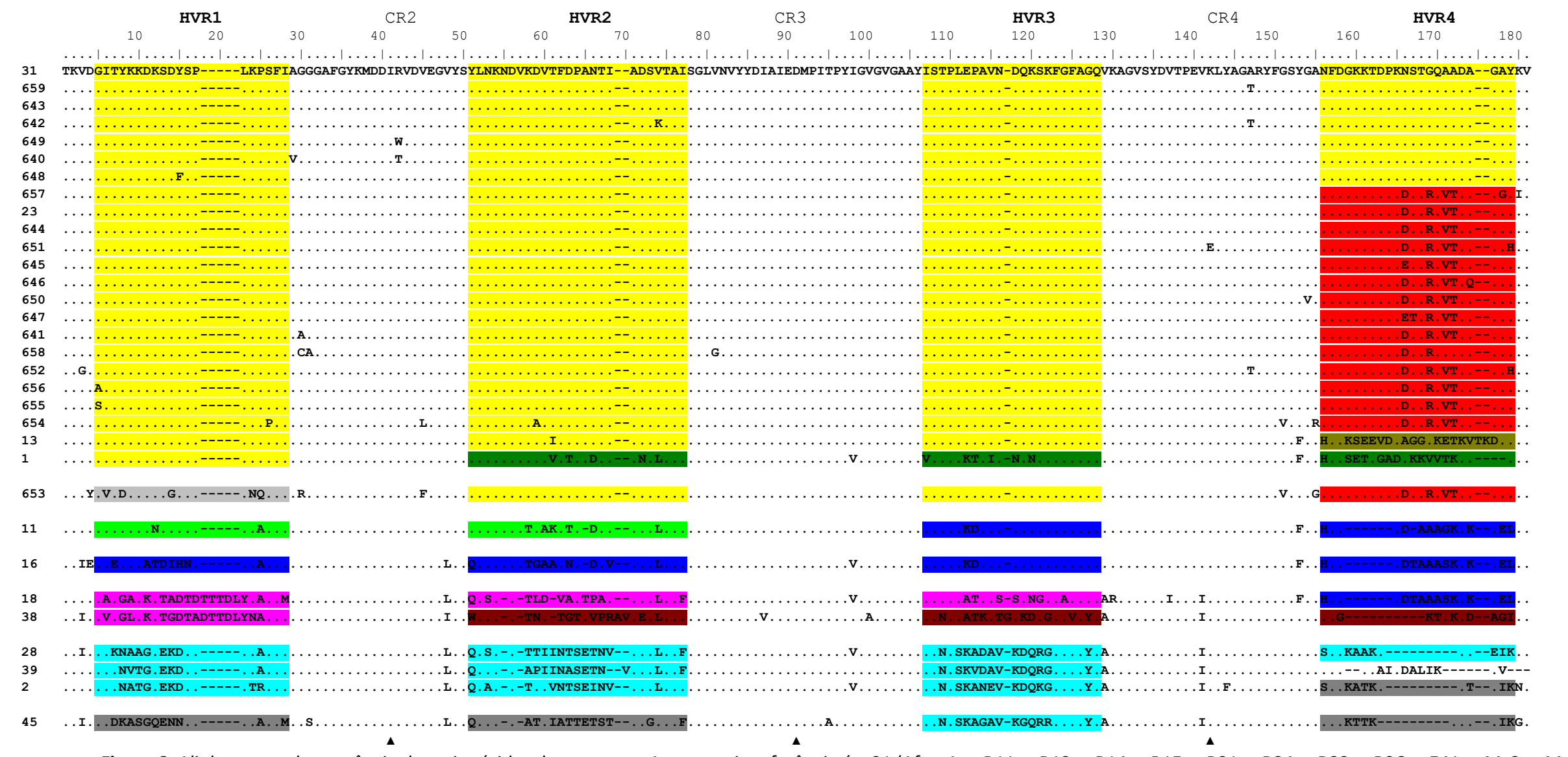

Figura 8: Alinhamento da sequência de aminoácidos do gene wsp. A sequencia referência é a 31 (Afra_A: wB11, wB12, wB14, wB15, wB21, wB24, wB33, wB36, wE41, wMx3, wM×5, wGu1, wCo1, wPe1, wPe2, wAr1, wAr2, wAr3, Aobl_A_wBo1, Dmel_A_wMel). Motivos de aminoácidos nos HVRs são codificados pela cor, com base na similaridade de polimorfismos comuns dentro de cada HVR. O HVR1 é usado como a região de referência inicial para o agrupamento das sequências. 
A segunda análise indicando a possível existência de recombinação entre linhagens de Wolbachia que infectam Anastrepha foi feita pela análise filogenética das sequências de nucleotídeos do conjunto dos haplótipos, mas considerando cada HVR e parte das $\mathrm{CRs}(\mathrm{HVR}+)$ isoladamente, como mostra a Figura 9. As quatro árvores geradas pelo método da parcimônia, mostram alto suporte estatístico e claramente, que as relações evolutivas entre os 22 haplótipos variam consideravelmente entre as quatro regiões do gene. Podem-se avaliar as relações evolutivas entre as sequências em cada motivo (subgrupos terminais nas árvores) e também, que existe um "embaralhamento" dessas relações entre as HVRs, pois determinadas sequências presentes em um determinado clado em uma HVR, encontram-se associadas à sequências diferentes em outros clados. Tomando-se alguns exemplos, na árvore da HVR1+ (Figura 8), pode-se observar a formação de alguns subgrupos, um com as linhagens 28 (invAr) e 45 (lonEu) (vermelho), outro pelos haplótipos 653 (fraMxJic), 18 (kueEu) e 38 (apeEu) (verde claro). Na árvore da HVR2+, as linhagens 45 e 28 se separam (vermelho), o mesmo ocorrendo com a linhagem 653 que se separa dos haplótipos 18 e 38, que permanecem juntos. Na árvore da HVR3+, observa-se que os haplótipos 28 e 45 ficam próximos (vermelho) e os haplótipos 8, 38 e 653 ficam separadas (verde), enquanto que na árvore da região HVR4+, observa-se a separação das linhagens similares 28 e 45 (vermelho); o mesmo ocorrendo com as 18 , 38 e 653 (verde). É provável que este embaralhamento, assim como o visto aquele detectado nas sequências de aminoácidos, deva-se, segundo Baldo et al. (2007), à processos de recombinação entre linhagens distintas da Wolbachia. 

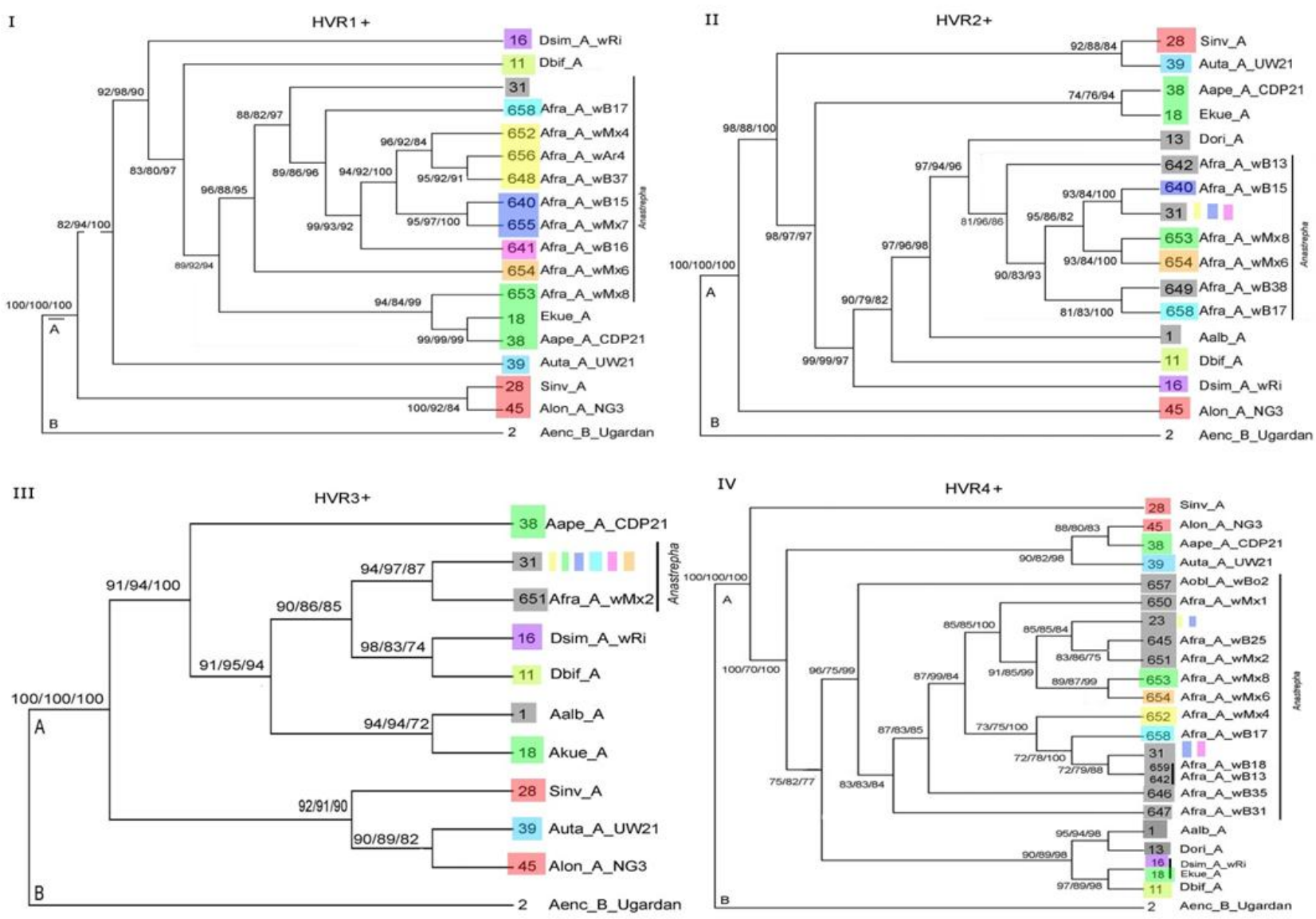

Figura 9. Árvores filogenéticas das quatro regiões do wsp abrangendo HVR+. Cores destacam os exemplos discutidos no texto (ver Resultados) e mostram mudanças na filogenia através das diferentes regiões wsp. 
A análise de recombinação pelo método do $\mathrm{MAXCHI}$ evidenciou a existência de possíveis eventos entre os haplótipos estudados neste trabalho, mas também não encontrou uma das sequências parentais para todos os casos, como mostra alguns exemplos da Figura 10.

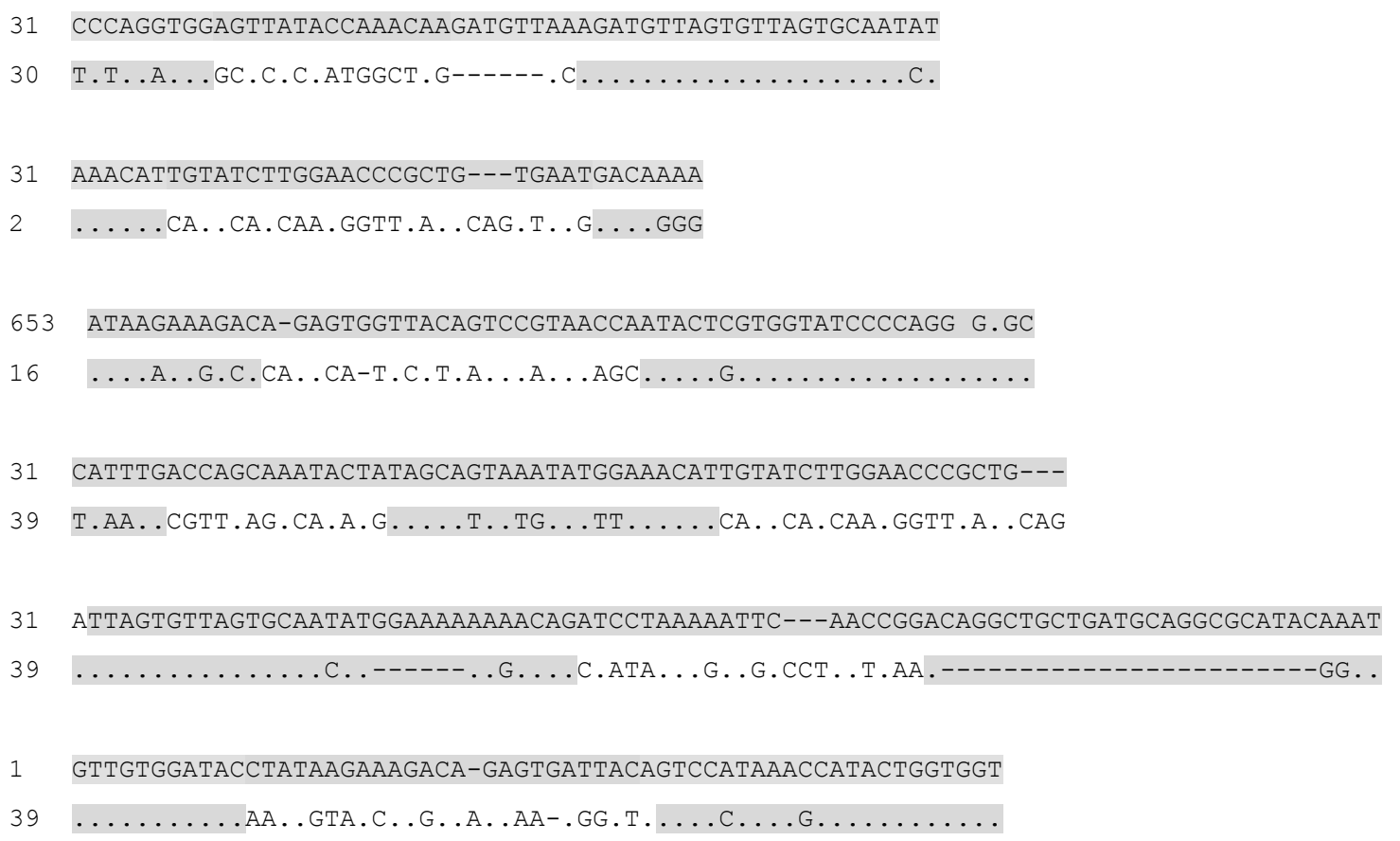

Figura 10. Exemplos de possíveis recombinantes do gene wsp determinados pelo programa MAXCHI. Em cada alinhamento estão mostrados apenas os sítios polimórficos e somente dois haplótipos, um do quais seria o recombinante e o outro, um dos parentais. O segundo parental não foi encontrado pela presente análise. As regiões marcadas mostram o compartilhamento entre os haplótipos.

A inspeção visual dos padrões de motivos nas HVRs e alterações nas relações filogenéticas, assim como a análise pelo $\mathrm{MAXCHI}$, não permitiram determinar com segurança os possíveis eventos de recombinação, pois para tanto, seria necessário determinar quais as sequências recombinantes e as duas parentais. Como para as espécies de Anastrepha estudadas uma grande parte das sequências são únicas, não é possível encontrar-se as duas sequências parentais. Para as demais, um maior número de sequências do Gene Bank deveria ser examinado, o que, entretanto, não era o objetivo do presente trabalho.

\section{Comparação entre as filogenias do MLST (genes concatenados) e do gene wsp}

Em diversos estudos, a análise das relações filogenéticas entre linhagens de Wolbachia foi feita utilizando-se a sequência completa do gene wsp. Assim, para efeito 
de possíveis comparações, no presente estudo uma análise filogenética foi feita de modo similar. Nessa análise, foram geradas árvores pelos métodos da máxima verossimilhança, "Neighbor joining" e máxima parcimônia, que apresentaram topologias similares e alto suporte de bootstrap. Assim, foi escolhida a árvore gerada pela máxima parcimônia para representar as relações filogenéticas entre os haplótipos da Wolbachia (Figura 11, wsp). Os haplótipos 28 (invAr), mais basal, 39 (utaEu) e 45 (lonEu) ficam próximos, formando um ramo distinto. O haplótipo 38 (apeEu) forma um ramo distinto. Outro ramo é formado pelo haplótipo 18 (kueEu). O haplótipo 16 (simEu) forma um ramo distinto, assim como os haplótipos 11 (bifEu), 1 (albTa) e 13 (oriJa). Assim como nas filogenias anteriores, as linhagens de Wolbachia do gene wsp encontradas em Anastrepha formam um clado distinto, no qual vemos o haplótipo 646 (sp3BrPet) formar um ramo mais basal e os haplotipos 651 (fraMxApa) e 652 (fraMxChi) ficaram próximos, formando um ramo distinto. Outro grupo "interno" é formado pelos haplótipos 641(sp1BrUbe), mais basal; 657 (oblBrMir); 23 (sp2Br: Pet; Uba; Gut; sp3BrPet); 658 (sp1Brlmb) e 653 (fraMxJic) e 654 (fraMxTap) próximos. Outro grupo "interno" é formado pelos haplótipos 656 (fraArMis), mais basal; 655 (fraMxTeo) formando um ramo e 645 (sp2BrCai) e 647 (sp3BrSal) próximos. Os haplótipos 644 (sp2BrPet) e 650 (fraMxApa) ficaram próximos, formando um ramo distinto. Outro grupo "interno" é formado pelos haplótipos 643 (sp1BrRne), que forma um ramo mais basal. Os haplótipos 642 (sp1BrSen) e 659 (sp1Brlra) ficaram próximos, formando um ramo distinto. Outro ramo é formado pelos haplótipos 31 (sp1Br: Ara, Bot, Ibi, Itr, Itr, Jac, Jam, Lor, Mir, Pir, Sal, Sis, Slp, Tri, Gua, Gum; sp2Br: Ber, Illb, Ilc, Ite, Per, Sse, Tau, Uba, Par; sp3Br: Ber, Ilc, Jam, Per, Sal, Slp, Tau, Uba, Cai; sp4EqGuy; fraMx: Chi, Qur, Tap; fraGuGuc; fraCoTol; fraPe: Lmo, Piu; fraAr: Com, Hmo, Tuc; oblBr: Bar, Bot, Ils, Ind, Per, Rpr, Tau; melEu) e 640 (sp1Brlta). Outro ramo é formado pelos haplótipos 648 (sp3BrGut) e 649 (sp3BrRne).

A Figura 11 mostra uma comparação entre as árvores geradas pelos genes concatenados do MLST e pelo gene wsp. Na árvore do MLST, é possível observar oito clados (identificados pelas cores): um com os haplótipos 2, 29, 65 e 75 (lilás); outro, com os haplótipos 12, 34, 73 (azul claro); em um terceiro os haplótipos 334, 343 e 344 (azul escuro); no quarto, um grupo formado pelos haplótipos encontrados no México: 335, 336, 337, 338 e 346 (cinza claro); o quinto grupo é formado pelos haplótipos 13, 331 e 332 (cinza escuro); o sexto, pelos haplótipos 330, 333 e 339 (vermelho); o sétimo pelos haplótipos 1, 329 e 345 (amarelo);o oitavo, pelos haplótipos 341 e 342 (verde) e os haplótipos 17, 19 e 340 que formaram ramos distintos. 
Em contraste com o MST, a árvore formada pelo gene wsp, não suporta os grupos formados, inclusive mostrando que os haplótipos que tinham sequências similares ao ST-1 do MLST, separam-se em diversos ramos distintos (Figura 11, wsp). 


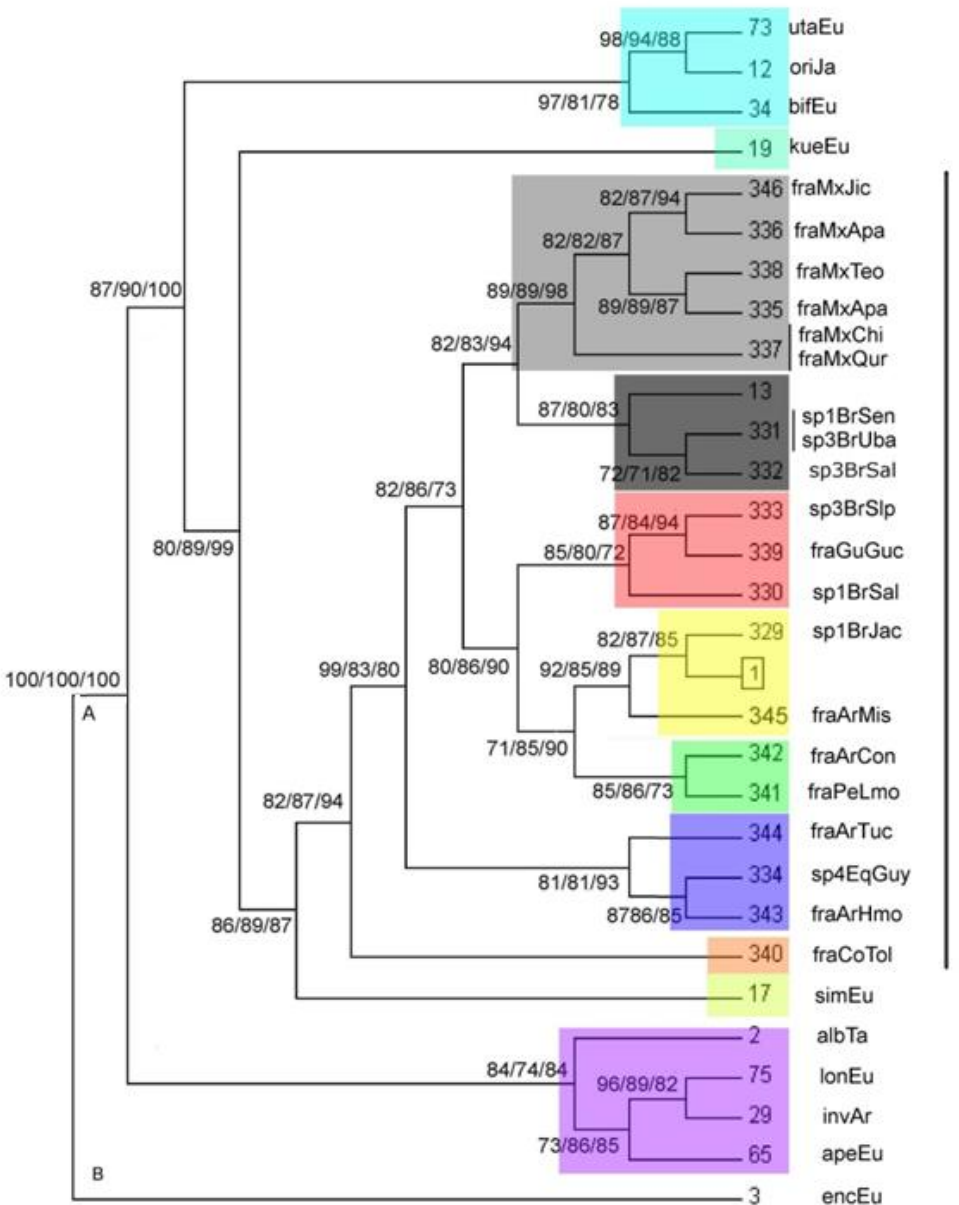

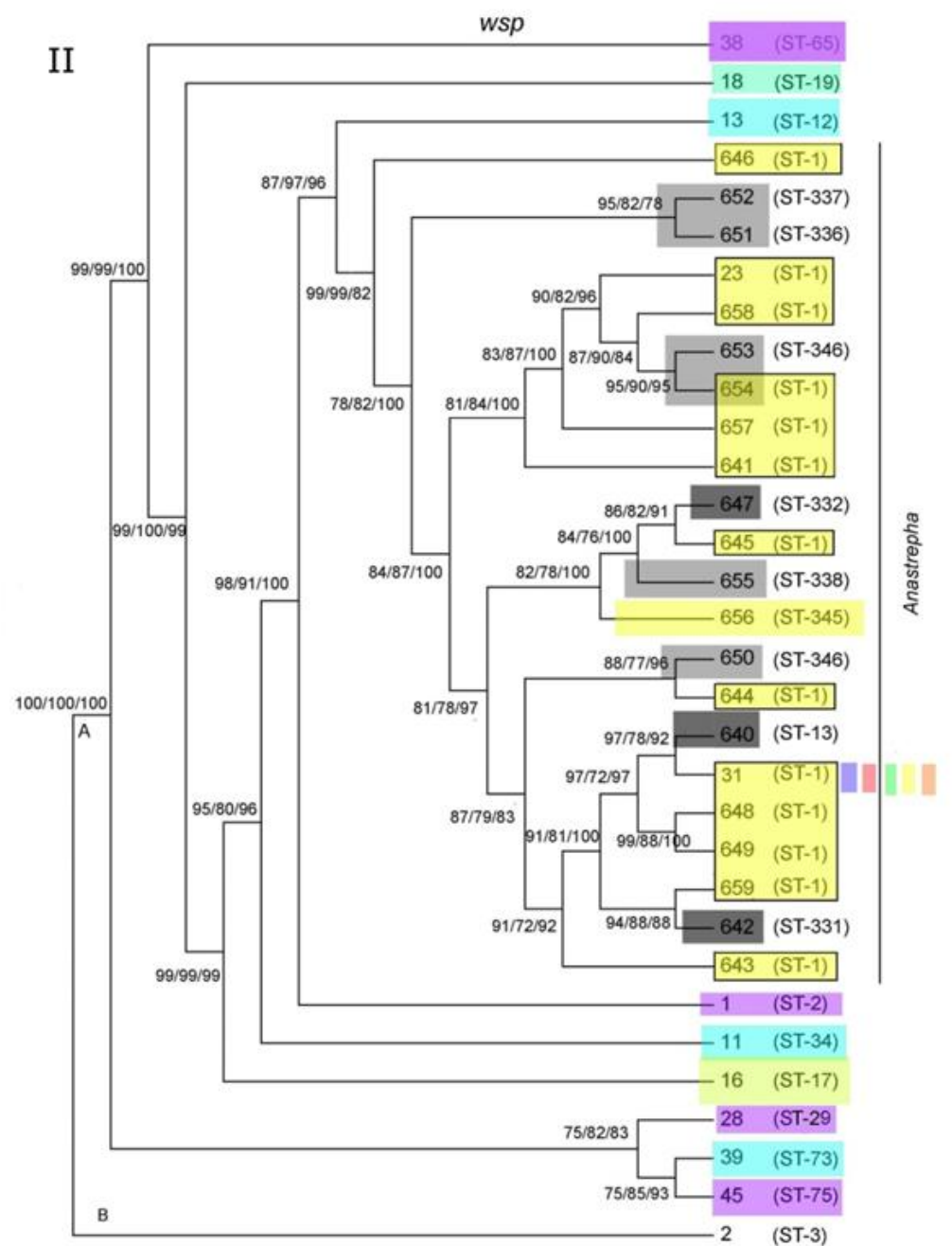

Figura 11: Esquerda: Árvore baseada nos cinco genes concatenados que formam o MLST. Direita: árvore baseada no gene wsp. Colorido: grupos formados na árvore do MLST e no wsp. 


\section{Análise de efeitos da Wolbachia em A. sp.1 e em A. obliqua}

Morfologia dos ovários. Foram estudadas fêmeas infectadas $(N=16)$ e curadas $(N=$ 16) de A. sp. 1 e infectadas $(\mathrm{N}=15)$ e curadas $(\mathrm{N}=11)$ de $A$. obliqua, que foram agrupadas em três categorias de acordo com o desenvolvimento dos ovários: estágio precoce, onde os ovaríolos continham folículos muito jovens; um segundo estágio, mais adiantado, com folículos já com células nutridoras bem visíveis (Figura 12) e um último estágio, no qual já existiam ovos maduros. A análise das preparações coradas pelo DAPI, mostrou que não haviam diferenças visíveis, entre os ovários de fêmeas infectadas e das curadas, nesta análise morfológica. Foram observadas pequenas ma formações, p. exemplo, distribuição irregular de células foliculares, núcleos picnóticos (Figura 12), mas estas ocorreram com frequência muito baixa e tanto em fêmeas infectadas, como nas não infectadas, de ambas as espécies de hospedeiros.
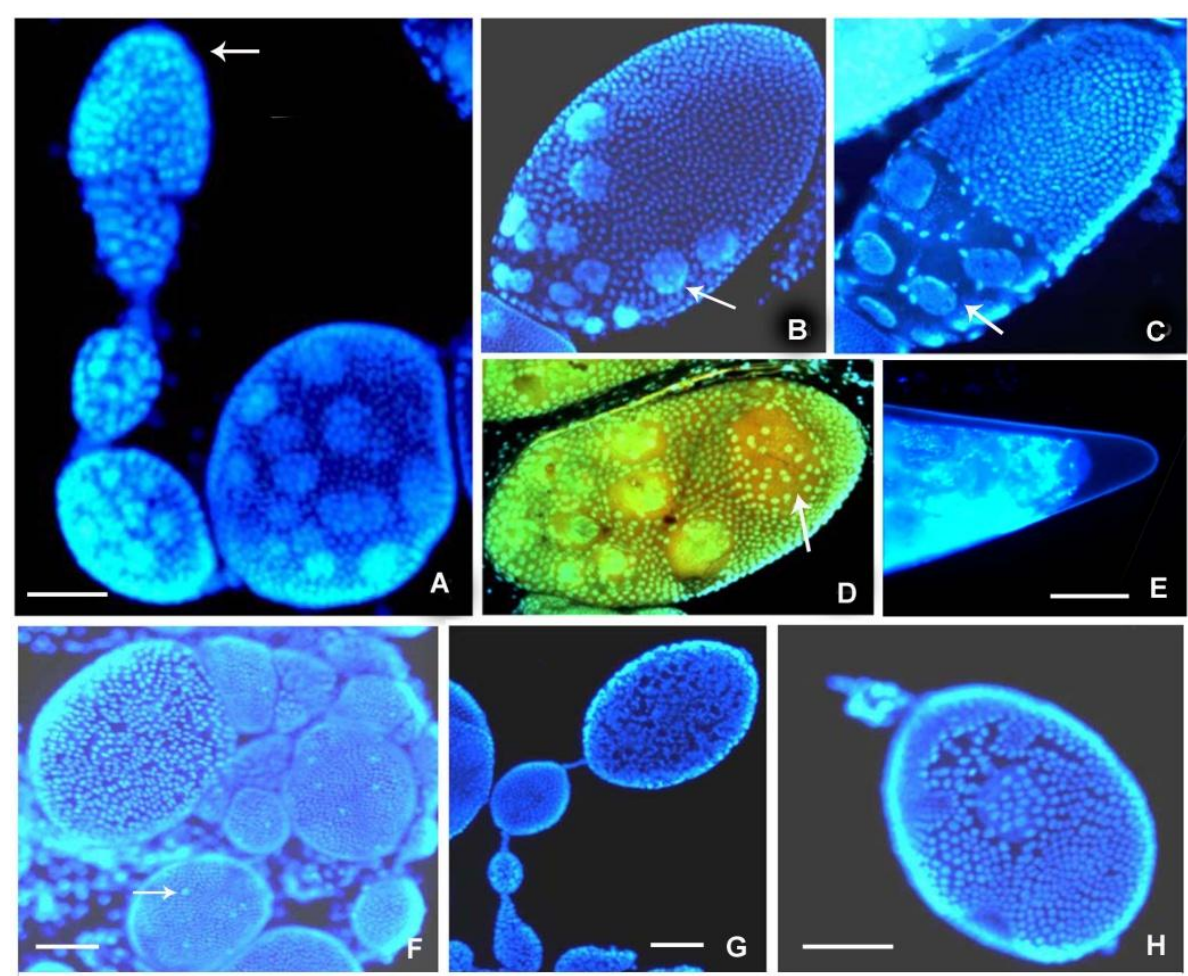

Figura 12: Exemplos de folículos ovarianos de Anastrepha em diferentes estágios de desenvolvimento (A-D), que são idênticos em $A$. sp.1 e $A$. obliqua, infectados ou curados. A$C$, corados pelo DAPI e D, corado pela acridina alaranjada (AO). (A) Extremidade distal do folículo onde se situam as ovogônias; $(B, C, D)$ Estágios onde se notam as células nutridoras (setas) e a região do oócito ( $D$, corado em avermelhado pela $A O$, seta). (E) Extremidade posterior de um ovo em um folículo, corado pelo DAPI, mostrando as bactérias infectantes (pontos brilhantes); (F-H) Folículos contendo aparente má formações: irregularidades na disposição das células foliculiares $(F, G, H)$ e também a presença de núcleos picnóticos $(F$, setas). Barra em $A=100$ um e é válida para todas as figuras; $(B, C, D)$ mesma escala que em $A$.

Produção de espermatozoides: Amostras de 4 a 10 machos infectados e igual número de machos curados de cada espécie de hospedeiros, foram coletadas em dias 
alternados após a emergência das imagos. A produção de espermatozoides em cada coleta (dias) de cada tratamento (infectados e curados) foi estimada pela contagem de cistos em determinado estágio da espermiogênese nessas amostras, estando os valores médios mostrados na Figura 13. Nota-se, que a produção de espermatozoides aumenta progressivamente após a emergência, atingindo um máximo em torno do dia 12 a.e. (após a emergência) em $A$. sp.1 e no dia 20 a.e. em $A$. obliqua, decrescendo nos dias seguintes. Uma análise de variância com 2-parâmetros (dias vs. tratamento, Tabelas XII), mostrou que as diferenças foram significativas ao longo do tempo, mas que as diferenças entre indivíduos infectados e curados não foram significativas em ambas às espécies de hospedeiros.

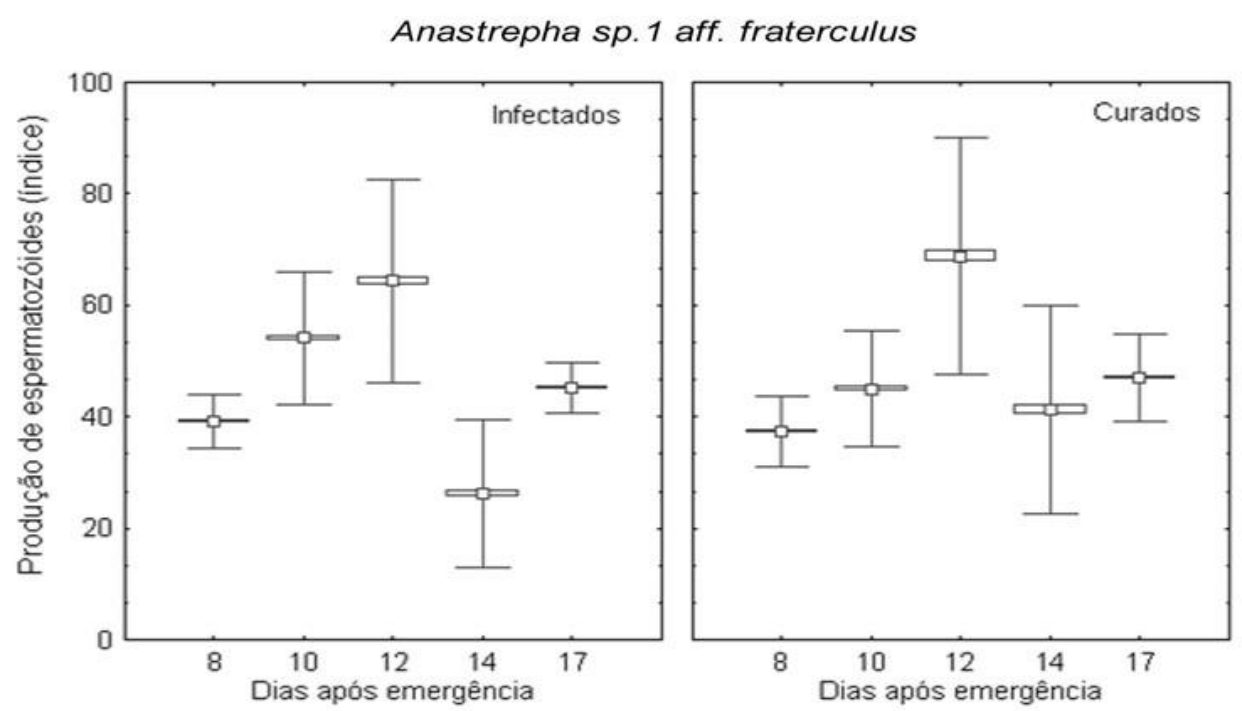

Anastrepha obliaua
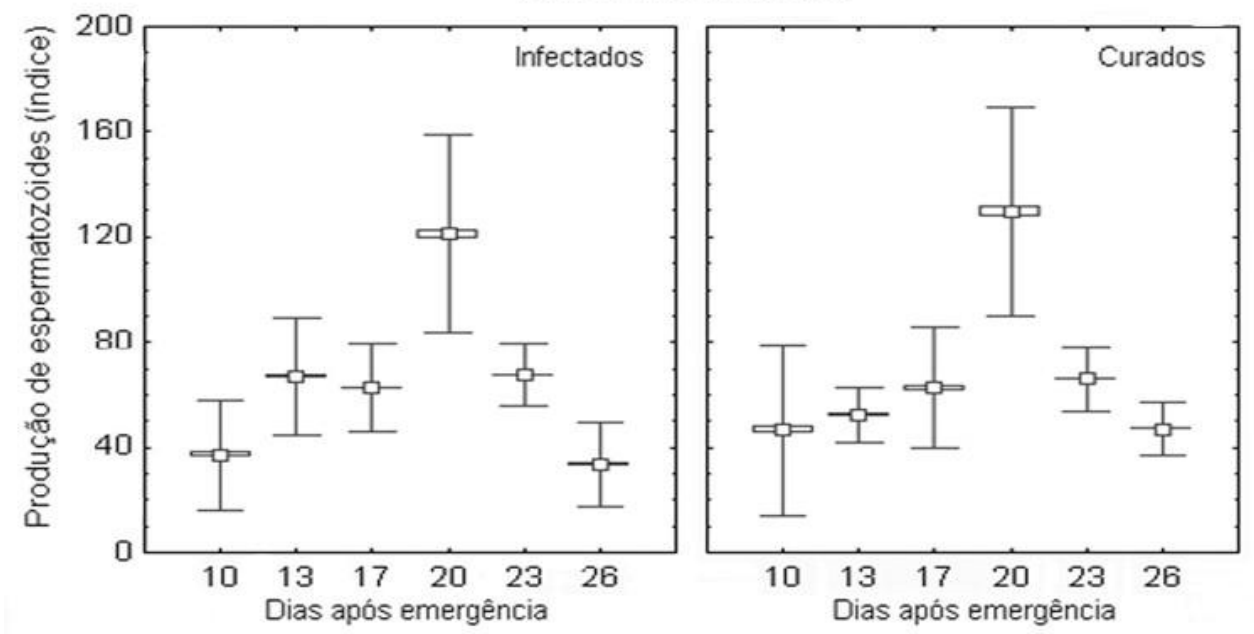

Figura 13: Produção e espermatozoides e dias após a emergência de indivíduos de A. sp.1 e $A$. obliqua infectados e curados. 
Tabela XII. Análise de variância da produção de espermatozóides em A. sp.1 e A. obliqua A. Anastrepha sp.1 aff. fraterculus

\begin{tabular}{l|llllll}
\hline & Efeito & Efeito & Erro & Erro & & \\
& gl & MS & gl & MS & F & P \\
\hline Tratamento (Inf;Cur) & 1 & 334,70 & 4 & 299,29 & 1,12 & 0,350 \\
Dias & 4 & 1970,20 & 4 & 299,29 & 6,58 & $0,047^{*}$ \\
Trat x Dias & 4 & 299,30 & 37 & 275,53 & 1,09 & 0,377 \\
\hline B. Anastrepha obliqua & 1 & 106,5 & 5 & 287,7 & 0,37 & 0,5695 \\
\hline Tratamento (Inf;Cur) & 5 & 9111,61 & 5 & 287,7 & 31,67 & $0,0009^{* *}$ \\
Dias & 5 & 287,7 & 57 & 625,74 & 0,46 & 0,8045 \\
Trat x Dias & & & & & & \\
\hline
\end{tabular}

Fecundidade: Esta análise envolveu cruzamentos entre machos e fêmeas infectados tirados das colônias de cada espécie e cruzamentos entre indivíduos não infectados, tirados da geração F1 das colônias respectivas. Para cada espécie, foram feitos quatro tipos de cruzamentos: (1) entre machos e fêmeas infectados; (2) entre machos e fêmeas não infectados; (3) entre fêmeas infectadas e machos não infectados e (4) entre fêmeas não infectadas e machos infectados. Para cada tipo de cruzamentos, foram obtidas entre 11 e 15 amostras, coletadas em dias alternados durante aproximadamente um mês.

Nos cruzamentos de $A$. sp.1 infectados (1), foi obtido um total de 1.020 ovos, enquanto que nos cruzamentos de moscas curadas (2), obteve-se 349 ovos. Nos cruzamentos de fêmeas infectadas com machos curados (3), obteve-se 379 ovos e nos cruzamentos recíprocos (4), obteve-se 292 ovos. O teste de Kruskal-Wallis mostrou diferenças significativas ( $K W=23,45 ; \mathrm{P}<0,001)$ (Figura 14A). Pode-se comparar a produção de ovos entre as fêmeas infectadas e não infectadas pelos resultados dos cruzamentos $1+3$ (infectadas) e 2+4 (não infectadas). O teste de MannWhitney mostrou que as primeiras produzem mais ovos que as segundas $\left(U=97,0, U^{\prime}=\right.$ $387,0 ; P=0,0007)$.

Nos cruzamentos de $A$. obliqua infectadas (1), foi obtido um total de 800 ovos, enquanto que nos cruzamentos com indivíduos curados (2), obteve-se 672 ovos, nos cruzamentos entre fêmeas infectadas com machos curados (3) obteve-se 382 ovos e nos cruzamentos recíprocos (4), obteve-se 207 ovos. O teste de Kruskal-Wallis mostrou diferenças significativas ( $\mathrm{KW}=14,55 ; \mathrm{P}=0,0022)$ (Figura 14B). Em $A$. obliqua, as fêmeas infectadas (cruzamentos $1+3$ ) e as não infectadas (cruzamentos $2+4)$, produzem quantidade de ovos que não diferem estatisticamente entre elas, como mostra o teste estatístico de Mann-Whitney $\left(U=230,5, U^{\prime}=363,5 ; P=0,1846\right)$. 
Fertilidadade: A taxa de eclosão dos ovos nos cruzamentos de indivíduos de $A$. sp1 infectados (1) foi de $87,4 \%(n=1020)$ e nos cruzamentos entre indivíduos não infectados (2), a taxa foi de 64,2 \% ( $n=349)$. Quando fêmeas infectadas de $A$. sp1 foram cruzadas com machos não infectados (3), a taxa de eclosão de ovos foi de $43,8 \%(n=379)$ e nos cruzamentos recíprocos (4), a taxa de eclosão dos ovos foi de 20,9\% ( $n=292)$, Análise de variância, com os dados percentuais transformados em $\operatorname{arcosen} \sqrt{ } P$, mostrou que as diferenças são significativas $(F=39,06 ;$ g.l. $=3,40$; $\mathrm{P}<0.001$ ) (Figura $14 \mathrm{C}$ ). Nessa Figura, também está mostrado o valor do $\mathrm{IC}_{\text {cor }}$ que foi de $54,01 \%$. Ignorando-se o cruzamento 4 (incompatível pela IC), os dados permitem estimar a influência dos machos nos cruzamentos. Assim, machos infectados produzem maior progênie (cruzamento 1) que os machos não infectados (cruzamento 3) quando são cruzados com fêmeas infectadas ( $t=5,716 ; g . I=20 ; P<0,001)$. Por outro lado, machos não infectados produzem maior progênie quando cruzados com fêmeas não infectadas (cruzamento 2) que os cruzados com fêmeas infectadas (cruzamento 3), embora a diferença esteja próxima do nível de significância $(\mathrm{t}$ = 2,196; g.I = 20; $\mathrm{P}=0.04)$.

Em A. obliqua, nos cruzamentos entre indivíduos infectados, a taxa de eclosão foi de $89,9 \%$ ( $n=800)$ e nos cruzamentos entre indivíduos não infectados, a taxa de eclosão foi de 60,6\% (n=672). Nos cruzamentos entre fêmeas infectadas com machos não infectados, a taxa de eclosão foi de $56,3 \%$ (n=382) e nos cruzamentos recíprocos, a taxa de eclosão caiu para 24,6\% ( $n=207)$. Análise de variância, com os dados percentuais transformados em arcosen $\sqrt{ }$, mostrou que as diferenças entre os cruzamentos são significativas $(F=18,82 ;$ g.l. $=3,42 ; P<0,001)$. $O$ índice de $I_{\text {cor }}$ foi de 66,2\% (Figura 14D). Não considerando o cruzamento 4, que resulta em IC, podese notar que machos infectados produzem maior progênie (cruzamento 1) que machos não infectados (cruzamento 3), quando são cruzados com fêmeas infectadas ( $t=6,41$; g.l. $=25 ; P<0,001)$. Machos não infectados produzem progênies similares quando cruzados com fêmeas infectadas (cruzamento 3 ) ou com fêmeas não infectadas (cruzamento 2) ( $t=1,59 ;$ g.l. 23; $P=0,126)$. 
Anastrepha sp. 1 aff. fraterculus
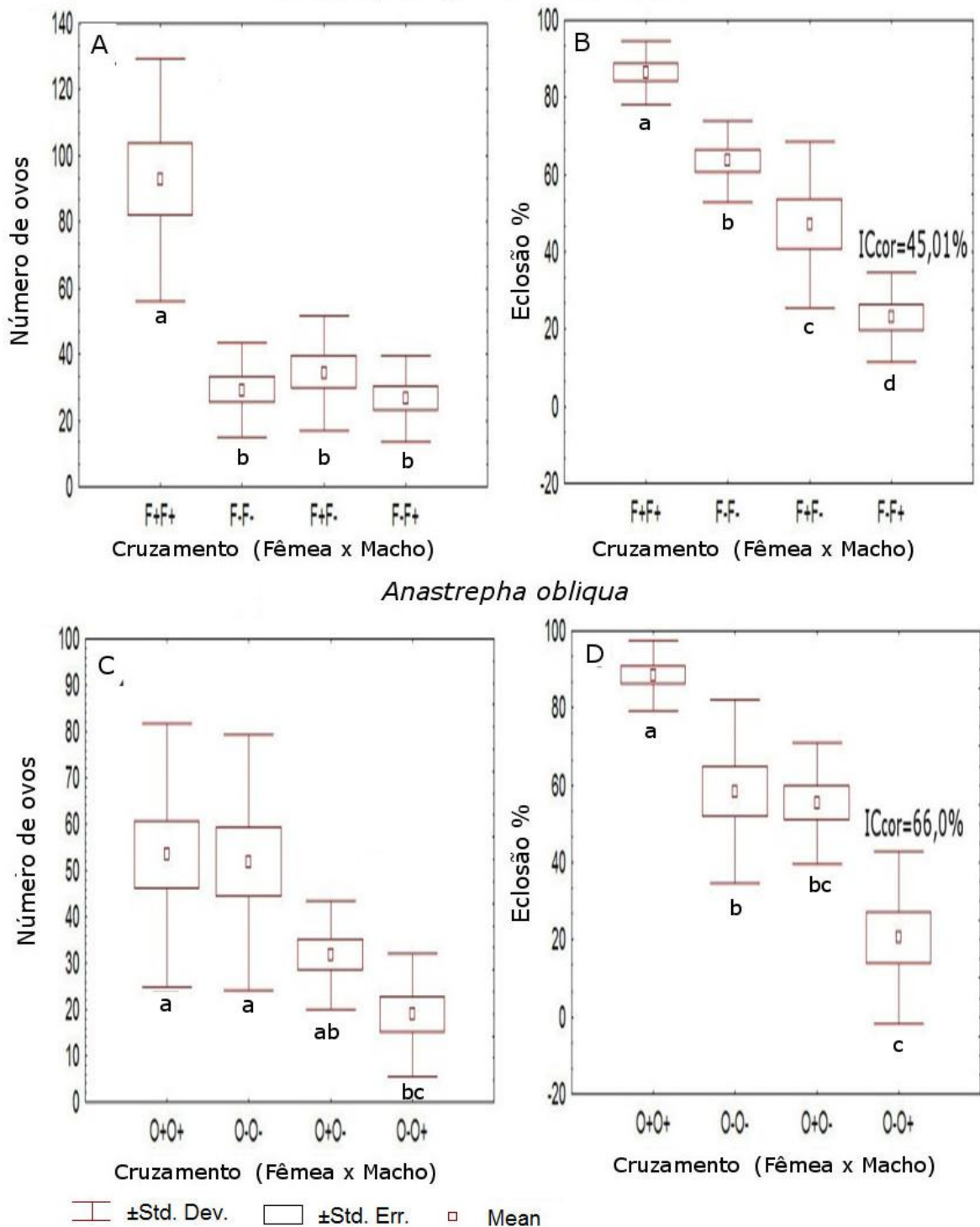

Figura 14. A: Número de ovos de A. sp1. . B: taxa de eclosão e $I C_{\text {cor }}$ de $A$. sp1. *Cruzamento com diferença significativa. C: Número de ovos de $A$. obliqua. D: taxa de eclosão e $\mathrm{IC}_{\mathrm{cor}}$ de $A$. obliqua. Letras distintas indicam diferenças significativas. Sinais + e - indicam presença ou ausência de infecção. 


\section{Discussão}

O estudo da Wolbachia intensificou-se nas últimas décadas particularmente pelo fato desse endossimbionte interferir e modificar o sistema reprodutivo em seus hospedeiros (Werren, 1997, 1998; Werren et al. 2008). No presente trabalho foi examinada a presença da Wolbachia em exemplares do complexo Anastrepha fraterculus de 37 localidades, do Brasil e de outras 14 áreas geográficas da Região Neotropical além de amostras de A. obliqua do Brasil. As localidades de origens das amostras foram escolhidas pela presença de distintos morfotipos do complexo fraterculus, como demonstrado por análise do marcador molecular ITS1 (Prezotto 2008) e pela análise morfométrica de características dos adultos (Hernández-Ortiz et al., 2012). No presente trabalho, apenas quatro indivíduos encontrados em populações de diferentes localidades do México (Chiapas, Jicayna, Tapachula e Teocelo) e um da Argentina (Concórdia), não estavam infectados, representando apenas 1,7\% do total de amostras estudadas (5 indivíduos não infectados em 292 estudados). Mascarenhas (2007) não encontrou infecção em uma amostra de Anastrepha serpentina de Natal (RN), porém a Wolbachia foi encontrada em indivíduos de uma população desta espécie em São Sebastião (SP). Recentemente, Martinez et al. (2012) encontraram populações de Anastrepha ludens do México sem a presença da bactéria. Além destes, os indivíduos de Ceratitis capitata da população de Mirassol não apresentaram infecção. Segundo Bourtzis et al. (1994) e Zabalou et al. (2004), a espécie C. capitata não seria infectada pela bactéria Wolbachia, embora Rocha et al. (2005) a tenham encontrado em uma amostra de população natural (São Bento do Sapucaí-SP) e em duas colônias de laboratório, uma de nosso laboratório e outra do Centro de Energia Nuclear na Agricultura-CENA/USP.

Em trabalhos prévios, a presença desta bactéria foi descrita em várias espécies de moscas-das-frutas da família Tephritidae e parasitoides a ela associados, tendo sido observado usualmente uma alta taxa de indivíduos infectados, entre $86 \%$ a $100 \%$ em diferentes amostras de Anastrepha (Mascarenhas, 2007; Coscrato et al., 2009; Marcon, 2009) Esta alta taxa de infecção em Anastrepha é maior que a encontrada em diversos grupos de organismos (Werren et al., 1995, West et al., 1998; Werren \& Windsor, 2000), em ácaros (Breewer \& Jacobs, 1996), formigas (Wenseleers et al., 1998), vespas (Schoenmaker et al., 2002) e em Pseudacton (Diptera) (Dedeinet et al., 2005). Por outro lado, Bennet et al. (2012) descreve altas taxas de infecção por Wolbachia em amostra de população de Nesophrosyne craterigena do Havaí (100\%) e Narita et al. (2008) encontraram frequência de infecção alta (85,7 a 100\%) em sete populações japonesas da borboleta Colias erate poliographus. No entanto, uma 
análise recente, envolvendo um grande número de espécies de artrópodos terrestres e também um grande número de indivíduos examinados por espécie, mostrou que a taxa de infecção é de cerca de $40 \%$, portanto, menor que as estimativas anteriores. Este mesmo trabalho, corroborando análises prévias, mostra que dentro de determinada espécie a maioria ou então, apenas alguns dos indivíduos estão infectados (Zug \& Hammerstein, 2012). As espécies de Anastrepha aparentam ambas as condições, alta taxa de infecção por espécie e também dentro de cada população.

Em todas as amostras de Anastrepha infectadas, estudadas neste trabalho, a Wolbachia pertencia ao supergrupo "A". Estes dados são semelhantes aos obtidos por Mascarenhas (2007), Coscrato et al. (2009), Cáceres et al. (2009) e Marcon (2009) que também acharam cepas de Wolbachia pertencentes ao supergrupo " $A$ " em diferentes espécies de Anastrepha, como em A. sp.1, A. sp.2, A. sp.3, A. sp.4, A. fraterculus s.l., A. amita, A. obliqua, A. sororcula, A. striata, A. serpentina, A. grandis, A. pickeli, de diferentes regiões do Brasil, Argentina, Equador e Peru. Até o presente momento, apenas uma população Anastrepha fraterculus s.l., em amostra de região desconhecida (Cáceres et al., 2009) e duas amostras de A. obliqua, coletadas em Indaiatuba e Caçapava (SP) (Mascarenhas, 2007), apresentaram dupla infecção, com cepas do supergrupo "A" e cepas do supergrupo "B" de Wolbachia. Além disso, populações de Anastrepha striata, presentes no México, apresentaram infecção com Wolbachia do supergrupo "B" (Martinez et al., 2012). Segundo Werren \& Windsor (2000), podem haver diferenças na capacidade de bactérias dos supergrupos " $A$ " e "B" em infectar diferentes grupos de hospedeiros. Anastrepha, de acordo com os dados obtidos, aparentemente seria mais propensa a ser infectada por Wolbachia do supergrupo " $A$ ".

Em algumas das amostras deste trabalho, duas espécies de hospedeiros derivaram do mesmo fruto, como $A$. sp.2 e $A$. sp.3 coletados em chapéu-de-sol (Terminalia cattapa) ou goiaba (Psidium guajava) em Bertioga, Ilha Comprida, Pedro de Toledo, Peruíbe, Ubatuba (SP) e Guaratuba (PR) e como $A$. sp.1 e A. sp.3 coletados em goiaba, nas localidades de Jambeiro, São Luís do Paraitinga (SP) e Rio Negrinho (SC). Nestes casos, as mesmas linhagens da bactéria Wolbachia (ST-1 e wsp-31 e wsp-23) foram encontradas infectando estes hospedeiros, Kittayapong et al. (2000) observaram que espécies de Bactrocera que emergiam de uma mesma amostra de frutos, estavam infectadas com a mesma linhagens de Wolbachia. $O$ mesmo poderia ocorrer entre espécies que estão infestando o mesmo fruto, ocorrendo nesta situação, trocas de linhagens da bactéria entre estas espécies, fato este que poderia explicar a presença das linhagens semelhantes. Transmissão horizontal já foi 
descrita em numerosas espécies de insetos (Werren \& O'Neil, 1997; Vavre et al., 1999) e também foi sugerida, anteriormente, na associação entre seis espécies de Anastrepha e cinco espécies de parasitóides braconídeos à elas associados, por apresentarem haplótipos idênticos de Wolbachia (Mascarenhas, 2007).

Analisando-se isoladamente os cinco genes que integram a metodologia do MLST nas diferentes entidades (morfotipos) do complexo fraterculus aqui estudadas, foram encontrados sete alelos para gene gatB, sendo cinco deles inéditos (um em comum a dois hospedeiros) e dois já descritos anteriormente, enquanto que para o gene $\operatorname{cox} A$ foram encontrados quatro alelos diferentes, sendo um já anteriormente descrito. Seis alelos foram encontrados no gene hcpA (quatro inéditos), nove no fts $Z$ (sete inéditos) e também nove alelos para o gene fbpA (oito inéditos). Em 42 espécies de outros hospedeiros, Baldo et al. (2006a) encontraram, respectivamente, 26, 27, 31, 28 e 25 alelos dos cinco genes. Assim, considerando-se os alelos desses genes, foram encontrados 34 variantes nas seis entidades do complexo (5,7 alelos/espécie), contra os 137 descritos por Baldo et al. (2006a) nas 42 espécies de outros insetos (3,7 alelos/espécie), dados que indicam que a variabilidade de linhagens de Wolbachia é alta em Anastrepha.

As inferências filogenéticas de cada um dos genes do MLST isoladamente demonstram que a utilização de um único gene não é suficiente para uma tipagem correta, dado o embaralhamento das posições relativas dos alelos dentro dos clados gerados para cada gene, além de que, o elevado nível de suporte para um clado, pode mascarar conflitos de locos únicos. Estes resultados estão de acordo com observações anteriores de Baldo et al. (2006ab) utilizando uma grande diversidade de espécies. Como esses autores demonstraram que parte desse embaralhamento é devido a uma alta taxa de recombinação intergênica apresentada pela Wolbachia, é provável que mecanismo similar esteja ocorrendo em Anastrepha.

A identificação dos alelos dos cinco genes mostrou que nas amostras do complexo fraterculus existiam 17 linhagens (ST, "strain types") inéditas e duas anteriormente descritas (ST-1 e ST-13). Por exemplo, Baldo et al. (2006a) encontraram 37 linhagens de Wolbachia em 42 espécies hospedeiras e Salunke et al. (2012) encontraram, na Índia, 13 novas linhagens de Wolbachia em 56 espécies de borboletas pertencentes a cinco diferentes famílias .

A filogenia gerada com os cinco genes concatenados, mostra que as linhagens encontradas em Anastrepha separam-se em um grande clado, distinto das linhagens de Wolbachia de outros hospedeiros. Além disso, demonstra que não há um 
agrupamento de linhagens de acordo com as regiões geográficas de origem das amostras, embora alguns clados tenham frequência maior de amostras de uma mesma região, ou morfotipo do complexo. Os resultados mostram que a metodologia do MLST fornece um excelente método para caracterização das estirpes Wolbachia em Anastrepha e também, para a discriminação entre as cepas de uma mesma espécie de hospedeiro, assim como demonstrado por Baldo et al. (2006a) para outras linhagens de Wolbachia de outros hospedeiros.

No presente trabalho, para efeito comparativo, as amostras do complexo fraterculus tipificadas pelo MLST foram também estudadas utilizando-se o gene wsp, através da metodologia do "Wsp Typing", proposta por Baldo et al. (2005). Foram encontrados 22 linhagens diversas, sendo 20 inéditas e duas anteriormente descritas em outros hospedeiros. Baldo et al. (2006a), também utilizaram a técnica do wsp, encontrando as mesmas linhagens identificadas pelo MLST, com exceção de uma, que não foi amplificada pelo wsp. Assim como para o MLST, as linhagens encontradas em Anastrepha formam um clado distinto. Porém, nota-se que as relações inferidas por perfis MLST e wsp, não são necessariamente concordante, mas complementares, resultados semelhantes aos de Baldo et al. (2006a).

No presente trabalho, embora tenha sido encontrado maior número de alelos utilizando o sequenciamento do gene wsp, a filogenia formada com os genes concatenados do MLST parece ser mais consistente ao formar os clados. Por exemplo, forma o clado "mexicano", que agrupa as linhagens encontradas nos hospedeiros de amostras populacionais do México, enquanto que na filogenia baseada somente no wsp, estas linhagens estão separadas. A filogenia do $w s p$, com base no conjunto de dados de uma mesma linhagem, não suporta a monofilia dos clados formados pelo MLST, fato semelhante foi observado por Baldo \& Werren (2007). Estes aspectos, referentes ao gene wsp, são devidos ao fato desse gene ser muito variável quanto a substituição de nucleotídeos e também, por apresentarem altas taxas de recombinação intragênica (Baldo et al., 2010).

No presente trabalho, encontramos evidências de recombinação no gene wsp em, pelo menos, 17 indivíduos do complexo fraterculus. A região HVR1 mostra pouca divergência entre os grupos, porém a HVR4 apresenta alta divergência, possivelmente devido ao resultado de recombinações. Entretanto, quando os métodos filogenéticos foram aplicados a este conjunto de dados, uma assinatura de recombinação na HVR4 foi mascarada por um elevado grau de semelhança entre as primeiras três HVRs, assim como ocorre em outros organismos infectados pela Wolbachia (Baldo et al., 
2006a). Desta forma, os dados apresentados no presente trabalho, corroboram a crítica feita por Baldo \& Werren (2007) sobre filogenias baseadas somente no gene wsp de Wolbachia. Segundo esses autores, muitos dos haplótipos isolados pelo estudo do wsp não representam haplótipos ou linhagens novas ou únicas e sim, são haplótipos produtos da recombinação entre haplótipos existentes naquele hospedeiro. Propõe que é necessária a utilização da metodologia do MLST, que se baseia não apenas em um, mas em cinco genes do ciclo celular bacteriano, para identificar com segurança as linhagens da Wolbachia. Por outro lado, a ocorrência de duas ou mais linhagens da bactéria em um mesmo hospedeiro existentes em uma mesma localidade, favoreceria a transferência horizontal e, portanto, uma possibilidade de recombinação entre as linhagens, como mostrou Yang et al. (2012) para uma comunidade da vespa do figo.

Além das modificações reprodutivas induzidas pelas Wolbachia, outros efeitos nas relações adaptativas entre essas bactérias e seus hospedeiros são conhecidas (rev. Werren et al. 2008). Dedeine et al. (2003) encontraram redução no desempenho reprodutivo das fêmeas de vespas, sugerindo um efeito das bactérias no valor adaptativo do hospedeiro. Análises de algumas possíveis relações da Wolbachia com um de seus hospedeiros do complexo fraterculus, $A$. sp.1, e com $A$. obliqua, ambas pertencentes ao grupo fraterculus, foram também realizados no presente trabalho. Para tanto, foi necessário o estabelecimento de colônias isentas de Wolbachia, pois não foram encontradas populações não infectadas de ambas as espécies. A eliminação da bactéria foi feita por tratamento térmico a $30^{\circ} \mathrm{C}$ (Werren, 1997; Boutzis \& O’Neill, 1998), pois, segundo Ribeiro (2008), foi o método mais adequado para eliminação das bactérias encontradas nestas espécies.

A análise da fecundidade de fêmeas infectadas em comparação com a de fêmeas não infectadas, quando cruzadas com machos infectados ou não infectados, mostrou que em A. sp.1 houve uma queda no número de ovos botados quando as bactérias foram eliminadas, mas que em $A$. obliqua não houve diferenças entre a fecundidade das duas condições das fêmeas. Em várias situações, a ausência da Wolbachia causa uma degeneração dos ovários, p. exemplo em Drosophila (Miller et al., 2012), na vesp Asobara tabita (Pannebaker et al., 2007), o que não foi observado nos ovários de Anastrepha isentas da bactéria.

Além das alterações impostas pela Wolbachia na fecundidade das fêmeas, a fertilidade também pode ser afetada, por exemplo, via a incompatibilidade citoplasmática (Werren et al. 2008, entre outros). Os resultados dos cruzamentos 
intraespecíficos, nos quais se verificou a redução na taxa de eclosão quando fêmeas curadas eram cruzadas com machos infectados, mostram a existência de IC mediada pela Wolbachia, corroborando resultados anteriores encontrados por Ribeiro (2008). Os dados do presente trabalho, mostram que a expressão da incompatibilidade é significativa em Anastrepha, atingindo altas taxas em comparação com outros sistemas descritos (Poinsot et al., 1998; Werren 1997; Dobson, 2003; Bourtzis et al., 2003), inclusive em outros gêneros de moscas-das-frutas, como em Rhagoletis cerasi (Riegler \& Stauffer, 2002), na qual foram encontradas duas linhagens distintas de Wolbachia (IC bidirecional) e em Ceratitis capitata (Zabalou et al., 2004). Além da fertilidade dos ovos, a Wolbachia também pode afetar o desempenho dos machos. Machos infectados, de ambas as espécies de Anastrepha ora estudadas, estão associados às maiores taxas de eclosão dos ovos (maiores progênies) do que os machos não infectados, quando ambos são cruzados com fêmeas infectadas. No entanto, esse melhor desempenho dos machos infectados em Anastrepha, parece não ser devido a maior número de espermatozoides produzidos, contrário ao descrito em Drosophila, onde os machos não infectados produzem menor número de espermatozóides (Snook et al., 2000). Por outro lado, machos não infectados de $A$. obliqua produzem progênies similares quando cruzados com fêmeas infectadas ou com fêmeas não infectadas, enquanto que machos não infectados de $A$. sp.1 produzem progênies ligeiramente maiores quando cruzados com fêmeas não infectadas. As causas do melhor desempenho dos machos infectados de Anastrepha permanecem desconhecidas.

A habilidade da bactéria Wolbachia de causar Incompatibilidade Citoplasmática (IC) em artrópodes tem gerado interesses em seu uso como mecanismo de controle de pragas, em substituição à Técnica do Inseto Estéril (Bourtzis, 2008; Werren et al., 2008). A Técnica do Inseto Incompatível (TII), na qual são introduzidos machos infectados com cepas de Wolbachia diferentes das encontradas em determinada região, tem sido desenvolvida como um mecanismo de controle populacional por indução a IC (Dobson et al., 2002; Zabalou, 2004; Xi et al., 2005) A técnica do TII tem amplas possibilidades de ser utilizada para controlar população de Culex quinquefasciatus em ilhas do Oceano Índico (Atyame et al., 2011). Zabalou et al. (2004; 2009) observaram a IC em Ceratitis capitata infectadas artificialmente, tendo grande potencial no uso da TII. O presente trabalho, ao demonstrar a existência de diferentes linhagens de Wolbachia em diferentes espécies e áreas geográficas do complexo fraterculus e também, a existência de IC ocorre com altas taxas, indica a possibilidade de aplicações da TII no manejo e controle desses insetos-praga. 
Os resultados deste trabalho sugerem que a Wolbachia interage diferentemente com $A$. sp.1 e com $A$. obliqua, como evidenciado pela fecundidade das fêmeas, pela maior efetividade de machos infectados e pelas valores de IC induzidas, de modo similar ao observado em outros insetos (p. ex., Poinsot et al. 1998; Clark et al., 2003; Zabalou et al., 2004). A Wolbachia apresenta, usualmente, uma relação parasítica com seus hospedeiros (rev. Werren et al. 2008). No entanto, são conhecidos casos onde a presença da Wolbachia provê benefícios adaptativos aos seus hospedeiros, p. exemplo, em Drosophila paulistorum (Miller et al., 2010), em D. simulans (Weeks et al., 2007), D. melanogaster (Koukou et al., 2006; Sun \& Cline, 2009), em Drosophila spp. (Peng et al., 2008) e no microhimenópero Asobara tabita (Pannebaker et al., 2007). Nesses casos, a relação da Wolbachia com seus hospedeiros evoluiu de parasitismo para um mutualismo incipiente ou até mesmo obrigatório, como em $A$. tabita. Esta transição é concebida em situações de longa associação entre a bactéria e seu hospedeiro (Werren, 1997, 1998; Werren et al. 2008). Os resultados obtidos no presente trabalho sugerem que exista uma condição de mutualismo entre a Wolbachia e o hospedeiro Anastrepha e, portanto, se verdadeira, indicaria que essa associação é, provavelmente antiga na história evolutiva desses organismos.

O fato de que diferentes linhagens de Wolbachia foram encontradas entre as espécies (ou morfotipos) do complexo fraterculus, seria uma indicação de que a incompatibilidade reprodutiva observada entre varias dessas entidades (Selivon et al. 2005; Vera et al., 2006; Cáceres et al. 2009; Rull et al., 2012), possam ter atuado e estar atuando, dentre outros fatores, a IC provocada pela existência de diferentes linhagens da Wolbachia. 


\section{Resumo}

Wolbachia é uma bactéria intracelular encontrada tanto nos tecidos somáticos quanto nos reprodutivos de diversas espécies de artrópodes e nematódeos. Estudos filogenéticos baseados nos genes 16S e ftsZ indicaram que o gênero Wolbachia congrega seis supergrupos taxonômicos ("A" a "F"). Infecções por Wolbachia têm sido associadas a diversas alterações na reprodução de seus hospedeiros, p. exemplo, a incompatibilidade citoplasmática (IC), partenogênese, feminização de machos genéticos e morte dos machos. A identificação das diferentes cepas da bactéria é mais precisa quando a análise por locos múltiplos (MLST) é aplicada. Infecção por Wolbachia foi descrita em diversas espécies de moscas-das-frutas da familia Tephritidae, Bactrocera ascita, Rhagoletis cerasi, Ceratitis capitata, nas quais a bactéria induz a incompatibilidade citoplasmática. No gênero Anastrepha, endêmico do Continente Americano, infecção por Wolbachia foi descrita em várias espécies pela análise do gene wsp, existindo também a indicação de que IC mediada por Wolbachia ocorra em duas espécies do grupo fraterculus. A ocorrência de IC aliada à sugestão do emprego da Wolbachia em programas de controle populacional das moscas-dasfrutas, impõem a necessidade de uma caracterização mais precisa das diferentes cepas da Wolbachia. No presente trabalho foram amplificados e sequenciados fragmentos dos genes gat $B, \operatorname{cox} A, h c p A, f t s Z$ e $f b p A$, que integram a metodologia de MLST ("Multiloci Sequence Typing") e do gene wsp da Wolbachia. Foram analisadas amostras populacionais do complexo de espécies crípticas de Anastrepha fraterculus do Brasil e da Argentina, Peru, Equador, Colômbia, Guatemala e México, além de amostras de Anastrepha obliqua do Brasil. Todas as amostras estavam infectadas com Wolbachia do supergrupo "A". Para os cinco genes, foram encontrados haplótipos únicos e outros já descritos anteriormente, determinando, assim, os alelos de cada um presentes nas amostras. O conjunto de cinco alelos de cada amostra determinou a linhagem da bactéria que estava presente. Comparação entre as análises filogenéticas das sequências de cada um dos genes isoladamente, mostrou discordância nas relações entre os alelos e amostras populacionais. As sequências dos cinco genes concatenadas, com 2079 pb, foram analisadas tendo sido encontrados 20 linhagens, com distâncias variando de 0,001 a 0,058. A análise filogenética isolou as linhagens de Wolbachia obtidas das amostras de Anastrepha em clados distintos, demonstrando que diferentes linhagens estão presentes nesses hospedeiros e regiões geográficas. Mostrou, também, que pode ocorrer mais que uma cepa de Wolbachia em uma mesma amostra populacional. Uma das linhagens foi detectada em duas espécies do complexo fraterculus e é, também, a mais comumente encontrada (ST1) em diferentes organismos. As sequências do wsp tinham cerca de $500 \mathrm{pb}$, tendo sido encontradas 22 sequências distintas. O nível de variabilidade de nucleotídeos não é uniforme ao longo do gene, formando um padrão com quatro regiões hipervariáveis, "HVRs". As distâncias genéticas entre os haplótipos de wsp mostrou uma variação de 0,001 a 0,235 . Foram observadas evidências de recombinação intragência entre os haplótipos do gene wsp. A análise filogenética também isolou os haplótipos de Wolbachia em clados distintos, porém, em contraste com o MLST, a árvore do gene wsp, não suporta os grupos monofiléticos gerados pelo MLST. Os resultados mostram que linhagens similares de Wolbachia estão disseminadas por vasta extensão do Continente Americano, além da presença de linhagens específicas em determinadas áreas geográficas. Análises de ovários e testículos de indivíduos infectados e não infectados (curados por tratamento térmico) de $A$. sp. 1 e de $A$. obliqua foram feitas para avaliar possíveis efeitos da Wolbachia nesses hospedeiros. A análise das preparações dos ovários, coradas pelo DAPI, não mostrou diferenças perceptíveis nesta análise morfológica entre fêmeas infectadas e não infectadas, de ambas as espécies. A produção de espermatozoides aumenta progressivamente durante alguns dias, após a emergência das imagos, e cai nos dias seguintes. A análise da produção de 
espermatozoides pelos machos infectados e pelos curados mostrou que as diferenças entre eles não foram significativas, em ambas as espécies de hospedeiros. Foram feitas estimativas da fecundidade de fêmeas infectadas e não infectadas, de ambas as espécies. Mostrou-se que fêmeas infectadas são mais fecundas que as não infectadas em $A$. sp.1, mas mostram fecundidade similar em $A$. obliqua. As taxas de eclosão de larvas foram também estimadas em cruzamentos intraespecíficos compatíveis (fêmeas infectadas ou não cruzadas com machos não infectados) e cruzamentos incompatíveis (fêmeas não infectadas cruzadas com machos infectados) de ambas as espécies. A fertilidade foi significativamente mais elevada entre os ovos produzidos pelas fêmeas infectadas, de ambas as espécies. Foi observado que machos infectados, em ambas as espécies, estão relacionados com os cruzamentos onde ocorreram as taxas mais altas de eclosão. Analisando os cruzamentos incompatíveis, foi demonstrada a presença de incompatibilidade citoplasmática (IC), como seria esperado pela atuação da Wolbachia. Foi mostrado um alto valor para os índices de IC em $A$. sp,1 (IC= $54,01 \%$ ) e em $A$. obliqua ( $\mathrm{IC}=66,2 \%$ ). Os resultados sugerem que podem existir relações mutualísticas insipientes da Wolbachia com suas espécies de Anastrepha hospedeiras. 


\section{Abstract}

Wolbachia is an intracellular bacteria found in somatic and in the reproductive tissues of various arthropods and nematodes. Phylogenetic studies based on $16 S$ and $\mathrm{fts} Z$ genes indicated the existence of six Wolbachia taxonomic supergroups ("A" through "F"). Infection of Wolbachia have been linked to several changes in the reproduction of their hosts, like cytoplasmic incompatibility $(\mathrm{Cl})$, parthenogenesis, feminization of genetic males and male killing. T Wolbachia infection has been described in several species of fruit flies of the family Tephritidae, like Bactrocera ascita, Rhagoletis cerasi, Ceratitis capitata, in which the bacteria induces cytoplasmic incompatibility. In Anastrepha, endemic to the American Continent, Wolbachia infection has been described in several species by analysis of the wsp gene, and there is also indications that Wolbachia-mediated $\mathrm{Cl}$ occurs in two species of the fraterculus group. The occurrence of $\mathrm{Cl}$ coupled with the suggestion of the use of Wolbachia in population supression programs, impose the need for a more precise characterization of the different strains of Wolbachia. The identification of the different strains of the bacteria is most accurate when the methodology of multiple loci (MLST) is applied. In this study fragments of genes gat $, \operatorname{cox} A, h c p A, f t s Z$ and $f b p A$, integrating the methodology MLST, and of wsp gene were amplified and sequenced. Population samples of the Anastrepha fraterculus.complex of cryptic species from Brasil, Argentina, Peru, Ecuador, Colombia, Guatemala and Mexico, and samples of A. obliqua from Basil were analysed. All samples were infected with supergroup "A" Wolbachia. For each of the five MLST genes, unique as well already known haplotypes were found. Phylogenetic analyses of each gene isolated showed incongruences in the relationships among haplotypes and population samples. The concatenated sequences of the five genes, with $2079 \mathrm{bp}$, were analyzed and 20 haplotypes were found, with distances ranging from 0.001 to 0.058 . Phylogenetic analysis of Wolbachia isolated haplotypes into distinct clades, demonstrating that different strains of Wolbachia were present in these hosts, and in distinct geographic areas. Hosts specific haplotypes were found as well as more than one strain of Wolbachia was found in given population samples. A haplotypes (ST1) was detected in two species of the complex and is also the most commonly found in different organisms. Twenty two different sequences of about 500 $\mathrm{bp}$ were found for the wsp gene. The level of nucleotide variability is not uniform along the gene, forming a pattern with four hypervariable regions, HVRs. Genetic distances between haplotypes showed a variation from 0.001 to 0.235 . Phylogenetic analysis of the haplotypes also isolated Wolbachia into distinct clades, but in contrast to the MLST, the tree formed by wsp gene does not support the monophily of some groups. The data show that strains of Wolbachia are disseminated along the American Continent, and also that there are specific strains in determined geographic areas. Analyses of ovaries and testes from infected and non infected (cured by heat treatment) individuals of $A$. sp. 1 and $A$. obliqua were made in search of possible effects of Wolbachia on its hosts. Ovaries from infected and cured females of both species, stained by DAPI, showed no visible differences in this morphological analysis. The production of sperms increases during few days after ermergence and drops out later one. Analysis of infected and cured males showed that the production of sperms were not significant between them, for both the host species. Fecundity of infected females of A, sp.1 was significantly higher than that of cured females, but was similar in $A$. obliqua, Egg hatching was scored in compatible intraspecies crosses and also in incompatibles crosses, of both species. Fertility was significntly higher for infected females of both species. Infected males of both species were found associated to crosses in which the higher egg hatching was observed. Analyses of incompatible crosses showed that $\mathrm{Cl}$ occurred at high rates in $A$. sp.1 $(\mathrm{Cl}=54.01 \%)$ and in $A$. obliqua $(\mathrm{Cl}=66.2 \%)$. The data suggest that an incipient mutualism may be present in the relationships of Wolbachia and its Anastrepha hosts. 


\section{Referências Bibliográficas}

AIKAWA, T.; ANBUTSU, H.; NIKOH, N.; KIKUCHI, T.; SHIBATA, F.; FUKATSU, T. Longicorn beetle that vectors pinewood nematode carries many Wolbachia genes on an autosome. Proceedings Biological Science, West Sussex, v. 276, n. 1674, p. 3791-3798, 2009.

ALBERTI, A. C.; CALCAGNO, G.; DAIDMAN, B. O.; VILARDI, J. C. Analysis of the genetic structure of a natural population of Anastrepha fraterculus (Diptera, Tephritidae). Annals of the Entomological Society of America, Lanham, v. 92, n. 5, p. 731-736, 1999.

ALBERTI, A. C.; RODRIGUERO, M. S.; CENDRA, P. G.; SAIDMAN, B. O.; VILARDI, J. C.. Evidence indicating that the Argentine populations of Anastrepha fraterculus (Diptera, Tephritidae) belong to a single biological species. Annals of the Entomological Society of America, Lanham, v. 95, p. 505-512, 2002.

ALMEIDA, F.; MOURA, A. S.; CARDOSO, A. F.; WINTER, C. E.; BIJOVSKY, A. T.; SUESDEK, L. Effects of Wolbachia on fitness of Culex quinquefasciatus (Diptera; Culicidae). Infection, Genetics and Evolution. Amsterdam, v. 11, n. 8, p. 21382143, 2011.

ALUJA, M. Bionomics and management of Anastrepha. Annual Review of Entomology. Palo Alto, v. 39, p. 1555-1578, 1994.

AMARAL P. M. Estudo da variabilidade isozímica de sete locos em larvas de populações naturais de Anastrepha (Díptera: Tephritidae). 1994. 74 p. Tese de Doutorado, Departamento de Biologia, Instituto de Biociências, USP, São Paulo, 1994.

ANDERSON, C. L.; KARR, T. L. Wolbachia: evolutionary novelty in a rickettsial bacteria. BMC Evolutionary Biology. London, v. 1, 10, doi:10.1186/1471-2148-110, 2001.

ARAKAKI, N.; MIYOSHI, T.; NODA, H. Wolbachia mediated parthenogenesis in the predatory thrips Franklinothrips vespiformis (Thysanoptera: Insecta). Royal Society of London. Proceedings B. Biological Sciences. London, v. 268, p. 1011-1016, 2001. 
ATYAME, C. M.; PASTEUR, N.; DUMAS, E.; TORTOSA, P.; TANTELY, M. L.; POCQUET, N.; LICCIARDI, S.; BHEECARRY, A.; ZUMBO, B.; WEILL, M.; DURON, O. Cytoplasmic incompatibility as a means of controlling Culex pipiens quinquefasciatus mosquito in the islands of the south-western Indian Ocean. PLoS Neglected Tropical Diseases. San Francisco, v. 5, n. 12, e1440, 2011.

BAKER, A. C.; STONE, W. E.; PLUMMER, C. C.; MACPHAIL, H. A review of studies on the mexican fruit fly and related mexican species. NIST Special Publication. Gaithersburg, v. 531, p. 1-155, 1944.

BALDO, L.; LO, N.; WERREN, J. H. Mosaic nature of the Wolbachia surface protein. Journal of Bacteriology. Washington DC, v. 187, p. 5406-5418, 2005.

BALDO, L.; DUNNING-HOTOPP, J. C.; JOLLEY, K. A.; BORDENSTEIN, S.; BIBER, A. S.; CHOUDHURY, R. R.; HAYASHI, C.; MAIDEN, M. C. J.; TETTELIN, H.; WERREN, J. H. Multilocus Sequence Typing System for the Endosymbiont Wolbachia pipientis. Applied and Environmental Microbiology. Washington DC, v. 72 , n. 11 , p. $7098-7110,2006 a$.

BALDO, L.; BORDENSTEIN, S.R.; WERNEGREEN, J. J.; WERREN, J. H. Widespread recombination throughout Wolbachia genomes. Molecular Biology and Evolution. Cary, v. 23, p. 437-449, 2006b.

BALDO, L.; WERREN, J. H. Revisiting Wolbachia Supergroup Typing Based on WSP: Spurious Lineages and Discordance with MLST. Current Microbiology. Secaucus, v. 55, p. 81-87, 2007.

BALDO, L.; DESJARDINS, C. A.; RUSSELL, J. A.; STALHHUT, J. K; WERREN, J. H. Accelerated microevolution in an outer membrane protein (OMP) of the intracellular bacteria Wolbachia. BMC Evolutionary Biology. London, v. 10: 48, doi: 10.1186/1471-2148-10-48, 2010.

BANDI, C.; ANDERSON, T. J. C; GENCHI, C.; BLAXTER, M. Phylogeny of Wolbachia in filarial nematodes. Royal Society of London. Proceedings B. Biological Sciences. Colchester, v. 265, p. 2407-2413, 1998.

BARR, N. B.; CUI, L.; MCPHERON, B. A.; Molecular systematics of nuclear gene period in genus Anastrepha (Tephritidae). Annals of the Entomological Society of America. Lanham, v. 98, n. 2, p. 173-180, 2005. 
BARTOLUCCI, A.; VERA, M. T.; YUSEF, V.; OVIEDO, A. Morphological Characterization of the Reprodutive System of Irradiated Anastrepha fraterculus. Fruit Flies of Economic Importance: From Basic to Applied Knowledge. Proceedings of the $7^{\text {th }}$ International Symposium on Fruit Flies of Economic Importance. 10-15 September 2006, Salvador, p. 44-52, 2008.

BASSO, A.; SONVICO, A.; QUESADA-ALLUE, L. A.; MANSO, F. Karyotipic and molecular identification of laboratory stocks of the South American fruit fly Anastrepha fraterculus (Wiedman) (Diptera: Tephritidae). Journal of Economic Entomology. Lanham, v. 96, n. 4, p. 1237-1244, 2003.

BEARD, C. B.; O'NEILL, S. L.; TESH, R. B.; RICHARDS, F. F.; AKSOY, S. Modification of arthropod vector competence via symbiotic bacteria. Trends in Parasitology. London, v. 9, p. 179-183, 1993.

BENNETT, G. M.; PANTOJA, N. A.; O'GRADY, P. M. Diversity and phylogenetic relationships of Wolbachia in Drosophila and other native Hawaiian insects. Fly. Austin, v. 6, n. 4, p. 273-283, 2012.

BINNINGTON, K. L.; HOFFMANN, A. A. Wolbachia-like organisms and cytoplasmic incompatibility in Drosophila simulans. Journal of Invertebrate Pathology. Maryland Heights, v. 54, p. 344-352, 1989.

BORDENSTEIN, S. R.; UY, J. J.; WERREN, J. H. Host genotype determines cytoplasmic incompatibility type in the haplodiploid genus Nasonia. Genetics. Bethesda, v. 164, p. 223-233, 2003.

BORDENSTEIN, S.; ROSENGAUS, R. B. Discovery of a novel Wolbachia super group in Isoptera. Current Microbiology. Secaucus, v. 51, n. 6, p. 393-398, 2005.

BOURTZIS, K.; NIRGIANAKI, A.; ONYANGO, P.; SAVAKIS, C. A prokaryotic dnaA sequence in Drosophila melanogaster: Wolbachia infection and cytoplasmic incompatibility among laboratory strains. Insect Molecular Biology. St Albans, v. 3, n. 3, p. 131-142, 1994.

BOURTZIS, K.; O'NEILL, S. L. Wolbachia infections and arthropod reproduction. Bioscience. Irvine, v. 48, p. 287-293, 1998. 
BOURTZIS, K. Wolbachia-based technologies for insect pest population control. Advances in Experimental Medicine and Biology. New York, v. 627, p. 104-113, 2008.

BREEUWER, J. A. J.; STOUTHAMER, R.; BURNS, D. A.; PELletieR, D. A.; WEISBURG, W. G.; WERREN, J. H. Phylogeny of cytoplasmic incompatibility microorganisms in the parasitoid wasp genus Nasonia (Hymenoptera: Pteromalidae) based on 16s ribosomal DNA sequences. Insect Molecular Biology. St Albans, v. 1, p. 25-36, 1992.

BREEWER, J. A. J.; JACOBS, G. Wolbachia: intracellular manipulators of mite reproduction. Experimental and Applied Acarology. London, v. 20, n. 8, p. 421434, 1996.

BRELSFOARD, C. L.; DOBSON, S. L. Wolbachia Effects on Host Fitness and the Influence of Male Aging on Cytoplasmic Incompatibility in Aedes polynesiensis (Diptera: Culicidae). Journal of Medical Entomology. Lanham, v. 48, n. 5, p. 10081015, 2011.

BUSH, G. L. The cytotaxonomy of the larvae of some Mexican fruit flies in the genus Anastrepha (Tephritidae: Diptera). Psyche. Stuttgart, v. 6, p. 87-101, 1962.

CACERES, C.; SEGURA, D. F.; VERA, M. T.; WORNOAYPORN, V.; CLADERA, J. L.; TEAL, P.; SAPOUNTZIS, P.; BOURTZIS, K.; ZACHAROPOULOU, A.; ROBINSON, A. S. Incipient speciation revealed in Anastrepha fraterculus (Diptera: Tephritidae) by studies on mating compatibility, sex pheromones, hybridization, and cytology. Linnean Society. Biological Journal. West Sussex, v. 97, p. 152-165, 2009.

CALLAINI, G.; DALLAI, R.; RIPARBELLI, M. G. Wolbachia-induced delay of paternal chromatin condensation does not prevent maternal chromosomes from entering anaphase in incompatible crosses of Drosophila simulans. Journal of Cell Science. Cambridge, v. 110, n. 2, p. 271-280, 1997.

CALVITTI, M.; MORETTI, R.; LAMPAZZI, E.; BELLINI, R.; DOBSON, S. L. Characterization of a new Aedes albopictus (Diptera: Culicidae)-Wolbachia pipientis (Rickettsiales: Rickettsiaceae) symbiotic association generated by artificial transfer of the wPip strain from Culex pipiens (Diptera: Culicidae). Journal of Medical Entomology. Lanham, v. 47, p. 179-187, 2010. 
CANAL N. A.; ZUCCHI, R. A. Parasitoides-Braconidae. In: Malavasi A.; Zucchi RA (ed). Moscas-das-frutas de importância econômica no Brasil: conhecimento básico e aplicado. Ribeirão Preto (SP). Holos Editora, 2000, p. 119-126.

CASIRAGHI, M.; BORDESSTEIN, S. R.; BALDO, L.; LO, N.; BENINATI, T.; WERNEGREEN, J. J.; WERREN, J. H.; BANDI, C. Phylogeny of Wolbachia pipientis based on gltA, groEL and fts $Z$ gene sequences: clustering of arthropod and nematode symbionts in the F supergroup, and evidence for further diversity in the Wolbachia tree. Microbiology. Berkshire, v. 151, n. 12, p. 4015-4022, 2005.

ChARLAT, S.; RIEGLER, M.; BAURES, I.; POINSOT, D.; STAUFFER, C. Incipient evolution of Wolbachia compatibility types. Evolution. Oxford, v. 58, p. 1901-1908, 2004.

CLARK, M. E.; VENETI, Z.; BOURTZIS, K.; KARR, T. L. Wolbachia distribution and cytoplasmatic incompatibility during sperm development: the cyst as the basic cellular unit of $\mathrm{Cl}$ expression. Mechanisms of Development. Amsterdam, v. 120, p. 185-193, 2003.

COSCRATO, V. E.; BRAZ, A. S. K.; PERONDINI, A. L. P.; SELIVON, D.; MARINO, C. L. Wolbachia in Anastrepha fruit flies (Diptera, Tephritidae). Current Microbiology. Secaucus, v. 59, p. 295-301, 2009.

CRESPIGNY, F. E.; PITT, T. D.; WEDELL, N. Increased male mating rate in Drosophila is associated with Wolbachia infection. Journal of Evolutionary Biology. Oxsford, v. 19, n. 6, p. 1964-1972, 2006.

CZARNETZKI, A. B.; TEBBE, C. C. Detection and phylogenetic analysis of Wolbachia in Collembola. Environmental Microbiology. West Sussex, v. 6, p. 35-44, 2004.

DEDEINE, F.; BOULETREAU, M.; VAVRE, F. Wolbachia requirement for oogenesis: occurrence within the genus Asobara (Hymenoptera, Braconidae) and evidence for intraspecific variation in A. tabida. Heredity. London, v. 95, p. 394-400, 2005.

DOBSON, S. L.; BOURTZIS, K.; BRAIG, H. R. Wolbachia infections are distributed throughout insect somatic and germ line tissues. Insect Biochemistry and Molecular Biology. Oxford, v. 29, p. 153-160, 1999.

DOBSON, S. L.; FOX, C. W.; JIGGINS, F. M. The effect of Wolbachia-induced cytoplasmic incompatibility on host population size in natural and manipulated 
systems. Proceedings Biological Sciences. West Sussex, v. 269, n. 1940, p. 437445, 2002.

DUNNING-HOTOPP, J. C.; CLARK, M. E.; OLIVEIRA, D. C.; FOSTER, J. M.; FISCHER, P.; MUÑOZ TORRES M. C.; GIEBEL, J. D.; KUMAR, N.; ISHMAEL, N.; WANG, S.; INGRAM, J.; NENE, R. V.; SHEPARD, J.; TOMKINS, J.; RICHARDS S.; SPIRO, D. J.; GHEDIN, E.; SLATKO, B. E.; TETTELIN, H.; WERREN, J. H. Widespread lateral gene transfer from intracellular bacteria to multicellular eukaryotes. Science. Washington DC, v. 317, n. 5845, p. 1753-1756, 2007.

ESTEBAN, M. R.; CAMPOS, M. C. C.; PERONDINI, A. L. P.; GODAY, C. Role of microtubules and microtubule organizing centers on meiotic chromosome elimination in Sciara ocellaris. Journal of Cell Science. Cambridge, v. 110, p. 721730, 1997.

EVANS, O.; CARAGATA, E. P.; MCMENIMAN, C. J.; WOOLFIT, M.; GREEN, D. C.; WILLIAMS, C. R.; FRANKLIN, C. E.; O'NEILL, S. L.; MCGRAW, E. A. Increased locomotor activity and metabolism of Aedes aegypti infected with a life-shortening strain of Wolbachia pipientis. The Journal of Experimental Biology. Queensland, v. 212, p. 1436-1441, 2009.

FELSENSTEIN, J. PHYLIP -- Phylogeny Inference Package (Version 3.2). Cladistics. West Sussex, v. 5, p. 164-166, 1989.

FIALHO, R. F.; STEVENS, L. Male-killing Wolbachia in flour bettle. Royal Society of London. Proceedings B. Biological Sciences. London, v. 267, p. 1469-1473, 2000 .

FIGUeIREDO, J. V. A.; PERONDINI, A. L. P.; RUGGIRO, E. M.; PREZOTTO, L. F.; SELIVON, D. External eggshell morphology of Anastrepha fruit flies (Diptera: Tephritidae). Acta Zoologica. West Sussex, v. 00, p. 1-9, 2011.

GHELELOVITCH, S. Sur le déterminisme génétique de la sterilité dans le croisement entre differentes souches de Culex autogenicus Roubaud. Academie des Sciences. Comptes Rendus. Biologies. Cedex, v. 24, p. 2386-88, 1952.

GOdAY, C.; SElivon, D.; PERONDINI, A. L. P.; GReCiANO, P. G.; RUIZ, M. F. Cytological characterization of sex chromosomes and ribosomal DNA location in Anastrepha species (Diptera,Tephtiridae). Cytogenetic and Genome Research. Basel, v. 114, p. 70-76, 2006. 
GORHAM, C. H.; FANG, Q. Q.; DURDEN, L. A. Wolbachia endosymbionts in fleas (Siphonaptera). The Journal of Parasitology. Lincoln, v. 89, n. 2, p. 283-289, 2003.

HEATH, L., VAN DER WALT, E., VARSANI, A. \& MARTIN D. P. Recombination patterns in aphthoviruses mirror those found in other picornaviruses. Journal of Virology. Washington DC, v. 80, p. 11827-11832, 2006.

HEDGES, L. M.; BROWNLIE, J. C.; O'NEILL, S. L.; JOHNSON, K. N. Wolbachia and virus protection in insects. Science. Washington DC, v. 322, n. 5902, p. 702, 2008.

HERNANDEZ-ORTIZ, V.; GOMEZ-ANAYA, J. A.; SINCHEZ, A.; MCPHERON, B. A.; ALUJA, M. Morphometric analysis of Mexican and South American populations of the Anastrepha fraterculus complex (Diptera:Tephritidae) and recognition of a distinct Mexican morphotype. Bulletin of Entomological Research. Cambridge, v. 94, p. 487-499, 2004.

HERNANDEZ-ORTIZ, V.; BARTOLUCCI, A. F.; MORALES-VALLES, P.; FRÍAS, D.; SELIVON, D. Cryptic Species of the Anastrepha fraterculus Complex (Diptera: Tephritidae): A Multivariate Approach for the Recognition of South American Morphotypes. Entomological Society of America. Lanham, v. 105, n. 2, p. 305318, 2012.

HERTIG, M.; WOLBACH, S. B. Studies on rickettsia-like microorganisms in insects. The Journal of Medical Research. New York, v. 44, n. 3, p. 329-74, 1924.

HERTIG M. The rickettsia, Wolbachia pipientis (gen. et sp. n.) and associated inclusions of the mosquito Culex pipiens. Parasitology. Cambridge, v. 28, p. 45386, 1936.

HILGENBOECKER, H.; HAMMERSTEIN, P.; SCHLATTMANN, P.; TELSCHOW, A.; WERREN, J. H. How many species are infected with Wolbachia? - A statistical analysis of current data. FEMS Microbiology Letters. Oxford, v. 281, p. 215-220, 2008.

HIROKI, M.; KATO, Y.; KAMITO, T.; MIURA, K. Feminization of genetic males by a symbiotic bacterium in a butterfly, Eurema hecabe (Lepidoptera: Pieridae). Naturwissenschaften. Heidelberg, v. 89, p. 167-170, 2002. 
HOFFMAN, A. A.; TURELLI, M.; SIMMONS, G. M. Unidirectional incompatibility between populations of Drosophila simulans. Evolution. Oxford, v. 40, p. 692-701, 1986.

HOFFMANN, A. A. Partial cytoplasmic incompatibility between two Australian populations of Drosophila melanogaster. Entomologia Experimentalis et Applicatta. West Sussex, v. 48, n. 1, p. 61-67, 1988.

HOFFMAN, A. A.; TURELLI, M. Unidirectional incompatibility in Drosophila simulans: inheritance, geographic variation and fitness effects. Genetics. Bethesda, v. 119, p. 435-444, 1988.

HOFFMANN, A. A.; TURELLI, M.; HARSHMAN, L. G. Factors affecting the distribution of cytoplasmic incompatibility in Drosophila simulans. Genetics. Bethesda, v. 126, p. 933-948, 1990.

HOFFMANN, A. A.; HERCUS, M.; DAGHER, H. Population dynamics of the Wolbachia infection causing cytoplasmic incompatibility in Drosophila melanogaster. Genetics. Bethesda, v. 148, p. 221-31, 1998.

HSIAO, C.; HSIAO, T. H. Rickettsia as the cause of cytoplasmic incompatibility in the alfalfa weevil, Hypera postica. Journal of Invertebrate Pathology. Maryland Heights, v. 45, n. 2, p. 244-46, 1985.

HURST, G. D.; JIGGINS, F. M.; VON DER SCHULENBURG, J. H. G.; BERTRAND, D.; STUART, A. W.; GORIACHEVA, I. I.; ZAKHAROV, I. A.; WERREN, J. H.; STOUTHAMER, R.; MAJERUS, M. E. N. Male-killing Wolbachia in two species of insect. Royal Society of London. Proceedings B. Biological Sciences. London, v. 266, p. 735-740, 1999.

HURST, G. D.; JOHNSON, A. P.; VON DER SCHULENBURG, J. H. G.; FUYAMA, Y. Male-killing Wolbachia in Drosophila: a temperature sensitive trait with a threshould bacterial density. Genetics. Bethesda, v. 156, p. 699-709, 2000.

JAENIKE, J. 2007. Spontaneous emergence of a new Wolbachia phenotype. Evolution. Rochester, v. 61, p. 2244-2252, 2000.

JAMNONGLUK, W.; KITTAYAPONG, P.; BAIMAI, V.; O'NEILL, S. L. Wolbachia infections of tephritid fruit flies: molecular evidence for five distinct strains in a single host species. Current Microbiology. Secaucus, v. 45, p. 255-260, 2002. 
JEYAPRAKASH, A.; HOY, M. A. Long PCR improves Wolbachia DNA amplification: wsp sequences found in $76 \%$ of sixty-three arthropod species. Insect Molecular Biology. St Albans, v. 9, p. 393-405, 2000.

JIGGINS, F. M.; HURST, G. D. D.; MAJERUS, M. E. N. Sex-ratio-distorting Wolbachia causes sex-role reversal in its butterfly host. Royal Society of London. Proceedings B. Biological Sciences. London, v. 267, p. 69-73, 2000.

JIGGINS, F. M.; VON DER SCHULENBURG, J. H.; HURST, G. D.; MAJERUS, M. E. Recombination confounds interpretations of Wolbachia evolution. Royal Society of London. Proceedings B. Biological Sciences. London, v. 268, n. 1474, p. 14231427, 2001.

JOWETT, T. Preparation of nucleic acids. In: Drosophila: A Practical Approach. DB Roberts, ed Roberts B (Information Printing, Oxford). p. 275-286, 1986.

JUCHAULT, P.; FRELON, M.; BOUCHON, D.; RIGAUD, T. New evidence for feminizing bacteria in terrestrial isopods: evolutionary implications. Academie des Sciences. Comptes Rendus. Biologies. Cedex. v. 317, p. 225-30, 1994.

KAGEYAMA, D.; NISHIMURA, $\quad$ G.; HOSHIZAKI, S.; ISHIKAWA, Y. Feminizing Wolbachia in an insect, Ostrinia furnacalis (Lepidoptera: Crambidae). Heredity. London, v. 88, n. 6, p. 444-449, 2002.

KAWAMURA, N. Fertilization and the first cleavage mitosis in insects. Development, Growth \& Differentiation. Richmond, v. 43, p. 343-49, 2001.

KAWASAKI, Y.; ITO, M.; MIURA, K.; KAJIMURA, H. Superinfection of five Wolbachia in the alnus ambrosia beetle, Xylosandrus germanus (Blandford) (Coleoptera: Curuculionidae). Bulletin of Entomological Research. Cambridge, v. 100, n. 2, p. 231-239, 2010.

KITTAYAPONG, P.; MILNE, J. R.; TIGVATTANANONT, S.; BAIMAI, V. Distribution of the reproduction-modifying bacteria, Wolbachia, in natural populations of tephritid fruit flies in Thailand. Science Asia. Bangkok, v. 26, p. 93-103, 2000. 
KITTAYAPONG, P.; MONGKALANGOON, P.; BAIMAI, V.; O'NEILL, S. L. Host age effect and expression of cytoplasmic incompatibility in field populations of Wolbachia-superinfected Aedes albopictus. Heredity. London, v. 88, n. 4, p. 270-274, 2002.

KITTAYAPONG, P.; JAMNONGLUK, W.; THIPAKSORN, A.; MILNE, J. R.; SINDHUSAKE, C. Wolbachia infection complexity among insects in the tropical rice-field community. Molecular Ecology. Oxford, v. 12, n. 4, p. 1049-1060, 2003.

KLASSON, L.; KAMBRIS, Z.; COOK, P. E.; WALKER, T.; SINKINS, S. P. Horizontal gene transfer between Wolbachia and the mosquito Aedes aegypti. BMC Genomics. London, v. 20, p. 10-33, 2009.

KOUKOU, K., PAVLIKAKI, H.; KILIAS, G.; WERREN, J. H.; BOURTZIS, K.; ALAHIOTIS, S. N. Influence of antibiotic treatment and Wolbachia curing on sexual isolation among Drosophila melanogaster cage populations. Evolution. Oxford, v. 60, n. 1, p. 87-96, 2006.

KRAAIJEVELD, K.; FRANCO, P.; DE KNIJFF, P.; STOUTHAMER, R.; VAN ALPHEN, J. J. Clonal genetic variation in a Wolbachia-infected asexual wasp: horizontal transmission or historical sex? Molecular Ecology. Oxford, v. 20, n. 17, p. 36443652, 2011.

KRUSKAL, W. H.; WALLIS, W. A. Use of ranks in one-criterion variance analysis. Journal of the American Statistical Association. Baltimore, v. 47, p. 583-621, 1952.

LASSY, C. W.; KARR, T. Cytological analysis of fertilization and early embryonic development in incompatible crosses of Drosophila simulans. Mechanisms of Development. Shannon, v. 57, p. 47-58, 1996.

LAVAGNOLLI, T. M. C.; MASCARENHAS, R. O.; ROCHA, L. S.; PERONDINI, A. L.; SELIVON, D. Deteç̧ão de Wolbachia em amostras de insetos da região Neotropical. In: $51^{\circ}$ Congresso Nacional de Genética, 2005, Águas de Lindóia, SP, resumo em CD-ROM.

LAVEN, H. Crossing experiments with Culex strains. Evolution. Oxford, v. 5, p. 37075, 1951. 
LAVEN, H. Speciation by cytoplasmic isolation in the Culex pipiens complex. Cold Spring Harbor Symposia on Quantitaive Biology. Woodbury, v. 24, p. 166-73, 1959.

LAVEN H. Eradication of Culex pipiens fatigans through cytoplasmic incompatibility. Nature. London, v. 261, p. 383-84, 1967.

LEU, S. J. C.; LI, J. K. K.; HSIAO, T. H. Characterization of Wolbachia postica, the cause of reproductive incompatibility among alfalfa weevil strains. Journal of Invertebrate Pathology. Maryland Heights, v. 54, p. 248-59, 1989.

LO, N.; CASIRAGHI, M.; SALATI, E.; BAZZOCCHI, C.; BANDI, C. How many Wolbachia supergroups exist? Molecular Biology and Evolution. Cary, v. 19, p. 341-346, 2002.

LOUIS, C.; NIGRO, L. Ultrastructural evidence of Wolbachia Rickettsiales in Drosophila simulans and their relationships with unidirectional crossincompatibility. Journal of Invertebrate Pathology. Maryland Heights, v. 54, p. 39-44, 1989.

MALAVASI, A.; ZUCCHI, R. A,; SUGAYAMA, R. L. BiogeografiA. Em: "Moscas das frutas de interesse econômico no Brasil: conhecimento básico e aplicado", Malavasi, A. e Zucchi, R.A. (eds.), Holos, Ribeirão Preto. 93-98, 2000.

MASCARENHAS, R. O. Endossimbionte Wolbachia em moscas-das-frutas do gênero Anastrepha (Tephritidae) e em vespas parasitóides (Braconidae) associadas. 2007. 80p. Dissertação de Mestrado. Departamento de Biologia, Instituto de Biociências, Universidade de São Paulo, USP, São Paulo, 2007.

MARCON H. S. Identificação da bactéria endossimbionte Wolbachia em populações de moscas-das-frutas do complexo Anastrepha fraterculus (Diptera: Tephritidae). 2009. 111p. Dissertação de Mestrado- Instituto de Biociências, Unesp, Botucatu, SP, 2009.

MARCON, H. S.; COSCRATO, V. E.; SELIVON, D.; PERONDINI, A. L. P.; MARINO, C. L. Variations in the sensitivity of different primers for detecting Wolbachia in Anastrepha (Diptera: Tephritidae). Brazilian Journal of Microbiology (Impresso). Rio de Janeiro, v. 42, p. 778-785, 2011 a. 
MARCON, H. S.; DOMINGUES, D. S.; COSCRATO, V. E.; SELIVON, D.; PERONDINI, A. L. P.; MARION, C. L. New mariner elements in Anastrepha species (Diptera: Tephritidae). Neotropical Entomology. Dordrecht, v. 40, n. 5, p. 568-574, 2011 b.

MARTÍNEZ, H.; TOLEDO, J.; LIEDO, P.; MATEOS, M. Survey of Heritable Endosymbionts in Southern Mexico Populations of the Fruit Fly Species Anastrepha striata and A. ludens. Current Microbiology. Secaucus, v. 65, n. 6, p. 711-718, 2012.

MAYNARD SMITH, J. (1992). Analyzing the mosaic structure of genes. Journal of Molecular Evolution. Secaucus, v. 34, p. 126-129, 1992.

MCMENIMAN CJ, LANE RV, CASS BN, FONG AW, SIDHU M, WANG YF, O'NEILL SL. Stable introduction of a life-shortening Wolbachia infection into the mosquito Aedes aegypti. Science. Washington DC, v. 323, p. 141-144, 2009.

MCNULTY, S. N.; FOSTER, J. M.; MITREVA, M.; DUNNING-HOTOPP, J. C.; MARTIN, J.; FISCHER, K.; WU, B.; DAVIS, P. J.; KUMAR, S.; BRATTIG, N. W.; SLATKO, B. E.; WEIL, G. J.; FISCHER, P. U. Endosymbiont DNA in endobacteria-free filarial nematodes indicates ancient horizontal genetic transfer. PLoS ONE. San Francisco, v. 5, n. 6, e11029, 2010.

MCPHERON, B. A.; HAN, H. Y.; SILVA, J. G.; NORRBOM, A. L. Phylogeny of genus Anastrepha and Toxotrypana (Trypetinae: Toxotrypanini) based upon $16 \mathrm{~S}$ rDNA mitochondrial sequences. In: Fruit flies (Tephritidae): phylogeny and evolution of behavior, M. Aluja e A.L. Norrbom (eds.), CRC Press, Boca Ratón, Florida. 343-361, 1999.

MENDES, L. O. T. Observações citológicas em "moscas-das-frutas". Bragantia. Campinas, v. 17, p. 29-39, 1958.

MILLER, W. J.; EHRMAN, L.; SCHNEIDER, D. Infectious speciation revisited: Impact of Symbiont-Depletion on female fitness and mating behavior of Drosophila paulistorum. PLoS Pathogens. San Francisco, v. 6, n. 12, e1001214, 2010.

MOREIRA, L. A.; ITURBE-ORMAETXE, I.; JEFFREY, J. A.; LU, G.; PYKE, A. T.; HEDGES, L. M.; ROCHA, B. C.; HALL-MENDELIN, S.; DAY, A.; RIEGLER, M.; HUGO, L. E.; JONHSON, K. N.; KAY, B. H.; MCGRAW, E. A.; VAN DEN HURK, A. F.; RYAN, P. A.; O'NEILL, S. L. A Wolbachia symbiont in Aedes aegypti limits infection with dengue, Chikungunya, and Plasmodium. Cell. Cambridge, v. 139, p. 1268-1278, 2009a. 
MOREIRA, L. A.; SAIG, E.; TURLEY, A. P.; RIBEIRO, J. M.; O'NEILL, S. L.; MCGRAW, E. A. Human probing behavior of Aedes aegypti when infected with a life-shortening strain of Wolbachia. PLoS Neglected Tropical Diseases. San Francisco, v. 3, e568.

MORGANTE, J. S.; MALAVASI, A.; BUSH, G. L. Biochemical systematics and evolutionary relationships of neotropical Anastrepha. Annals of the Entomological Society of America. Lanham, 73, p. 622-30, 1980.

MORGANTE, J. S.; SELIVON, D.; SOLFERINI, V. N.; MATIOLI, S. R. Evolutionary patterns in specialist and generalist species of Anastrepha. 133-47. In: M.Aluja \& P. Liedo (eds.). Fruit Flies: biology and management. Springer, New York. Proceedings of the 3th International Symposium on Fruit Flies of Economic Importance, 1993.

NARITA, S.; SHIMAJIRI, Y.; NOMURA, M. Strong cytoplasmic incompatibility and high vertical transmission rate can explain the high frequencies of Wolbachia infection in Japanese populations of Colias erate poliographus (Lepidoptera: Pieridae). Bulletin of Entomological Research. Cambridge, v. 99, n. 4, p. 385-391, 2008.

NEGRI, I., PELlECCHIA, M., MAZZOGLIO, P. J., PATETTA, A.; ALMA, A. Feminizing Wolbachia in Zyginidia pulula (Insecta, Hemiptera), a leafhopper with an XX/XO sex determination system. . Royal Society of London. Proceedings B. Biological Sciences. London, v. 273, p. 2409-2416, 2008.

NODA, H. Cytoplasmic incompatibility in allopatric field populations of the small brown planthopper, Laodelphax striatellus, in Japan. Entomologia Experimentalis et Applicatta. West Sussex, v. 35, p. 263-67, 1984.

NODA, H. Further studies on cytoplasmic incompatibility in local populations of Laodelphax striatellus in Japan (Homoptera: Delphacidae). Applied Entomology and Zoology. Tokyo, v. 22, p. 443-48, 1987.

NORRBOM, A. L.; ZUCCHI, R. A.; HERNÁNDEZ-ORTIZ, V. Phylogeny of the genera Anastrepha and Toxotrypana (Trypetinae: Toxotrypanini) based on morphology. p. 299-342. In: Fruit flies (Tephritidae): phylogeny and evolution of behavior. Aluja, M., Norrbom, A.L. (eds.) CRC Press, Boca Ratón, Florida, 1999.

O'NEILL, S. L. Cytoplasmic symbionts in Tribolium confusum. Journal of Invertebrate Pathology. Maryland Heights, v. 53, p. 132-34, 1989. 
O'NEILL, S. L.; GIORDANO, R.; COLBERT, A. M. E.; KARR, T. L.; ROBERTSON, H. M. 16S rRNA phylogenetic analysis of the bacterial endosymbionts associated with cytoplasmic incompatibility in insects. National Academy of Sciences. Proceedings. Washington DC, v. 89, p. 2699-702, 1992.

PANARAM, K.; MARSHALL, J. L. F supergroup Wolbachia in bush crickets: what do patterns of sequence variation reveal about this supergroup and horizontal transfer between nematodes and arthropods? Genetica. Dordrecht, v. 130, p. 53-60, 2007.

PANNEBAKKER, B. A.; PIJNACKER, L. P.; ZWAAN, B. J.; BEUKEBOOM, L. W. Cytology of Wolbachia-induced parthenogenesis in Leptopilina clavipes (Hymenoptera: Figitidae). Genome. Ottawa, v. 47, p. 299-303, 2004.

PANNEBAKKER, B. A.; LOPPIN, B.; ELEMANS, C. P. H.; HUMBLOT, L.; VAVRE, F. Parasitic inhibition of cell death facilitates symbiosis. National Academy of Sciences. Proceedings. Washington DC, v. 104, n. 1, p. 213-215, 2007.

PARASKEVOPOULOS, C.; BORDENSTEIN, S. R.; WERNEGREEN, J.; WERREN, J. H.; BOURTZIS, K. Towards a Wolbachia Multi Locus Strain Typing system: Discrimination of Wolbachia strains present in Drosophila species. Current Microbiology. Secaucus, v. 53, p. 388-395, 2006.

PENG, Y.; NIELSEN, J. E.; CUNNINGHAM, J. P.; MCGRAW, E. A. Wolbachia infection alters olfactory-cued locomotion in Drosophila spp. Applied and Environmental Microbiology. Washington DC, v. 74, n. 13, p. 3943-3948, 2008.

PERONDINI A. L. P. Um aparelho para contagem de grão nos autorradiogramas. Ciência e Cultura. São Paulo, v. 23, p. 86-87, 1971.

PIRES, A. O. Variações no padrão simétrico de cerdas em diferentes condições de desenvolvimento em Anastrepha (Diptera, Tephritidae). Tese de Doutorado, Departamento de Biologia, Instituto de Biociências, Universidade de São Paulo, USP, São Paulo, 2005.

POINSOT, D.; BOURTZIS, K.; MARKAKIS, G.; SAVAKIS, C.; MERCOT, H. Wolbachia transfer from Drosophila melanogaster into D. simulans: host effect and cytoplasmic incompatibility relationships. Genetics. Bethesda, v. 150, p. 227-237, 1998.

PREZOTTO, L. F. Análise do ITS1 do DNA ribossômico em espécies do complexo Anastrepha fraterculus (Diptera, Tephritidae). 2008, 66p. Dissertação Mestrado, 
Departamento de Biologia, Instituto de Biociências, Universidade de São Paulo, USP, São Paulo, 2008.

RAYCHOUDRY, R.; BALDO, L.; OLIVEIRA, D. C. S. G.; WERREN, J. H. Modes of acquisition of Wolbachia: Horizontal transfer, hybrid introgression, and codivergence in the Nasonia species complex. Evolution. Oxford, v. 63, n. 1, p. 165-183, 2009.

REED, K. M.; WERREN, J. H. Induction of paternal genome loss by the paternal-sexratio chromosome and cytoplasmic incompatibility bacteria (Wolbachia): a comparative study of early embryonic events. Molecular Reproduction and Development. Hoboken, v. 40, p. 408-418, 1995.

RIBEIRO, R. M. Wolbachia e Incompatibilidade Citoplasmática em Anastrepha sp.1 affinis fraterculus e $\boldsymbol{A}$. obliqua (Díptera: Tephritidae). 2009, 52 p. Dissertação Mestrado, Departamento de Biologia, Instituto de Biociências, Universidade de São Paulo, USP, São Paulo, 2009.

RICHARDSON, P. M.; HOLMES, W. P.; SAUL, G. I. I. The effect of tetracycline on reciprocal cross incompatibility in Mormoniella ( $D$. Nasonia) vitripennis. Journal of Invertebrate Pathology. Maryland Heights, v. 50, p. 176-83, 1987.

RIEGLER, M.; STAUFFER, C. Wolbachia infections and superinfections in cytoplasmically incompatible populations of the European cherry fruit fly Rhagoletis cerasi (Diptera, Tephritidae). Molecular Ecology. Oxford, v. 11, p. 2425-2434, 2002.

RIGAUD, T.; SOUTY-GROSSET, C.; RAIMOND, R.; MOCQUARD, J. P.; JUCHAULT, $P$. Feminizing endocytobiosis in the terrestrial crustacean Armadillidium vulgare Latr. (Isopoda): recent acquisitions. Endocytobiosis and Cell Research. Munich, v. 7, p. 259-73, 1991.

ROCHA, L. S.; MASCARENHAS, R. O.; PERONDINI, A. L. P.; SELIVON, D. Occurrence of Wolbachia in Brazilian Samples of Ceratitis capitata (Wiedemann) (Diptera: Tephritidae). Neotropical Entomology. Dordrecht, v. 34, n. 6, p. 10131015, 2005.

ROUSSET, F.; BOUCHON, D.; PINTUREAU, B.; JUCHAULT, P.; SOLIGNAC, M. Wolbachia endosymbionts responsible for various alterations of sexuality in arthropods. Royal Society of London. Proceedings B. Biological Sciences. London, v. 250, p. 91-98, 1992. 
ROWLEY, S. M.; RAVEN, R. J.; MCGRAW, E. A. Wolbachia pipientis in Australian spiders. Current Microbiology. Secaucus, v. 49, n. 3, p. 208-214, 2004.

ROZAS, J.; LIBRADO, P. DnaSP v5: A software for comprehensive analysis of DNA polymorphism data. Bioinformatics. Oxford, v. 25, n.11, p. 1451-1452, 2009.

RULL, J.; ABRAHAM, S.; KOVALESKI, A.; SEGURA, D. F.; ISLAM, A.; WORNOAYPORN, V.; DAMMALAGE, T.; SANTO TOMAS, U.; VERA, M. T. Random mating and reproductive compatibility among Argentinean and southern Brazilian populations of Anastrepha fraterculus (Diptera: Tephritidae). Bulletin of Entomological Research. Cambridge, v. 102, n. 04, p. 435-443, 2012.

SAMBROOK, J.; FRISCH, E.; MANIATIS, T. Molecular cloning: a laboratory manual. Cold Spring Harbor Laboratory Press, Cold Spring Harbor, NY. V. 1-3, 1989.

SANTOS, P. Variabilidade do DNA mitocondrial em populações de três espécies de Anastrepha (Diptera: Tephritidae). 1994. 312p. Dissertação de Mestrado. Departamento de Biologia, Instituto de Biociências, Universidade de São Paulo, São Paulo, SP, 1994.

SASAKI, T.; ISHIKAWA, H. Transinfection of Wolbachia in the mediterranean flour moth, Ephestia kuehniella, by embryonic microinjection. Heredity. London, v. 85, p. 130-135, 2000.

SELIVON, D.; MORGANTE, J. S.; RIBEIRO, A. F.; PERONDINI, A. L. P. Extrusion of masses of yolk during embryonary development of the fruit fly Anastrepha fraterculus. Invertebrate Reproduction and Development. Rehovot, v. 29, p. 1-7, 1996.

SELIVON, D.; PERONDINI, A. L. P. Eggshell morphology in two cryptic species of Anastrepha fraterculus (Diptera: Tephritidae). Annals of the Entomological Society of America. Lanham, v. 91, p. 473-478, 1998.

SELIVON, D.; PERONDINI, A. L. P.; MORGANTE, J. S. Haldane's rule and other aspects of reproductive isolation observed in the Anastrepha fraterculus complex (Diptera, Tephritidae). Genetics and Molecular Biology. Ribeirao Preto, v. 22, p. 507-510, 1999. 
SELIVON, D.; PERONDINI, A. L. P.; RIBEIRO, A. F.; MARINO, C. L.; LIMA, M. M. A.; COSCRATO, V. E. Wolbachia endossymbiont in a species of the Anastrepha fraterculus complex (Anastrepha: Diptera: Tephritidae). Invertebrate Reproduction \& Development. Rehovot, v. 42, p. 121-127, 2002.

SELIVON, D.; PERONDINI, A. L. P.; GODAY, C.; SÁNCHEZ, L.; RUIZ, M. F. Caracterização de regiões heterocromáticas dos cromossomos mitóticos e do DNA ribossômico de espécies de Anastrepha (Diptera, Tephritidae). $50^{\circ}$. Congresso Nacional de Genética, Florianópolis, Setembro de 2004 (CD do Congresso), 2004a.

SELIVON, D.; VRETOS, C.; FONTES, L.; PERONDINI, A. L. P. New variant forms in the Anastrepha fraterculus complex, p. 253-258. Proc. $6^{\text {th }}$ International Fruit Flies Symposium, 6-10 May, Stellenbosh, South Africa, B. Barnes (ed.), Isteg Scientific Publications, Irene, South Africa, 2004b.

SELIVON, D., PERONDINI, A. L. P.; MORGANTE, J. S. A genetic-morphological characterization of two cryptic species of the Anastrepha fraterculus complex (Diptera, Tephritidae). Annals of the Entomological Society of America. Lanham, v. 98, n. 3, p. 367-381, 2005.

SALUNKE, B.K.; SALUNKHE, R.C.; DHOTRE, D. P.; WALUJKAR, S. A.; KHANDAGALE, A. B.; CHAUDHARI, R.; CHANDODE, R. K.; GHATE, H. V.; PATOLE, M. S.; WERREN, J. H.; SHOUCHE, Y. S. Determination of Wolbachia diversity in butterflies from Western Ghats, India, by a multigene approach. Applied and Environmental Microbiology. Washington DC, v. 78, n. 12, p. 4458-4467, 2012.

SERBUS, L. R.; CASPER-LINDLEY, C.; LANDMANN, F.; SULLIVAN, W. The genetics and cell biology of Wolbachia-host interactions. Annual Review of Genetics. Palo Alto, v. 42, p. 683-707, 2008.

SHOEMAKER, D. D.; MACHADO, C. A.; MOLBO, D.; WERREN, J. H.; WINDSOR, D. M.; Herre, E. A. The distribution of Wolbachia in fig wasps: correlations with host phylogeny, ecology and population structure. Royal Society of London. Proceedings B. Biological Sciences. London, v. 269, n. 1506, p. 2257-2267, 2002. 
SMITH-CALDAS, M. R. B.; MCPHERON, B. A.; SILVA, J. G.; ZUCCHI, R. A. Phylogenetic relationships among species of the fraterculus group (Anastrepha: Diptera: Tephritidae) inferred from DNA sequences of mitochondrial cytochrome oxidade I. Neotropical Entomology. Dordrecht, v. 30, p. 565-573, 2001.

SNOOK, R. R.; CLELAND, S. Y.; WOLFNER, M. F.; KARR, T. L. Offsetting Effects of Wolbachia Infection and Heat Shock on Sperm Production in Drosophila simulans: Analyses of Fecundity, Fertility and Accessory Gland Proteins. Genetics. Rockville Pike, v. 155, p. 167-178, 2000.

SOLFERINI, V. N.; MORGANTE, J. S. Karyotype study of eight species of Anastrepha (Diptera: Tephritidae). Caryologia.Florence, v. 40, p. 229-41, 1987.

STECK, G. J. Biochemical systematics and population genetic structure of Anastrepha fraterculus and related species (Diptera: Tephritidae). Entomological Society of America. Annals. Lanham, v. 84, p. 10-28, 1991.

STECK, G. J.; SHEPPARD, W. S. Mitochondrial DNA variation in Anastrepha fraterculus. In: M. Aluja P. Liedo Fruit flies biology and management. 9-14. Springer New York, 1993.

STONE, A. The fruit flies of the genus Anastrepha. U.S. Department Of Agriculture, Miscellaneous Publication. Washington DC, n. 439, p. 1-112, 1942.

STOUTHAMER, R.; LUCK, R. F.; HAMILTON, W. D. Antibiotics cause parthenogenetic Trichogramma (Hymenoptera/Trichogrammatidae) to revert to sex. National Academy of Sciences. Proceedings. Washington DC, v. 87, p. 24242427, 1990.

STOUTHAMER, R.; LUCK, R. F. Influence of microbe-associated parthenogenesis on the fecundity of Trichogrammadeion and $T$. pretiosum. Entomologia Experimentalis Applicatta. West Sussex , v. 67, p. 183-192, 1993.

STOUTHAMER, R.; KAZMER, D. J. Cytogenetics of microbe associated parthenogenesis and its consequences for gene flow in Trichogramma wasps. Heredity. London, v. 73, p. 317-327, 1994.

SUESDECK-ROCHA, L.; BERTANI, R.; SILVA-JUNIOR, P. I.; SELIVON, D. The first record for Wolbachia in a scorpion: the parthenogenetic yellow scorpion Tityus 
serrulatus (Scorpiones, Buthidae). Revista lberica de Aracnología. Zaragoza, v. 14, p.183-184, 2007.

SUN, S.; CLINE, T. W. Effects of Wolbachia infection and ovarian tumor mutations on sex-lethal germline functioning in Drosophila. Genetics. Rockville Pike, v. 181, p. 1291-1301, 2009.

TAVARÉ, S. "Some Probabilistic and Statistical Problems in the Analysis of DNA Sequences". Lectures on Mathematics in the Life Sciences (American Mathematical Society). Providence, v. 17, p. 57-86, 1986.

TAMURA, K.; PETERSON, D.; PETERSON, N.; STECHER, G.; NEI, M.; KUMAR, S. MEGA5: Molecular Evolutionary Genetics Analysis using Maximum Likelihood, Evolutionary Distance, and Maximum Parsimony Methods. Molecular Biology and Evolution. Cary, v. 28, p. 2731-2739, 2011.

TEIXEIRA, L.; FERREIRA, A.; ASHBURNER, M. The bacterial symbiont Wolbachia induces resistance to RNA viral infections in Drosophila melanogaster. PLoS Biology. San Francisco, v. 6, n. 12, p. 2753-2763, 2008.

THOMPSON, J. D.; HIGGINS, D. G.; GIBSON, T. J. ClustalW: Improving the sensivity of progressive multiple sequence alignment through sequence weighting, positionsspecific gap penalties and weight matrix. Nucleic Acids Research. Oxford, v. 22, n. 22, p. 4673-4680, 1994.

TRAM, U.; SULLIVAN, W. Role of delayed nuclear envelope breakdown and mitosis in Wolbachiainduced cytoplasmic incompatibility. Science. Washington DC, v. 296, p. 1124-1126, 2002.

TRAM, U.; FERREE, P. M.; SULLIVAN, W. Identification of Wolbachia-host interacting factors through cytological analysis. Microbes and Infection. Cedex, v. 5, n. 11, p. 999-1011, 2003.

TRAM, U.; FREDRICK, K.; WERREN, J. H.; SULLIVAN, W. Paternal chromosome segregation during the first mitotic division determines Wolbachia-induced cytoplasmic incompatibility phenotype. Journal of Cell Science. Cambridge, v. 119, p. 3655-3663, 2006. 
TURLEY, A. P.; MOREIRA, L. A.; O'NEILL, S. L.; MCGRAW, E. A. Wolbachia Infection Reduces Blood-Feeding Success in the Dengue Fever Mosquito, Aedes aegypti. PLoS Neglected Tropical Diseases. San Francisco, v. 3, n. 9, e516, 2009.

VANDEKERCKHOVE, T. T.; WATTEYNE, S.; WILLEMS, A.; SWINGS, J. G.; MERTENS, J.; GILLIS, M. Phylogenetic analysis of the 16S rDNA of the cytoplasmic bacterium Wolbachia from the novel host Folsomia candida (Hexapoda, Collembola) and its implications for wolbachial taxonomy. FEMS Microbiology Letters. Oxford, v. 180, p. 279-286, 1999.

VAVRE, F.; FLEURY, F.; LEPETIT, D.; FOUILLET, P.; BOULÉTREAU, M. Phylogenetic evidence for horizontal transmission of Wolbachia in host-parasitoid associations. Molecular Biology and Evolution. Cary, v. 16, n. 12, p. 1711-1723, 1999.

VERA, M. T.; CÁCERES, C.; WORNOAYPORN, V.; ISLAM, A.; ROBINSON, A. S.; DE LA VEJA, M. H.; HENDRICHS, J.; CAYOL, J. P. Mating Incompatibility Among Populations of the South American Fruit Fly Anastrepha fraterculus (Diptera: Tephritidae). Entomological Society of America. Annals. Lanham, v. 99, n. 2, p. 387-397, 2006.

WADE, M. J.; STEVENS, L. Microorganism mediated reproductive isolation in flour beetles (genus Tribolium). Science. Washington DC, v. 227, p. 527-28, 1985.

WEEKS, A. R.; BREEUWER, J. A. Wolbachia-induced parthenogenesis in a genus of phytophagous mites. Royal Society of London. Proceedings B. Biological Sciences. London, v. 268, p. 2245-2251, 2001.

WEEKS, A. R.; TURELLI, M.; HARCOMBE, W. R.; REYNOLDS, K. T.; HOFFMAN, A. A. From Parasite to Mutualist: Rapid Evolution of Wolbachia in Natural Populations of Drosophila. PLoS Biology. San Francisco, v. 5, n. 5, p. 997-1005, 2007.

WEISBURG, W. G.; DOBSON, M. E.; SAMUEL, J. M.; DASCH, G. A.; MALLAVIA, L. P. Phylogenetic diversity of Rickettsiae. Journal of Bacteriology. Washington DC, v. 171, p. 4202-6, 1989.

WEISS, E.; MOULDER, J. W. Order I. Rickettsiales Gieszczkiewicz. In Bergey's Manual of Systematic Bacteriology, Vol. 1, ed. NR Krieg, JG Holt, Baltimore, p. 687729, 1984. 
WENSELEERS, T.; ITO, F.; VAN BORM, S.; HUYBRECHTS, R.; VOLCKAERT, F.; BILLEN, J. Widespread occurrence of the microorganism Wolbachia in ants. Royal Society of London. Proceedings B. Biological Sciences. London, v. 265, n. 1404, p. 1447-1452, 1998.

WERREN, J. H.; WINDSOR, D. W.; GUO, L. Distribution of Wolbachia in neotropical arthropods. Royal Society of London. Proceedings B. Biological Sciences. London. v. 262, p. 147-204, 1995.

WERREN, J. H. Biology of Wolbachia. Annual Review of Entomology. Palo Alto, v. 42, p. 589-609, 1997.

WERREN, J. H.; O'NEILL, S. The evolution of heritable symbionts. In Influential Passengers:inherited microorganisms and arthropod reproduction. S. O'Neill, A. Hoffman and J.H. Werren, eds, Oxford University Press, 1997.

WERREN, J. H.; BEUKEBOOM, L. W. Sex determination, sex ratios and genetic conflict. Annual Review of Ecology, Evolution, and Systematics. Palo Alto, v. 29, p. 233-261, 1998.

WERREN, J. H.; WINDSOR, D. M. Wolbachia infection frequencies in insects: evidence of a global equilibrium? Royal Society of London. Proceedings B. Biological Sciences. London. v. 267, p. 1277-1285, 2000.

WERREN, J. H.; BARTOS, J. D. Recombination in Wolbachia. Current Biology. Cambridge, v. 11, n. 6, p. 431-435, 2001.

WERREN, J. H.; BALDO, L.; CLARK, M. E. Wolbachia: Master Manipulators of Invertebrate Biology. Nature Reviews Microbiology. London, v. 6, n. 10, p. 741-51, 2008.

WEST, S. A.; COOK, J. M.; WERREN, J. H.; GODFRAY, H. C. J. 1998. Wolbachia in two insect host-parasitoid communities. Molecular Ecology. Oxford, v. 7, p. 14571465, 1998.

WHITE, I. M.; ELSON-HARRIS, M. M. Fruit flies of economic significance: their identification and bionomics. CAB International, Wallingford, 1992.

WU, M.; SUN, L. V.; VAMATHEVAN, J.; RIEGLER, M.; DEBOY, R.; BROWNLIE, J. C.; MCGRAW, E. A.; MARTIN, W.; ESSER, C. Phylogenomics of the reproductive 
parasite Wolbachia pipientis wMel: a streamlined genome overrun by mobile genetic elements. PLoS Biology. San Francisco, v. 2, n. 3, p. 327-341, 2004.

XI, Z.; KHOO, C. C.; DOBSON, S. L. Wolbachia establishment and invasion in an Aedes aegypti laboratory population. Science. Washington DC, v. 310, n. 5746, p. 326-328, 2005.

YEN, J. H.; BARR, A. R. New hypothesis of the cause of cytoplasmic incompatibility in Culex pipiens. Nature. London, v. 232, p. 657-58, 1971.

ZABALOU, S.; RIEGLER, M.; THEODORAKOPOULOU, M.; STAUFFER, C.; SAVAKIS, C.; BOURTZIS, K. Wolbachia-induced cytoplasmic incompatibility as a means for insect pest population control. National Academy of Sciences. Proceedings. Washington DC, v. 101, p. 15042-15045, 2004.

ZABALOU, S.; APOSTOLAK,I A.; LIVADARAS, I.; FRANZ, G.; ROBINSON, A. S.; SAVAKIS, C.; BOURTZIS, K. Incompatible insect technique: incompatible malesfrom a Ceratitis capitata genetic sexing strain. Entomologia Experimentalis et Applicata. West Sussex, v. 132, p. 232-240, 2009.

ZAR, J.H. Biostatistical analysis. Prentice Hall, Upper Saddle River, NJ, 1999.

ZEH, D. W.; ZEH, J. A.; BONILLA, M. M. Wolbachia, sex ratio bias and apparent male killing in the harlequin beetle riding pseudoscorpion. Heredity. London, v. 95, n. 1, p. 41-49, 2005.

ZHOU, W.; ROUSSET, F.; O'NEILL, S. Phylogeny and PCR-based classification of Wolbachia strains using wsp gene sequences. Royal Society of London. Proceedings B. Biological Sciences. London, v. 265, n. 1395, p. 509-515, 1998.

ZUCCHI, R. A. Diversidad, Distribuición y Hospederos del Género Anastrepha en Brasil. In: V. Hernándes-Ortiz (Ed.), Moscas de la fruta en Latinoamérica (Diptera: Tephritidae): diversidad, biologia y manejo. S y G editores, Distrito Federal. 77-1, 2007.

ZUCCHI, R. A. 2008. Fruit flies in Brazil: Anastrepha species and their hosts plants and parasitoids. http://www.lea.esalq.usp.br/anastrepha/ (último acesso em 01/11/2012) 
ZUH, R.; HAMMERSTEIN, P. Still a Host of Hosts for Wolbacia:Analysis of Recent Suggests That $40 \%$ of Terrestrial Arthropod Species Are Infected. PLoS ONE. San Francisco, v. 7, n. 6, p.1, e79825843, 2012. 
Anexos

\section{Sequências MLST concatenadas}

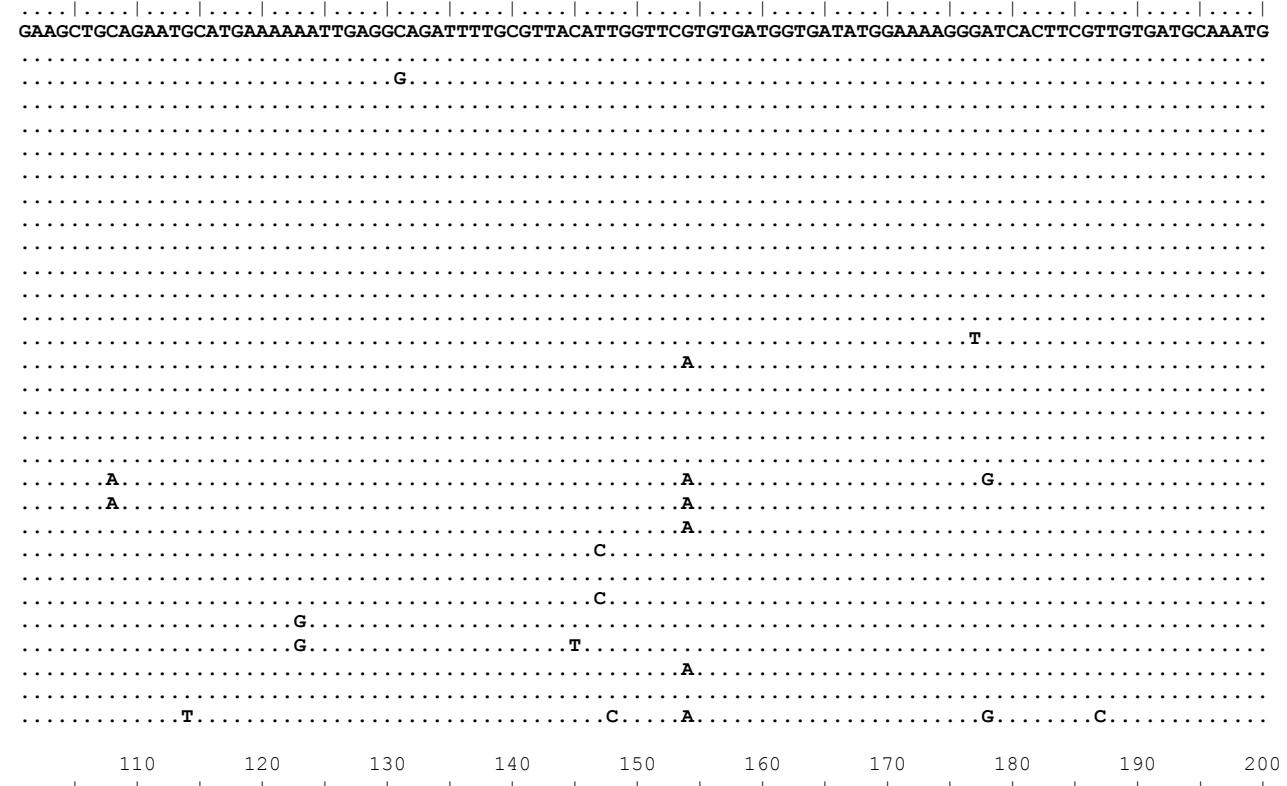

TTTCTGTCCGCCTAAAAGGCAGTAGTACATTTGGCACTCGTTGTGAAATAAAAAATCTGAACTCGATACGTTATATTGTGCAAGCTATAGACTATGAAAT

330

332

333

335

336
337

337
338
339

339

340

341
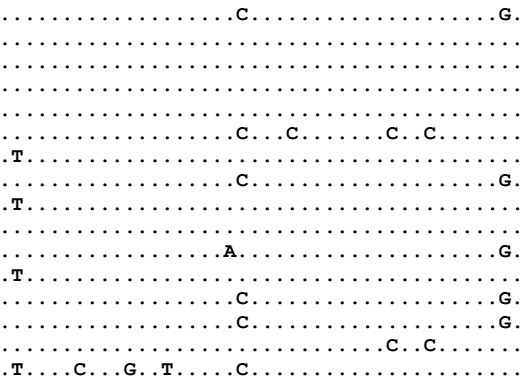
330 331 332 332 334

334
335
336

336

337
338

338

339

341

342

$(343$

344
345 


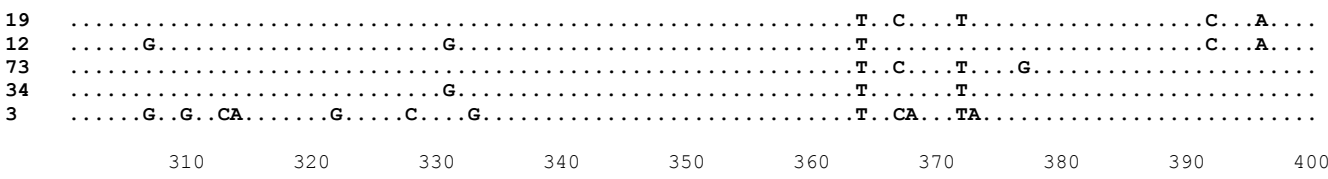

GAGGATGCAAGCGATTATAGATACTTCCCTGAGCCTGATTTATTACCTGTTGAGGTAAGCCAGGATAAAATGCGCACAAAAGGATGTCATTAACTAAGA

T

331

332

333

335

336

338

339

341
342

343

344
345
346
75

2

17

$\cdots$

A. $\ldots \ldots \cdots \cdots \cdots C$

A. . . .

A. A $\ldots \ldots \ldots$ C

А...

410

420

.AA

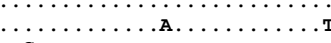

TGCCACTGTTTGTTTGGTCTGTCTTGCTAACAGCATTTATGTTGATTGTTGCCTTACCAGTGCTTGCCGGTGCTATAACTATGCTTCTTACTGATCGCAA

329

330

332

333

334
335

336

337

338
339

340

341

341
342
343
344

344
345

346

75

29

65

13

13
17
19

19
12
73
34

34
3

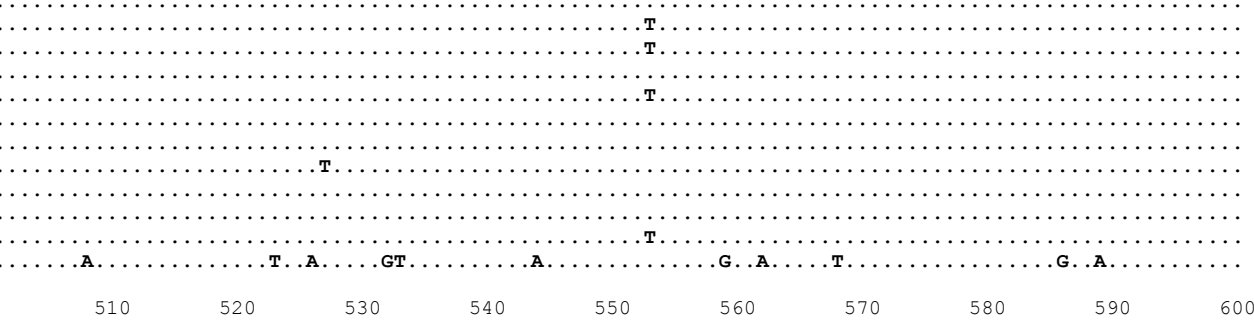

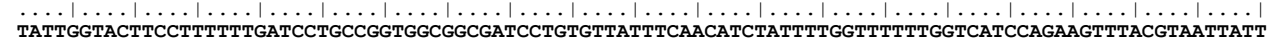

329

331

332

334

335

336

338

339
340

340
341

341
342

343

344
345

346

75
29
65

65 .

2
13
17
19

12 .

12
73
34

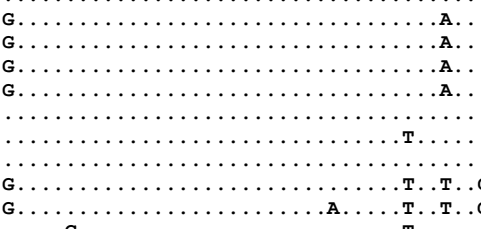

.c.

т. т.

T. 
3

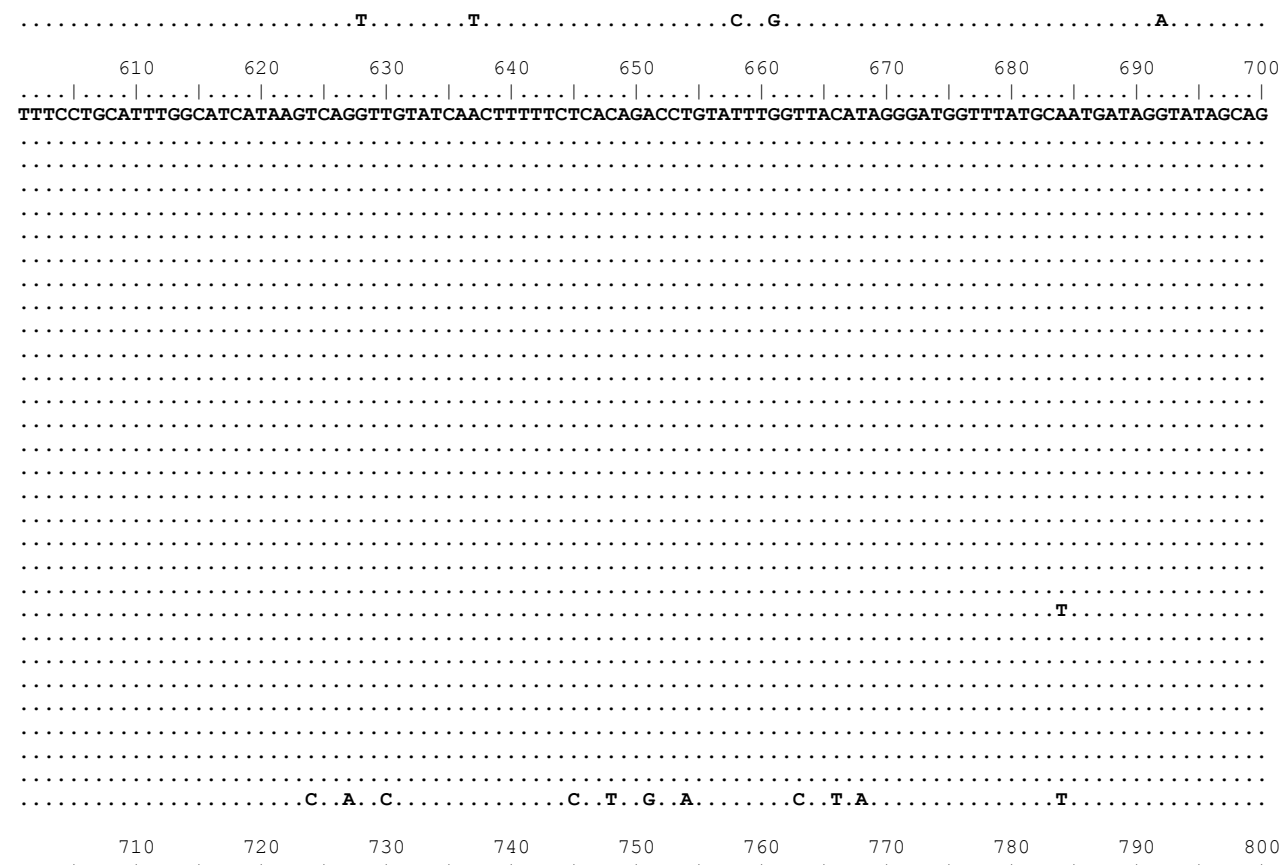

TATTTGGCTTTATGGTTTGGGTCACCATATGTTCACTGTTGGGCTTAGTGCTGACGCTGCTGCATTTTTTGATCCCGAACTCAACCCGGCCTTCGCTC 329 330

331

332

333

\begin{tabular}{l}
333 \\
334 \\
\hline
\end{tabular}

335

336
337

337
338

339
340
341
342

341
342

343
344

344
345

346

346
29
29

65

2

13

17

19
12
73

73
34
3

C

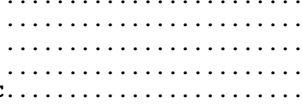

G.A

TGCTATATTTGCTGCACGCAAGGAAAATCTACCAAAA GATAAAATAGAAACA CAATAAAAAATGCAACTGGTAACGTTGCTGGAGAAAATTACGAGGAA

330

331

333

334

335

336
337

337
338

338
339

340
341

341
342

343

344
345

345
346

75

75
29
65

65

2

$810 \quad 820$

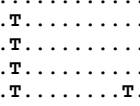

.

A. . TTT.

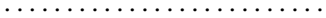

........
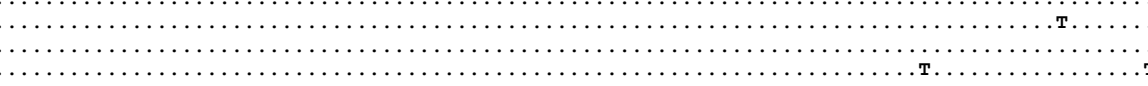

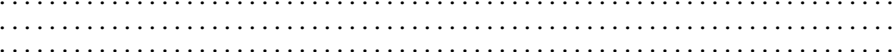

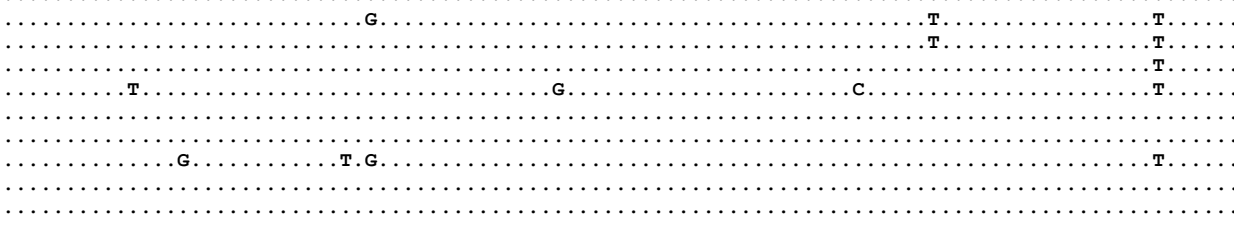

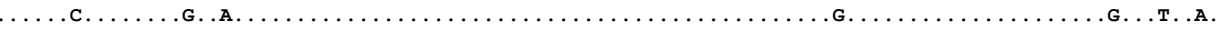

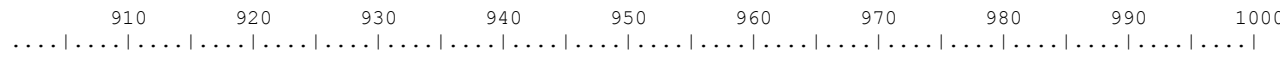




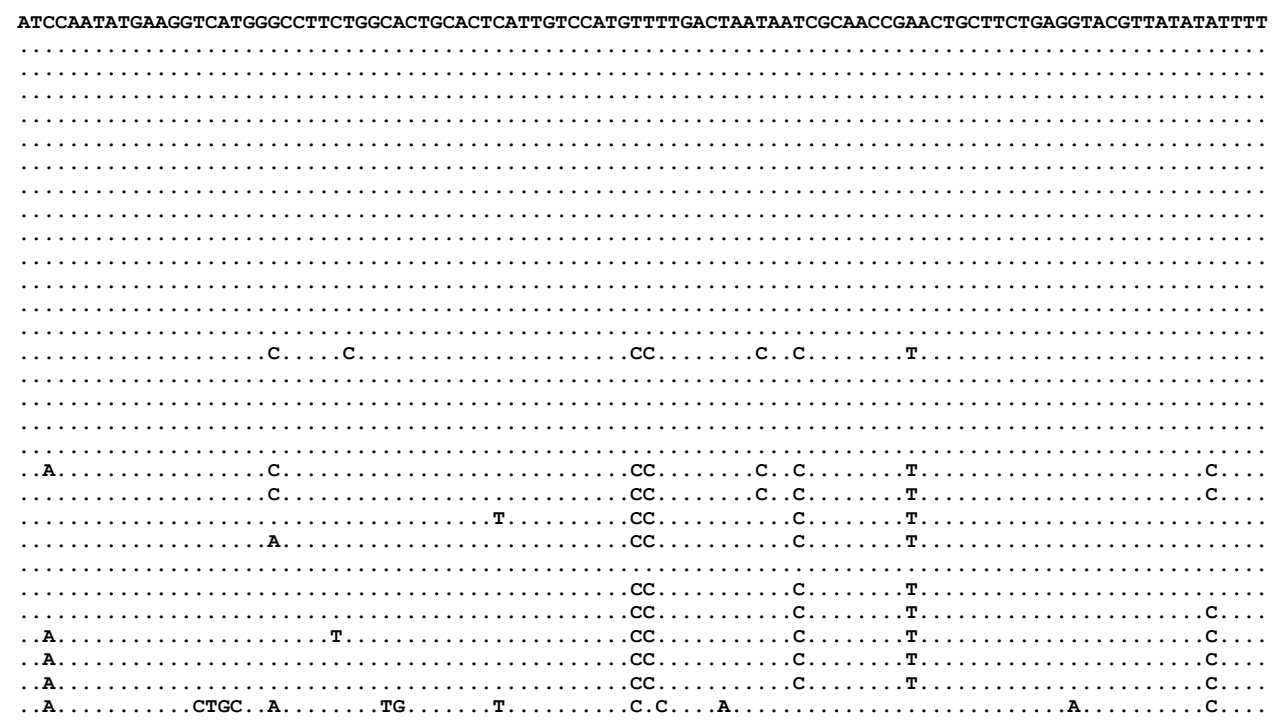

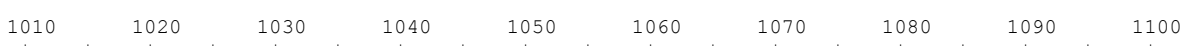

CTCGCAAGGTGGAAACTTGGGAGAACAGGAAGTGTTAGTTACCTTTTCGATCATGTAGGCTTAATCGTCTATAAAGCAGAGGGTGTGAATTTGATGA 329 331

332

333

335

336

337

338

$$
\begin{aligned}
& 340 \\
& 341
\end{aligned}
$$

342

342
343

343
344

345
346

346
75
29

29
65

$\cdots$

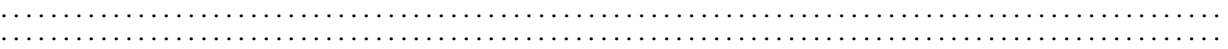

...........

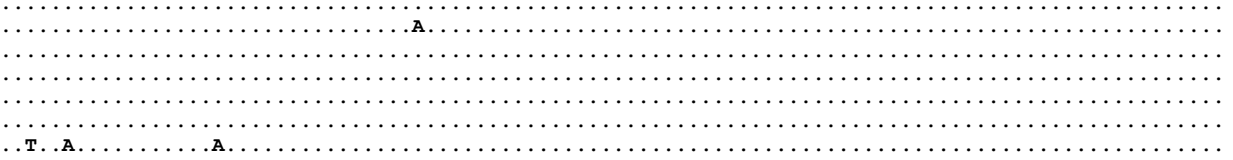

T.A

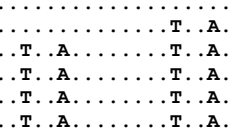

T. . . . . . .T.

А.

..................

TA.............A.A.....

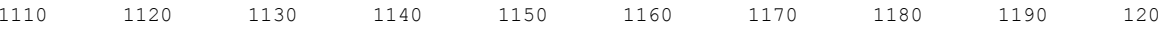

TTTATTCAGTCATGGAATCGAATTAGAAGTATTGAATGTTGAGGAAAATGACAAAGAAGGATTACACGTTATAACTTGTGAAATAAAAGATTTTGGTAAA

329

331

332

333

334

335
336

337

338

340
341
342
343

343

344
345
346

75
29
65

2

13

17

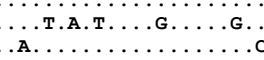

T.A..........G

T.A.T. .G. . . G
T.A.T.

т.A.т...G....G.

A

т.АСт . . . . . T

А. .

GTACGCGATGCCTTTGGTGGTACTGGAACCGGTGCAGCACCGGTAATTGCAAAAGCAGCCAGAGAAGCA GAGCCGCAGTTAAGGATAGAGCGCCAAAAG 
332
333
334
335
336
337
338
339
340
341
342
343
344
345
346
75
29
65
2
13
17
19
12
73
34
3

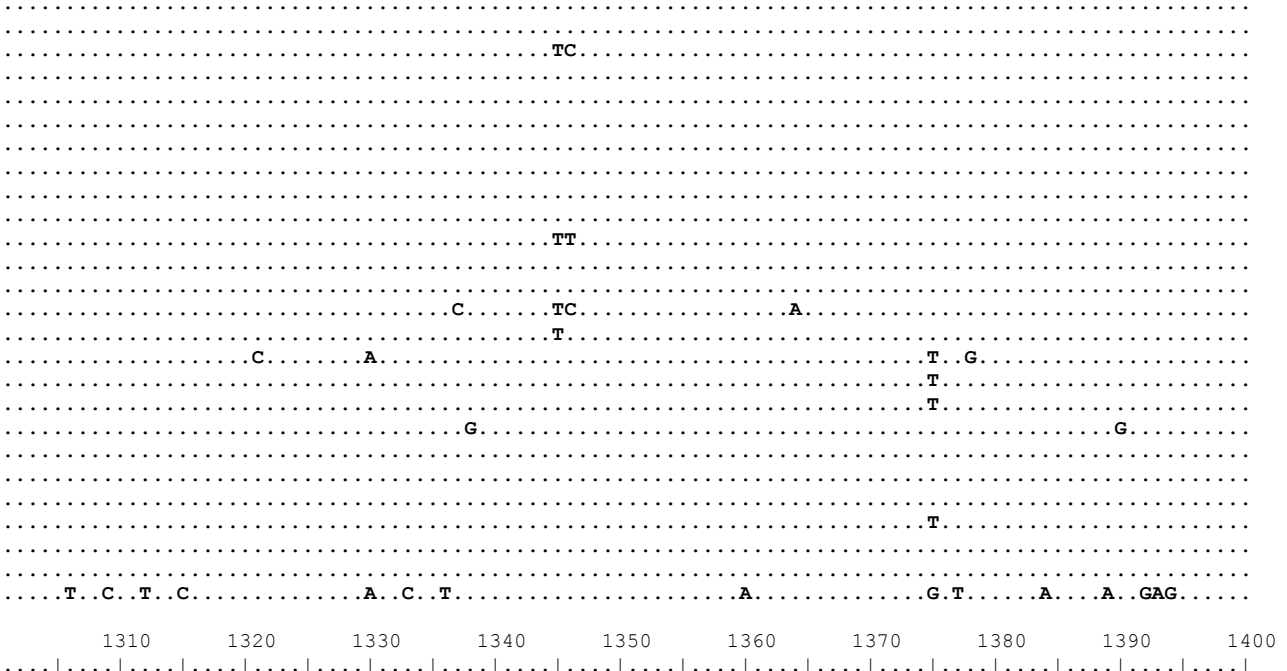

AAAAAAAGATATTGACTGTTGGAGTTGTAACTAAACCGTTCGGTTTGAAGGTGTGCGCGTATGCGCATTGCAGAGCTTGGACTTGAAGAACTGCAAAA

329
330
331
332
333
334
335
336
337
338
339
340
341
342
343
344
345
346
75
29
65
2
13
17
19
12
73
34
3

.

40

341

342
343
344

344

345

75
29

2

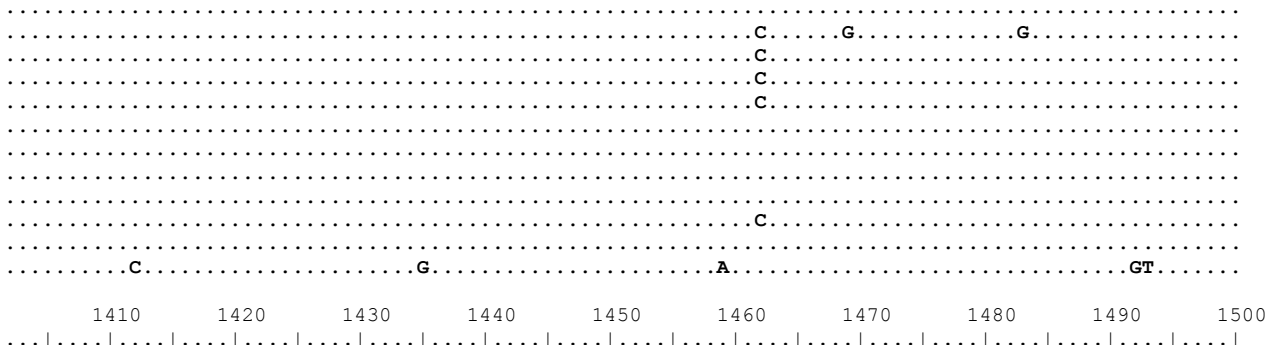

ATACGTGGATACACTTATTGTCATTCCAAATCAGAATTTATTTAGAATTGCAAATGAAAAAACTACATTTTCTGATGCATTTAAACTTGCTGATAATGTT

329
330
331
332
333
334
335
336
337
338
339
340
341
342
343
344
345
346
75
29
65
2
13
17
19
12
73
34
3

A.

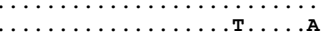

т.с.

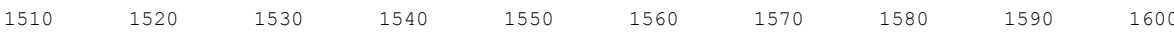

CTGCACATTGGCATCAGAGGAGTAACTGACTTGATGGTCATGCCAGGGCTTATTAATCTTGACTTCGCTGATATAGAAACAGTAATGAGCGAGATGGGCA

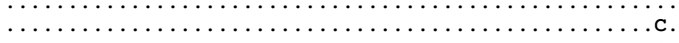




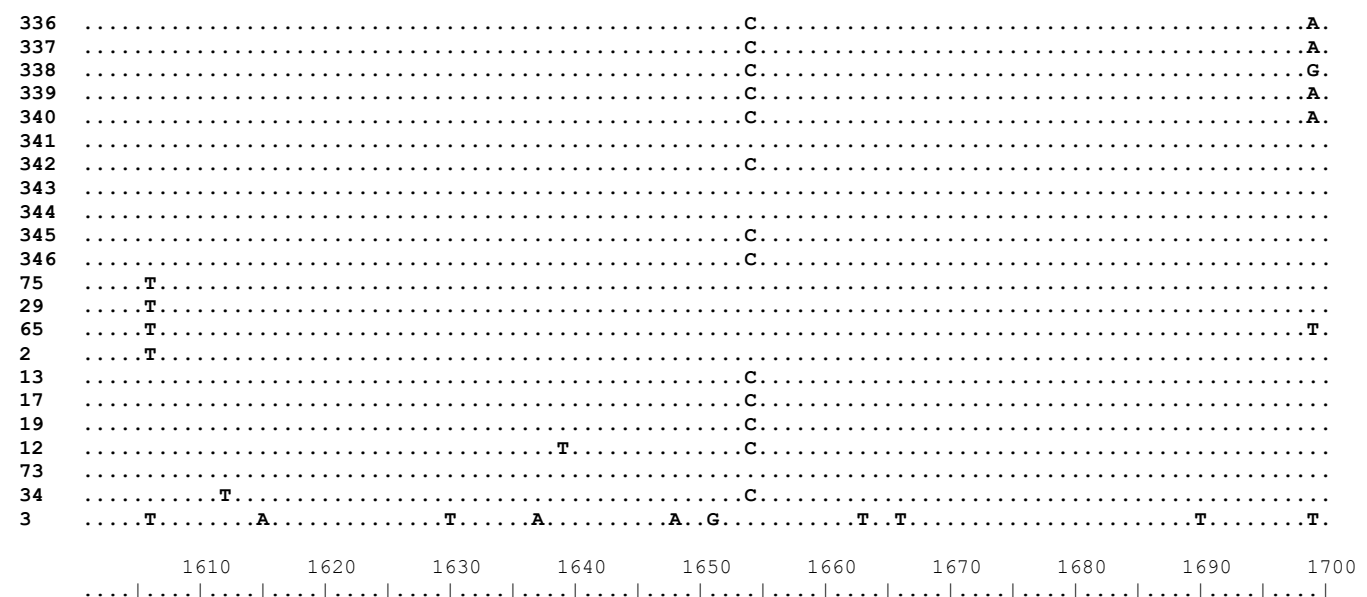

AAGCGATGATCGGCACCGGAGAGGAGAAGGAGAAGATAGAGCATTAGTGCTGGAATGCTCCCACTTATTTTGAAACTTAATAGTTCCACTCTTTACA

329

330

331

332

334

335

336
337

338

338
339

340
341

341
342

342
343

343
344
345

344
345
346

346
75

75
29

65

13

17
19

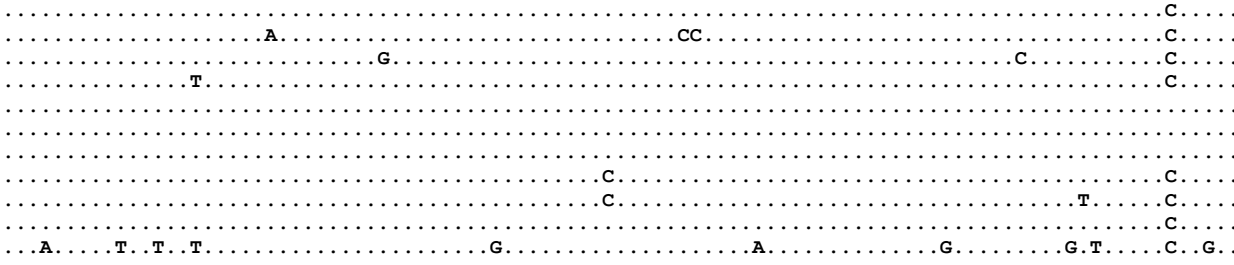
1710
1730
1740
$1750 \quad 1760$
$1770 \quad 1780$
$1790 \quad 1800$

TTCAAAGGATCTAACCTCTGATCAGGCAATAACCTCTTCTGTGAAAGATGCGCTGCGTTTGGGATGCTTAGCTGTCGGATTTACTATATATCCTGGTTCI

$$
\begin{aligned}
& 329 \\
& 330 \\
& 331 \\
& 332 \\
& 333 \\
& 334 \\
& 335 \\
& 336 \\
& 337 \\
& 338 \\
& 339 \\
& 340 \\
& 341 \\
& 342 \\
& 343 \\
& 344 \\
& 345 \\
& 346 \\
& 75 \\
& 29 \\
& 65 \\
& 2 \\
& 13 \\
& 17 \\
& 19 \\
& 12 \\
& 73 \\
& 34 \\
& 3
\end{aligned}
$$

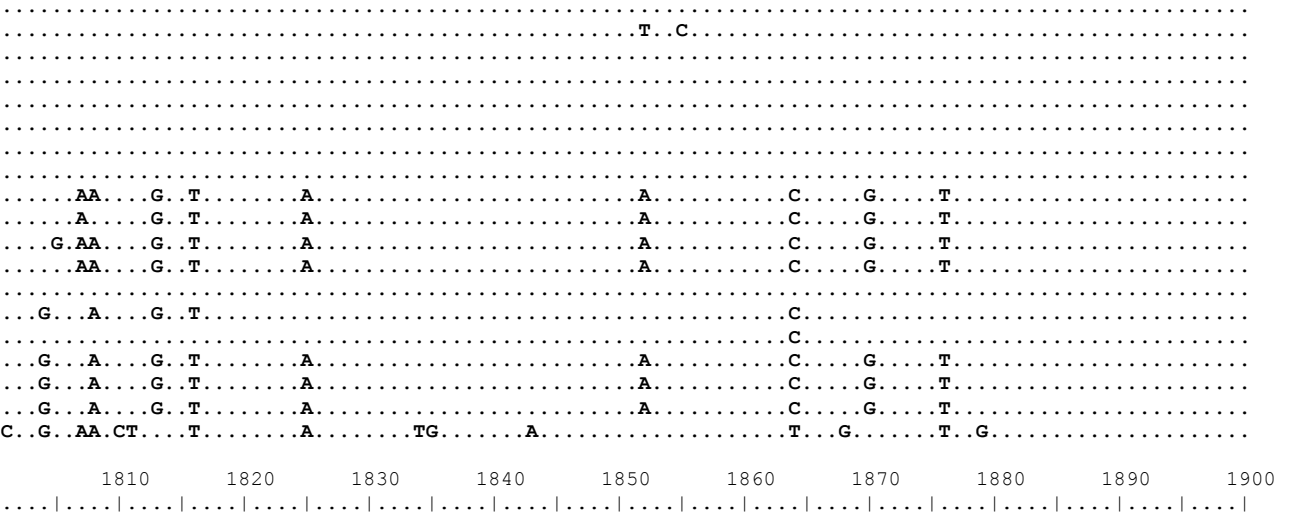

GCTAAGTGTTTGGATATGATGGAGGAAGCCCGTGGAATCATAGCTGAAGCCAAATCTTATGGACTTGCAGTAGTGCTATGGTCTTATCCACGCGGTGAAG 


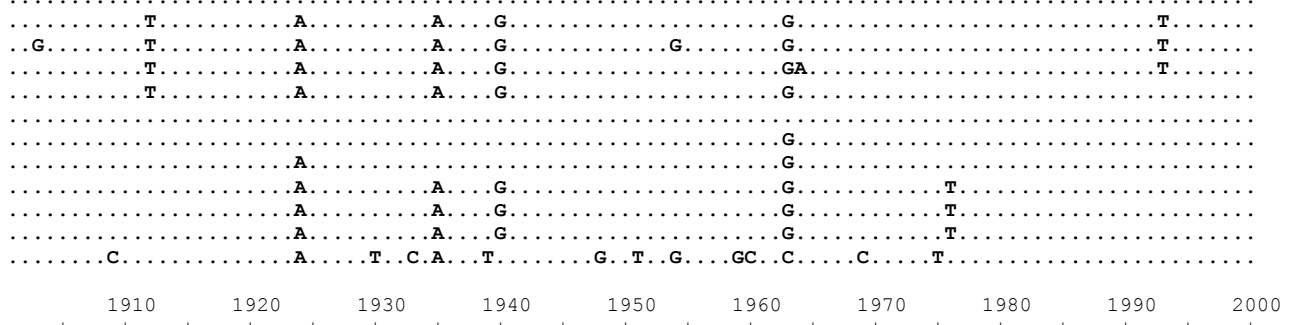

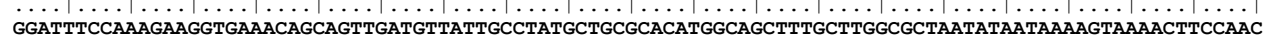

330

331

332

334

335

336
337

337
338

338
339

340
341

341
342

342
344

344
345
346

346

75
29
65
2
13
17
19
12
73
34
3

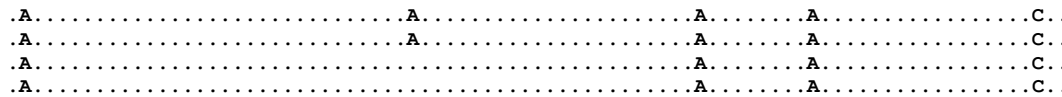

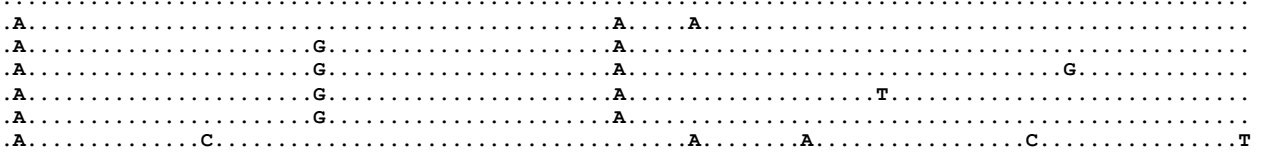

$2010 \quad 2020 \quad 2030 \quad 2040 \quad 2050 \quad 2060 \quad 2070$

TAAATATTTGGAAAGGAGAAAATAGAACAGAAAATATTGATCATTATCTAAAGAATTGAATATGTTAAAAGGTCT

329

330

331

332

334

335

336
337

338

339
340

340
341

341
342
343
344

344
345
346
75

75
29

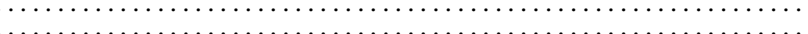

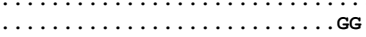

G.

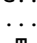

G
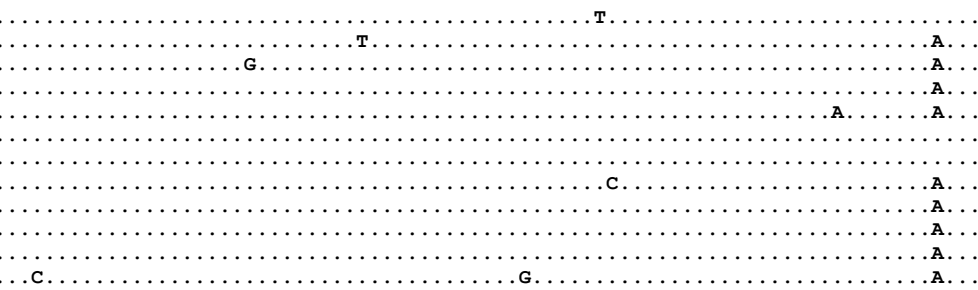

\section{Sequencias wsp}

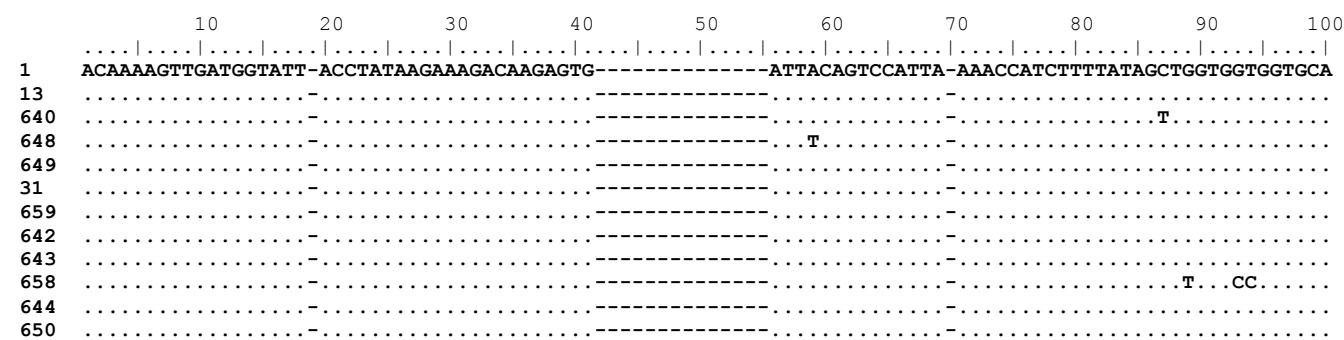




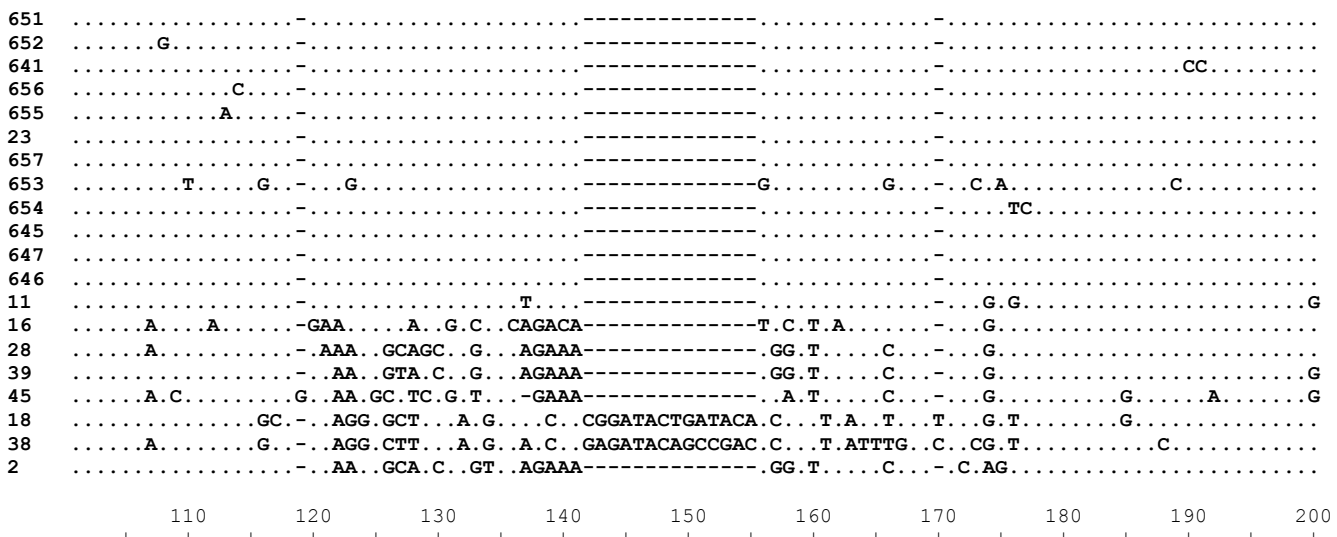

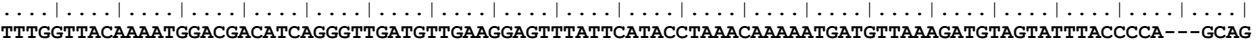

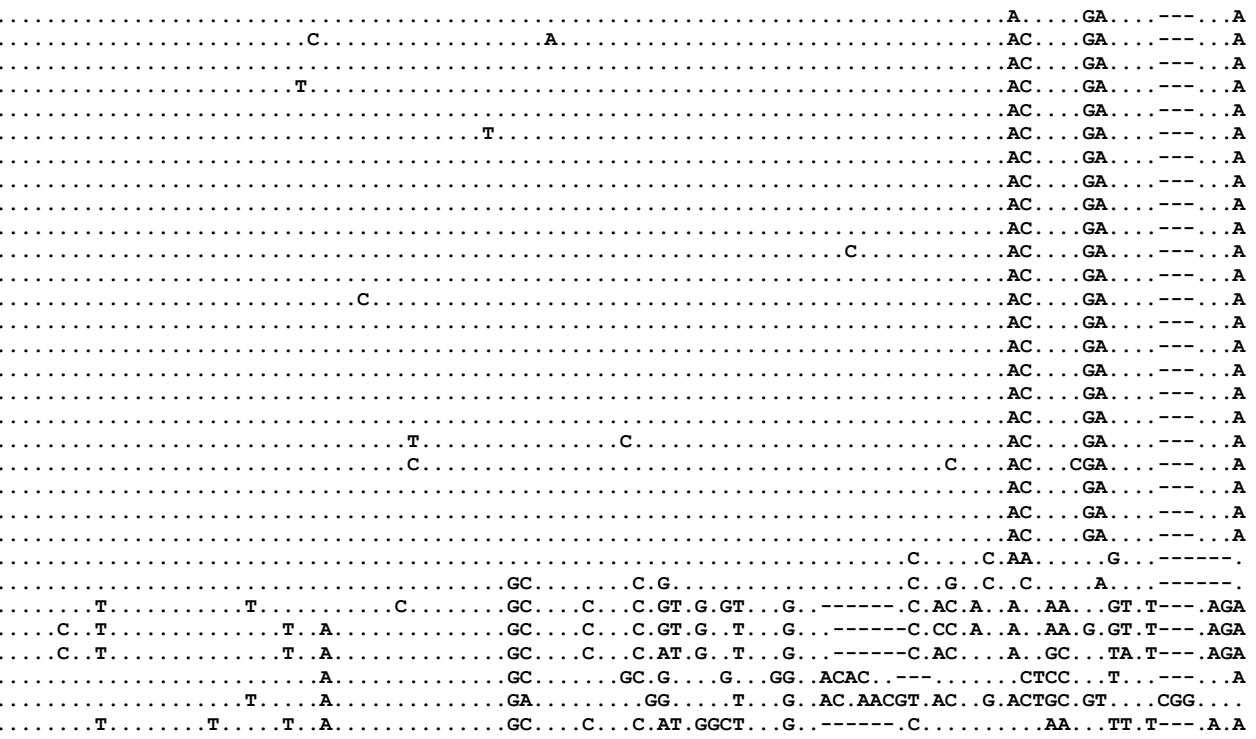
210
$220 \quad 230$
240
260
$270 \quad 280$
$290 \quad 300$

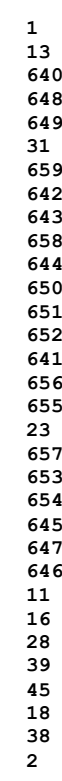

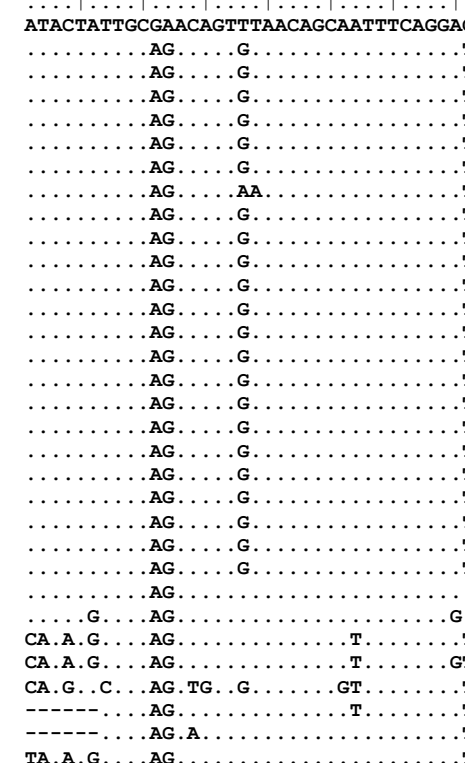

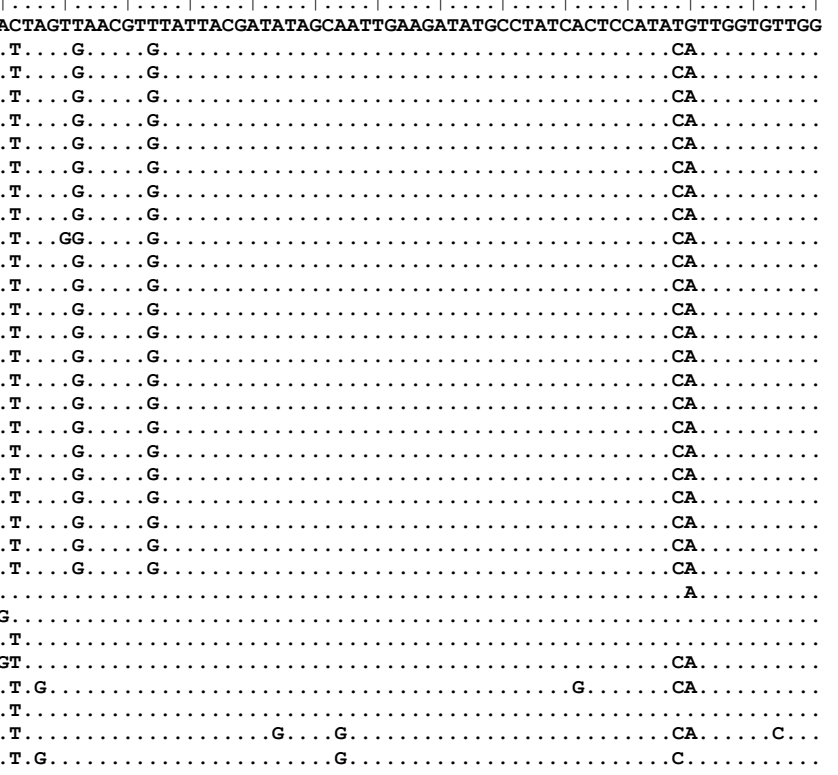

$$
\begin{array}{lllllllll}
310 & 320 & 330 & 340 & 350 & 360 & 370 & 380 & 390
\end{array}
$$

400

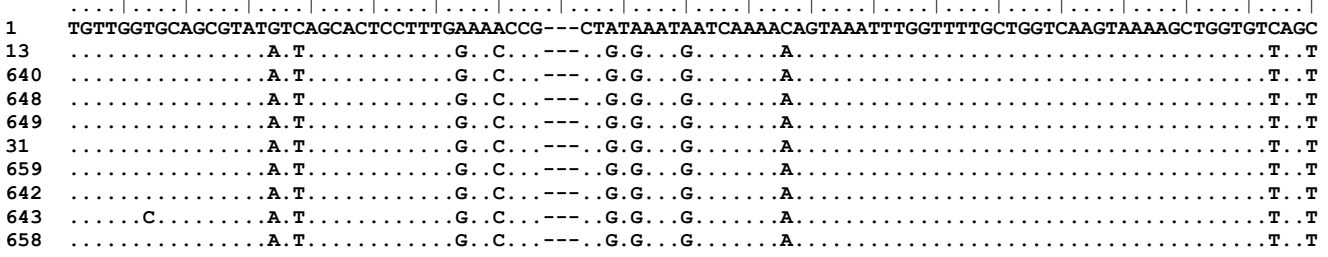




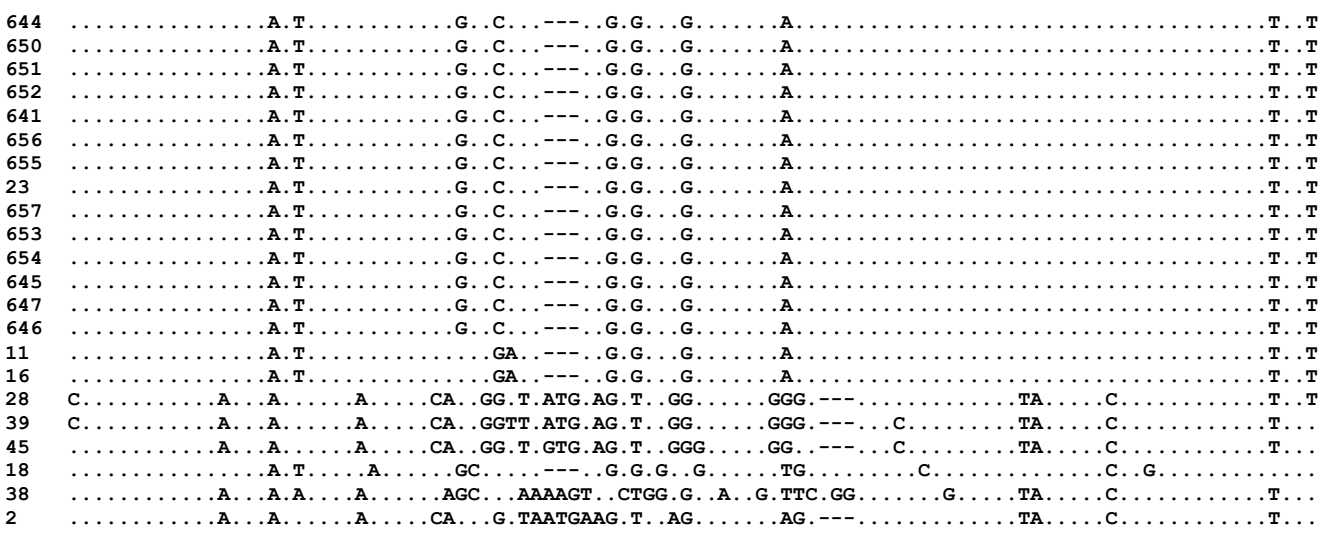
640
648
649
31
659
642
643
658
644
650
651
652
641
656
655
23
57
653
645

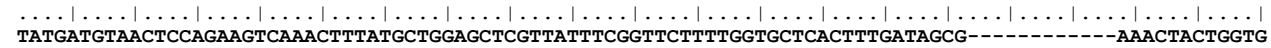

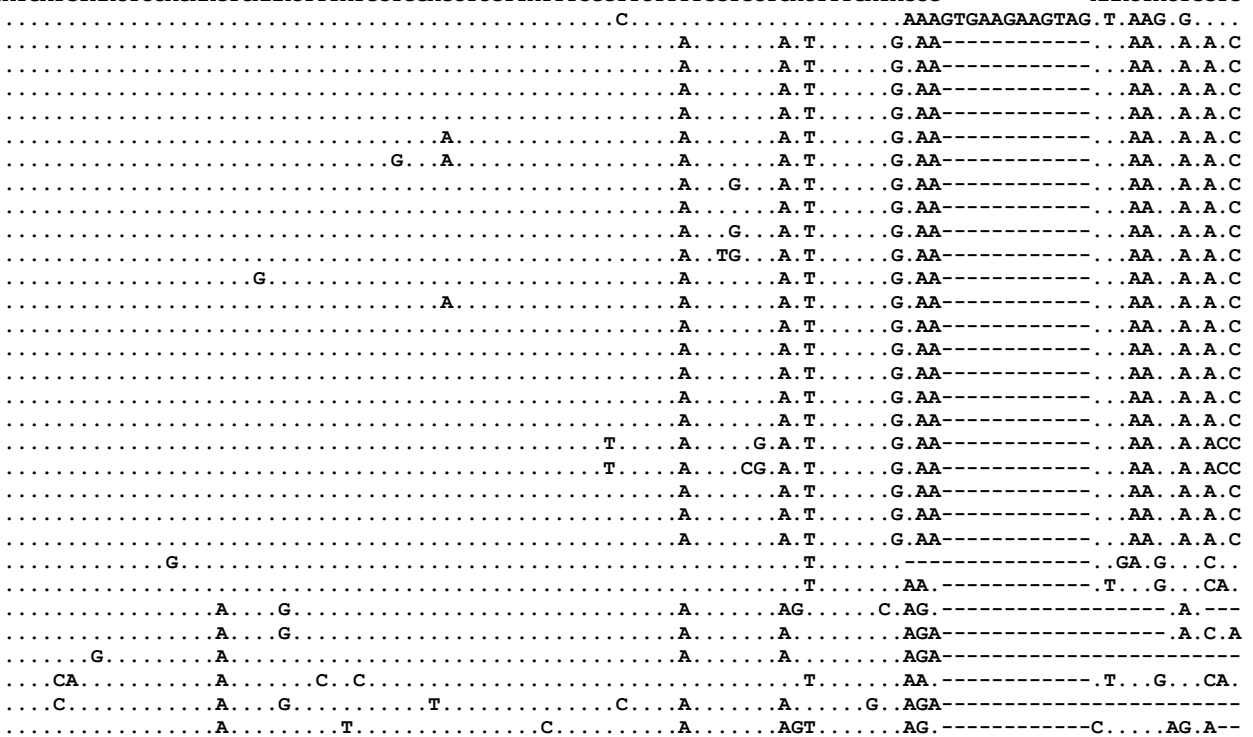

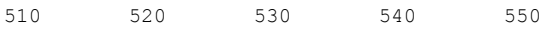

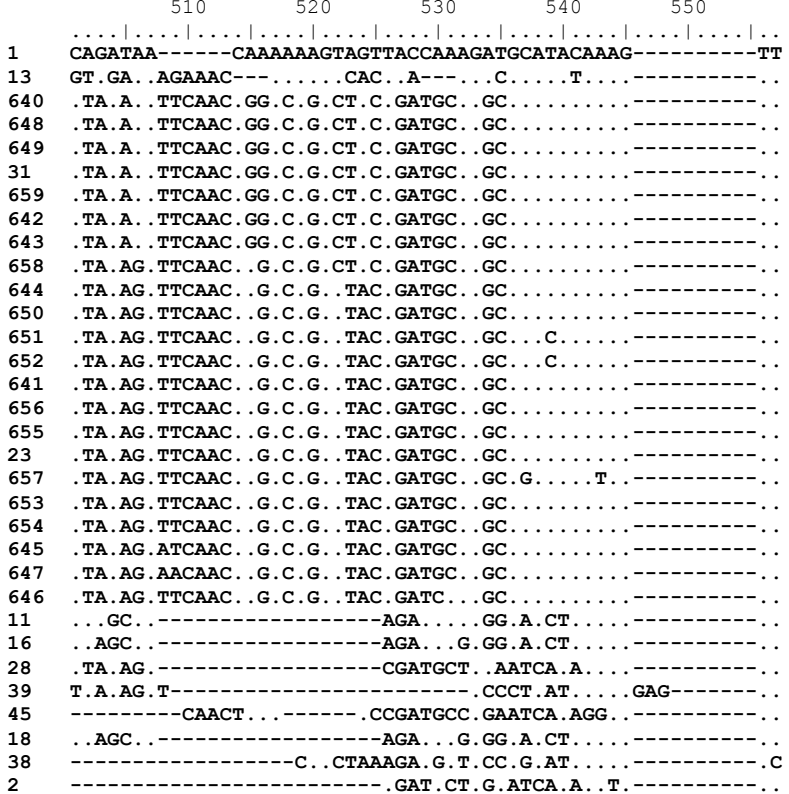

